U.S. DEPARTMENT OF THE INTERIOR

U.S. GEOLOGICAL SURVEY

\title{
National Seismic-Hazard Maps: Documentation June 1996
}

By Arthur Frankel

Charles Mueller

Theodore Barnhard

David Perkins

E.V. Leyendecker

Nancy Dickman

Stanley Hanson

and Margaret Hopper

\section{pen-File Report 96-532}

This report is preliminary and has not been reviewed for conformity with U.S. Geological Survey editorial standards. Any use of trade, product, or firm names is for descriptive purposes only and does not imply endorsement by the U.S. Government.

\section{Denver, CO}




\section{CONTENTS}

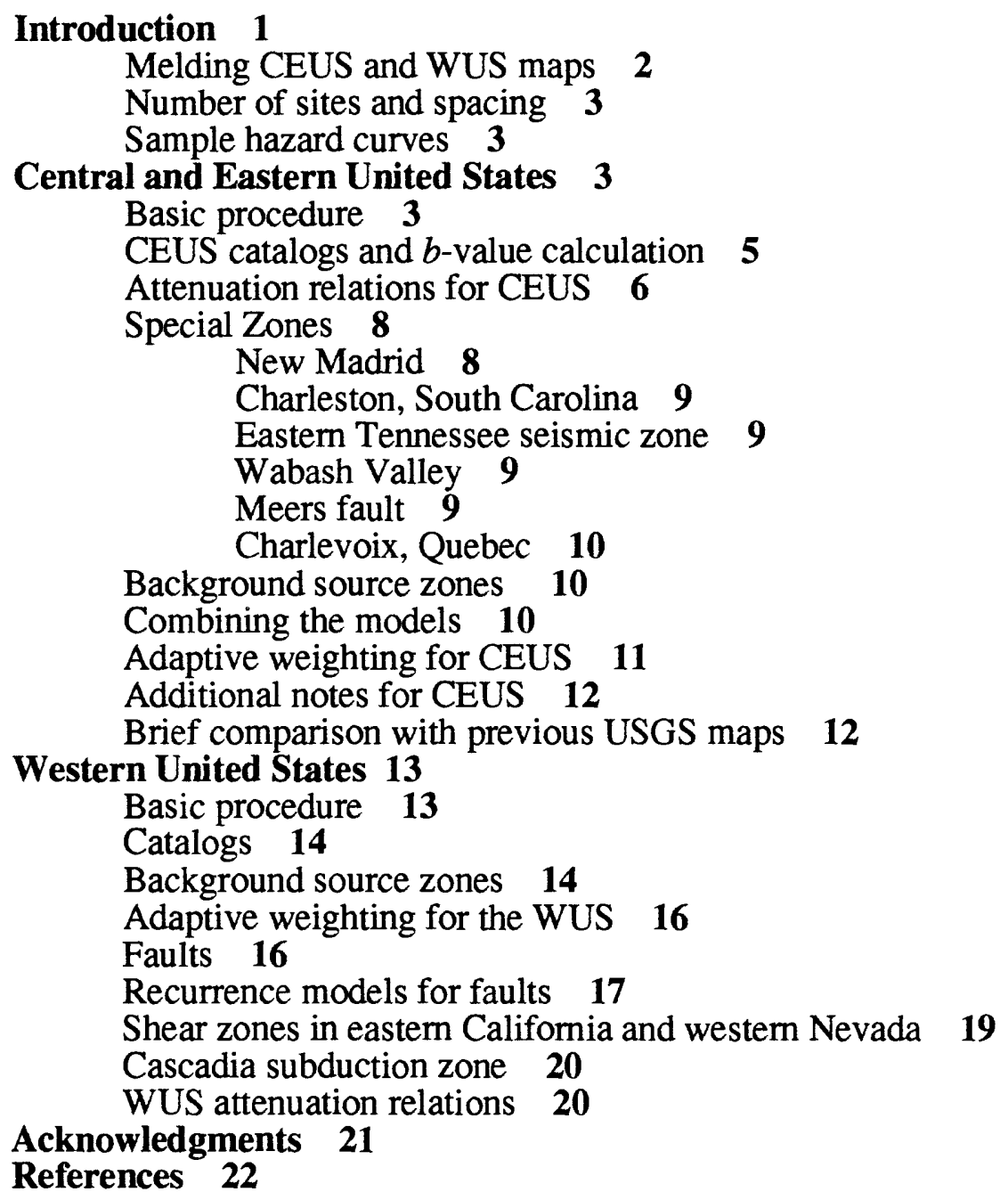

LIST OF ILLUSTRATIONS 26

Figures 1 through $27 \quad \mathbf{2 8 - 5 5}$

\section{APPENDIX A}

Ground motions for NEHRP B-C boundary sites in CEUS 56 Tables Al through A-7 $\quad \mathbf{6 1 - 6 9}$

\section{APPENDIX B}

\section{Seismic-hazard maps for the Conterminous United States 70}




\section{National Seismic-Hazard Maps: Documentation June 1996}

By Arthur Frankel, Charles Mueller, Theodore Barnhard, David Perkins, E.V. Leyendecker, Nancy Dickman, Stanley Hanson, and Margaret Hopper

\section{INTRODUCTION}

New seismic-hazard maps have been prepared by the U.S. Geological Survey for the conterminous United States. In June 1996, these maps were placed on the Internet World Wide Web (http://gldage.cr.usgs.gov/eq/). The color maps can be viewed on the Web or downloaded to the user's computer for printing. Black-and-white variations of the maps are contained in Appendix B.

Interim maps were placed on the Web site in December 1995 for review and comment. The June 1996 maps are the result of revision in light of these reviews and comments. The June 1996 maps represent the products released for this round of map-making. We expect to revise these maps on a 1-1/2- to 2-year cycle as new fault parameters become available and as our methodology is further refined.

This document describes the procedures used to make the maps, the geologic and seismologic inputs to these maps, and the ground-motion relations used for the maps. Most of this documentation was previously used to describe the interim maps. We have added text which explains the changes made for the June 1996 maps. The maps and hazard curves included in this documentation have been revised from the interim documentation to reflect those used in the June 1996 maps. Color versions of the maps and the documentation are available on our Web site.

The hazard maps depict probabilistic ground motions and spectral response with $10 \%, 5 \%$, and $2 \%$ probabilities of exceedance (PE) in 50 years. These maps correspond to return times of approximately 500,1000, and 2500 years, respectively. The maps are based on the assumption that earthquake occurrence is Poissonian, so that the probability of occurrence is timeindependent. The methodologies used for the maps were presented, discussed, and substantially modified during six regional workshops convened by the USGS from June 1994 to June 1995

\section{Regional workshops on Seismic -Hazards Mapping convened by the USGS for input and feedback on methodology for 1996 maps}

1. Pacific Northwest, Seattle, June 7-8, 1994.

2. Northeastern U.S., Lamont-Doherty Earth Observatory, August 2-3, 1994.

3. Northern California, Menlo Park, CA, November 15-16, 1994.

4. Intermountain West, Salt Lake City, February 15-16, 1995.

5. Central and southeastern U.S., Memphis, April 18-19, 1995.

6. Southern California, Pasadena, June 28-29, 1995.

7. Alaska, Anchorage, scheduled for Sept. 1996.

One of the primary features of the new maps is the use of smoothed historical seismicity as one component of the hazard calculation. This idea is similar in philosophy to the methodology used by EPRI (1986) and O'Hara (unpub. data, 1994), where locally determined $a$ and $b$ values were 
used as part of the hazard calculations. Our procedure is more similar to that of Jacob and others (1994), although aspects of our hazard calculation differ from theirs. The mathematics of the procedure used in the USGS maps is described in Frankel (1995) and the reader is referred there for more details.

Another important aspect of this study is the use of alternative models of seismic hazard in a logic tree formalism. For the central and Eastern United States (CEUS), different models based on different reference magnitudes are combined to form the hazard maps. In addition, we use large background zones based on broad geologic criteria as alternative source models for the CEUS and the Western United States (WUS). These background zones are meant to quantify hazards in areas with little historic seismicity but with the potential to produce major earthquakes. The background zones were developed from extensive discussions at the regional workshops.

For the WUS, a big advance in the new maps is the use of geologic slip rates to determine fault recurrence times. We have used slip rates from about 500 faults or fault segments in the June maps.

The hazard maps do not consider the uncertainty in seismicity or fault parameters. We used preferred values of maximum magnitudes and slip rates (see below). The next stage of this effort is the quantification of uncertainties in hazard curves for selected sites.

The national hazard maps are not meant to be used for Mexico, areas north of $49^{\circ} \mathrm{N}$. lat., and offshore the Atlantic and Gulf of Mexico coasts of the United States

\section{Melding CEUS And WUS Maps}

$\mathrm{O}$ ne of the major tasks was combining the CEUS and WUS hazard calculations into one set of national maps. We did separate calculations for the two regions whose delineation was based on the inferred boundary of ground-motion attenuation. The plausible location of this transition between CEUS and WUS attenuation was discussed at the Intermountain West workshop. In that workshop we decided to use a boundary located along the eastern edge of the Basin and Range province (fig. 1). Both the Rocky Mountain region and the Colorado Plateau were assigned to the CEUS attenuation. The area of New Mexico and westernmost Texas was assigned to the WUS attenuation zone. The previous USGS maps (for example, Algermissen and others, 1990) used an attenuation boundary farther to the east along the Rocky Mountain front.

Two sets of hazard calculations were done using different attenuation relations. First we produced two catalogs of earthquakes separated by the attenuation boundary. For earthquakes west of the boundary we used the WUS attenuation relations, and for earthquakes east of the boundary we used CEUS attenuation relations. The hazard calculations were done with a sizeable overlap between runs. The CEUS run was extended westward to $115^{\circ} \mathrm{W}$. The WUS run was extended eastward to $100^{\circ} \mathrm{W}$. For each site we then added the rates of exceedance for the two sets of runs so that the hazard contribution for earthquakes on the other side of the attenuation boundary was included. We should note that we used WUS attenuation relations for WUS earthquakes, even for sites located east of the attenuation boundary. It would have been computationally difficult to consider how much of the path was contained in the CEUS attenuation province. Also, the attenuation relation is dependent on the stress drop, so basing the relation that we used on the location of the earthquake rather than the receiver is reasonable. 


\title{
Number of Sites and Spacing
}

\begin{abstract}
site spacing of $0.1^{\circ}$ in latitude and longitude was used for the WUS and $0.2^{\circ}$ for the CEUS. AThis resulted in hazard calculations at about 65,000 sites for the WUS runs and 35,000 sites for the CEUS runs. Some of these sites were in the overlap area between $100^{\circ}$ and $115^{\circ} \mathrm{W}$. long. The hazard curves calculated for the CEUS on a $0.2^{\circ}$ grid were interpolated to yield a set of hazard curves on a $0.1^{\circ}$ grid. These curves were then added to the hazard curves from the WUS runs. A grid of hazard curves with $0.1^{\circ}$ spacing was thereby obtained for the entire conterminous United States. This grid consisted of hazard curves for about 150,000 sites.
\end{abstract}

\section{Sample Hazard Curves}

The maps were constructed from the mean hazard curves; that is, the mean probabilities of exceeedance (PE) as a function of ground motion or spectral response. Figure 2 shows a set of mean hazard curves used in making the June 1996 maps. For reference, 10\% PE in 50 years corresponds to an annual frequency of exceedance of $2.1 \times 10^{-3} ; 5 \% \mathrm{PE}$ in 100 years corresponds to $1.03 \times 10^{-3}$; and $2 \% \mathrm{PE}$ in 50 years corresponds to $4.04 \times 10^{-4}$. The sites in this plot with highest hazard are San Francisco and Los Angeles. The lowest hazard site in this plot is St. Paul, Minn. This plot shows the general difference in slope of the hazard curves of the CEUS versus the WUS. This difference has been noted in other studies. We show other hazard curves below.

\section{CENTRAL AND EASTERN UNITED STATES}

Note: For simplicity in nomenclature we have included southeastern Canada and northeastern Mexico in our definition of CEUS. Similarly, parts of Mexico and Canada are included in the section entitled "Western United States."

\section{Basic Procedure}

$\mathrm{T}^{\mathrm{s}}$ he basic procedure for constructing the CEUS portion of the hazard maps is diagrammed in figure 3. On the left side, we considered four models of hazard. Model 1 is based on mb3.0 and larger earthquakes since 1924. Model 2 is derived from $\mathrm{mb}_{\mathrm{b}} 4.0$ and larger earthquakes since 1860. Model 3 is produced from mb5.0 and larger events since 1700. In constructing the hazard maps we assigned model 1 a weight twice that of models 2 and 3 . The weighting of the alternative models is discussed below.

For models 1-3, we followed the procedure in Frankel (1995) to construct the hazard maps directly from the historic seismicity. The number of events greater than the minimum magnitude are counted on a grid with spacing of $0.1^{\circ}$ in lat. and long. The logarithm of this number represents the maximum likelihood a-value for each grid cell. Note that the maximum likelihood method counts a mb5 event the same as a mb-3 event in the determination of a-value. Then the gridded a-values are smoothed using a Gaussian function. We used a Gaussian with a correlation distance of $50 \mathrm{~km}$ for model 1 and $75 \mathrm{~km}$ for models 2 and 3. The $50-\mathrm{km}$ distance was chosen because it is similar in width to many of the trends in historic seismicity in the CEUS. In 
addition, it is comparable to the error in location of mb-3 events in the period of 1924-75, before the advent of local seismic networks. We have also made trial hazard maps using correlation distances of 25 and $100 \mathrm{~km}$ for $\mathrm{mb} \geq 3$ events. The $25 \mathrm{~km}$ case produced very grainy-looking maps whose peak values were not much larger than the $50 \mathrm{~km}$ case. The $100-\mathrm{km}$ case tended to over-smooth the results obscuring localized areas of higher seismicity. One problem with using such a large correlation distance occurs when two areas of high seismicity are separated by about one correlation distance. After smoothing, one can get higher values in the region between the active zones than in the zones themselves. This is not a desirable result. We used a larger correlation distance for models 2 and 3 since they include earthquakes further back in time with poorer estimates of locations.

Model 4 (fig. 3) consists of large background source zones. This alternative is meant to quantify hazard in areas with little historical seismicity but with the potential to generate damaging earthquakes. These background zones are detailed in a later section of this text. The sum of the weights of models 1-4 is one. For a weighting scheme that is uniform in space, this ensures that the total seismicity rate in the combined model equals the historic seismicity rate. We will describe later our spatially varying weighting scheme which slightly exceeds the historic seismicity rate.

We used a regional b-value of 0.95 for models 1-4 in all of the CEUS except Charlevoix, Quebec (see below). We determined this b-value from our catalog for events east of $105^{\circ} \mathrm{W}$. (see below). We have also produced hazard maps based on locally derived b-values. We showed these at the Memphis workshop and most participants felt they should not be used, largely because of the relatively short time of the catalog compared with the local rate of $\mathrm{mb}^{4}$ and greater events. It is the local rate of mb4 and larger events relative to the mb3 events that controls the locallydetermined $b$-values. It is important to note, however, that by combining models 1-3 we are essentially including the effects of locally-variable $b$-values. For example, model 3 will have high values where there have been $m b \geq 5$ events historically. These will tend to be areas of low $b-$ values derived on a local basis. The same can be said of model 2 and areas with mb4 events. Conversely, areas with high $b$-values will be lacking in $\mathrm{mb}^{4}$ and $\mathrm{mb}^{5}$ events and will have low values for models 2 and 3. By adding the PE's from models 1-3 together with weighting we are accounting, to some extent, for the local variations in b-value derived from historic seismicity.

Figure 4 shows a map of the CEUS $\mathbf{M}_{\max }$ values used for models 1-4 (bold $\mathbf{M}$ refers to moment magnitude). These values were discussed at two of the workshops and represent the consensus of the Memphis workshop. These $\mathbf{M}_{\max }$ zones correspond to the background zones used in model 4. Most of the CEUS is divided into a cratonic region and a region of extended crust. Rus Wheeler (see Wheeler, 1995) drew the dividing line based on the landward limit of rifting of Grenville age and older crust during the opening of the Iapetan (proto-Atlantic) ocean about 500 m.a. We assigned an $\mathbf{M}_{\max }$ of 6.5 for the cratonic area. For the Wabash Valley zone we used an $\mathbf{M}_{\max }$ of 7.5 in keeping with magnitudes derived from paleoliquefaction evidence (Obermeier and others 1992). We used a $\mathbf{M}_{\max }$ of 7.5 in the zone of extended crust outboard of the craton. This large $\mathbf{M}_{\max }$ was motivated by the magnitude of the 1886 Charleston event (M7.3, Johnston, 1996b), since the workshop participants felt such a large event could not be ruled out in other areas of the extended crust. An $\mathbf{M}_{\max }$ of 6.5 was used for the Rocky Mountain zone and the Colorado Plateau, consistent with the magnitude of the largest historic events in these regions. A $\mathbf{M}_{\max }$ of 7.2 was used for the gridded seismicity within the Charleston areal source zone (see below), so that there would be no overlap between the magnitudes used in the gridded seismicity hazard calculation and that from the areal zone, where M7.3 events are included. Extending the $\mathbf{M}_{\max }$ used for the gridded seismicity to $\mathbf{M} 7.5$ in Charleston would make no significant difference to the hazard values. All of the above $\mathbf{M}_{\mathbf{m a x}}$ values are moment magnitudes. A minimum mb of 5.0 was used in all the hazard calculations for the CEUS. 
Model 5 (fig. 3, right) consists of the contribution from large earthquakes $(\mathbf{M}>7.0)$ in four specific areas of the CEUS: (1) New Madrid; (2) Charleston, S.C.; (3) the Meers fault in southwest Oklahoma; and (4) the Cheraw Fault in eastern Colorado. This model has a weight of 1. We describe how we treated these special areas in a later section. There are three other areas in the CEUS that we call special zones: eastern Tennessee, Wabash Valley, and Charlevoix. They are detailed in a later section.

Frankel (1995) shows hazard maps based on earlier versions of models 1, 3, 4, and 5, for reference.

\section{CEUS Catalogs and b-value Calculation}

The primary catalog used for the CEUS for longitudes east of $105^{\circ}$ is Seeber and Armbruster (1991), which is a refinement of the EPRI (1986) catalog. We supplemented this with the PDE catalog from 1985-95. In addition, PDE; DNAG; Stover and Coffman (1993); and Stover, Reagor, and Algermissen (1984) catalogs were searched to find events not included in Seeber and Armbruster (1991). Mueller and others (1996) describe the treatment of catalogs, adjustment of rates to correct for incompleteness, the removal of aftershocks, and the assignment of magnitudes.

One of the most crucial parameters affecting the hazard maps is the magnitude of the events. For the CEUS, we used a catalog based on the mblg magnitude scale. We assumed that the preferred magnitudes in Seeber and Armbruster represented mblg. and that mblg equal $\mathrm{mb}$ in the CEUS. Treatment of magnitudes in the other catalogs is described in Mueller and others (1996).

In a few cases, events were deleted or moved. For example, the $1909 \mathrm{mb}-5.0$ event in northern Illinois was moved to the location specified in Stover and Coffman (1993) and consistent with felt reports. The preferred location is $1^{\circ} \mathrm{N}$. of that in Seeber and Armbruster ( 1991), placing it just west of Chicago. Based on information provided by Martin Chapman we moved the location of the 1916 Skyland event in western North Carolina farther to the west. We also removed from the catalog earthquakes induced by fluid injection, such as the events near Denver's Rocky Mountain Arsenal, events near Rangely, Colo., and events near Cogdell, Tex. (Davis and Pennington, 1989).

Aftershocks and other dependent events were removed from the catalog before calculations of completeness times, and a and b-values (see Mueller and others, 1996).

Completeness times for different magnitude ranges (say events greater than mbref) were determined by plotting cumulative numbers of events against time for events with magnitude between mbref and mbref +0.5 (for example, 3.0 and 3.5). An example of such a plot is shown in Figure 5a, for $\mathrm{mb}_{\mathrm{b}}$ 3.0-3.5 in the major portion of the CEUS. There is an increase of slope or detection rate at about 1924 and another increase of slope at about 1975. The rate appears to taper off from about 1985-1995. We use 1924 as the beginning of the counting period for events with magnitudes $>3.0$. Next we adjusted the total rate of $\mathrm{mb}_{\mathrm{b}} 3.0$ and larger events to equal the rate observed since 1976. (See Mueller and others, 1996, for more details.) The cumulative number plots indicate that mb3.0 events are complete since about 1976 . Figure $5 \mathrm{~b}$ shows the cumulative number versus time plot for $\mathrm{mb}$ 3.0-3.5 in the New Madrid area. There is a strong increase in detection rate starting about 1927. The rate then decreases until about 1950 when it increases to a fairly constant rate. Therefore, using 1976 as a start of the completeness period for mb3.0 and larger events is reasonable for this region. Veneziano and Van Dyck (1986) and 
Bollinger and others (1989) found a similar completeness time for mb-3 events in specific areas in the CEUS.

For the entire CEUS catalog east of $105^{\circ}$ long. (excluding Charlevoix events), we calculated a bvalue of $0.96 \pm 0.02$, based on the maximum likelihood (ML) of Weichert (1980) using different completeness periods for different magnitude ranges (see fig. 6). The beginning of the completeness periods were: 1976 for $\mathrm{mb}_{\mathrm{b}} 3.0-3.9,1940$ for $\mathrm{mb} 4.0-4.9,1860$ for $\mathrm{mb} 5.0-7.0$ and 1800 for $\mathrm{mb}_{\mathrm{b}} \geq 7.0$. A least-squares fit to the data also yields a $b$-value of 0.96 (fig. 6 ). Therefore, we used a regional b-value of 0.95 to calculate the hazard in the CEUS, based on rounding the calculated $b$-value of 0.96 to the nearest 0.05 . For the Charlevoix region we used the $b$-value of 0.76 based on the work of John Adams, Stephen Halchuck, and Dieter Weichert of the Geologic Survey of Canada (see Adams and others, 1996). This lower $b$-value was assigned to a roughly elliptical area about $40 \mathrm{~km}$ by $70 \mathrm{~km}$, encompassing the cluster of seismicity around Charlevoix.

Using a regional b-value of 0.95 ensures that the sum of the a-values in each of models 1 and 2 extrapolates to a rate of $\mathrm{mb} 5$ and greater events about equal to the historic rate (see fig. 6). Of course, model 3 is already based on the historic rate of mb5+ events. Thus, the maps are essentially constrained by the historic rates of $\mathrm{mb}_{\mathrm{b}} 5$ and greater events in the CEUS.

\section{Attenuation Relations for CEUS}

$\mathrm{T}$ The reference site condition used for the maps is specified to be the boundary between NEHRP classes B and C (Martin and Dobry, 1994), meaning it has an average shear-wave velocity of $760 \mathrm{~m} / \mathrm{sec}$ in the top $30 \mathrm{~m}$. This corresponds to a typical "firm-rock" site for the Western United States (see WUS attenuation section below), although many rock sites in the CEUS probably have much higher velocities. The basic motivation for using this reference site is that it corresponds to the average of sites classified as "rock" sites in WUS attenuation relations (see WUS attenuation section). In addition, we felt it would be less problematic to use this site condition for the CEUS than to use a soil condition. Most previously published attenuation relations for the CEUS are based on a hard-rock site condition. It is less problematic to convert these to a firm-rock condition than to convert them to a soil site, since there would be less concern over possible non-linearity for the firm-rock site compared to the soil site. Participants of the Applied Technology Council (ATC) 35 workshop on the national maps (Sept. 1995) recommended a rock-site reference, although the $B / C$ boundary was not specified.

For the CEUS, we used two, equally weighted, attenuation relations. Both sets of relations were derived by stochastic simulations and random vibration theory. First we used Toro and others (1993) formula based on mblg. The attenuation relations were multiplied by frequencydependent factors to convert them from hard-rock to firm-rock sites (see below and Appendix A). We derived coefficients for $0.3 \mathrm{sec}$ spectral response by interpolating the Toro and others (1993) coefficients for 0.2 and $0.5 \mathrm{sec}$.

The second set of relations was derived by us for firm-rock sites (see Appendix A). These relations were based on a Brune source model with a stress drop of 150 bars. The simulations contained frequency-dependent amplification factors derived from a hypothesized shear-wave velocity profile of a CEUS firm-rock site. We produced a series of tables of ground motions and response spectral values as a function of moment magnitude and distance (these tables are contained in the Appendix A). In the hazard program, we calculate the hazard over increments of mblg. Each mblg value has an associated rate of earthquake occurrence. We convert the mblg to a moment magnitude using the empirical relation of Johnston (1994; we used the relation in this pre-print which differs slightly from that in the 1996 published version; we used $\mathbf{M}=3.45$ - 
$0.473 \mathrm{mblg}+0.145 \mathrm{mblg}^{2}$ ). Thus, the rate of occurrence is assigned to the converted value of moment magnitude. This allows us to use the attenuation tables based on moment magnitude. Note that the magnitude conversion is not needed for the Toro and others (1993) relations, since they were based on mblg.

The magnitude conversion is needed when determining mblgmax values corresponding to $\mathbf{M}_{\max }$ values (moment magnitude). We used the Johnston (1994) conversion to find mblgmax's when using our new ground motion tables, to be consistent with the conversion used in the hazard code. We used the Boore and Atkinson (1987) conversion to find mblgmax's for Toro and others (1993).

For the large events in model 5, we used the attenuation relations for moment magnitude from Toro and others (1993) and our tables, with equal weights.

One key parameter was the site attenuation or kappa $\left(t^{*}\right)$ value. We chose a kappa value of 0.01 . This is much lower than site kappas found for typical Western United States rock sites. Our justification comes from work by Joe Fletcher using borehole recordings at Savannah River, S.C., of regional and local earthquakes. Fletcher determined kappa values for recordings made from a borehole sensor in bedrock and from a site at the top of the borehole on stiff soil. He found a difference of about 0.01 , implying that the kappa of this soil site was about 0.01 . Thus, we think this low value is reasonable to be used for a firm-rock site in the CEUS (see Appendix).

We also derived ratios between simulations using firm-rock site conditions and those using hard rock site conditions with the surface velocity and site kappa used by Toro and (1993). Values were found from the average ratios for M5.0-5.6 and distances of 10-50 km. We used these average ratios as factors to adjust the Toro and others (1993) hard-rock relations to firm-rock site conditions. We applied a factor of 1.52 for PGA, 1.76 for $0.2 \mathrm{sec}$ spectral response, 1.72 for 0.3 sec spectral response and 1.34 for $1.0-\mathrm{sec}$ spectral response. These factors were applied independently of magnitude and distance.

For CEUS hazard calculations for models $1-4$ we assumed a source depth of $5.0 \mathrm{~km}$ when using our new ground motion tables. Since we have a minimum hypocentral distance of $10 \mathrm{~km}$ in these tables, the probabilistic ground motions are insensitive to the choice of source depth. In the hazard progam, when hypocentral distances are $<10 \mathrm{~km}$ we set them to $10 \mathrm{~km}$ when using the tables. For the Toro and others (1993) relations, we used the fictitious depths that they specify for each period, so that our choice of source depth was not applied. For M8.0 events in New Madrid and M7.3 events at Charleston, we used a source depth of $10 \mathrm{~km}$ when using our tables.

For both sets of ground motion relations, we used values of $0.75,0.75,0.75$ and 0.80 for the natural logarithms of the standard deviation of PGA, 0.2-, 0.3-, and 1.0-sec spectral responses, respectively. These values are similar to the aleatory standard deviations reported in Senior Seismic Hazard Analysis Committee (1996). All spectral-response values shown in the maps correspond to $5 \%$ of critical damping.

For models 1-4 we used a maximum source-site distance of $500 \mathrm{~km}$ when calculating the hazard at each site. For model 5, we used a maximum source-site distance of $1000 \mathrm{~km}$ when calculating hazard at each site. On the 1.0-sec spectral maps, there are artifacts of the 1000-km maximum distance cut-off. On the $2 \%$ PE in 50 year map one can see some of the lowest contour levels about $1000 \mathrm{~km}$ from the New Madrid area. The M8.0 events at New Madrid still have a significant contribution to $1.0-\mathrm{sec}$ hazard, even at $1000 \mathrm{~km}$.

A cap in the MEDIAN ground motions was placed on the ground motions within the hazard code. We were concerned that the median ground motions of both the Toro and others, and the 
new Boore tables became very large ( $>2.5 \mathrm{~g}$ PGA) for distances of about $10 \mathrm{~km}$ for the $\mathbf{M} 8.0$ events for New Madrid. We capped the median PGA's at $1.5 \mathrm{~g}$. The median $0.3-$ and $0.2-\mathrm{sec}$ values were capped at $3.75 \mathrm{~g}$ which was derived by multiplying the PGA cap by 2.5 (the WUS conversion factor). This only affected the PGA values for the $2 \% \mathrm{PE}$ in 50-year maps for the area directly above the three fictitious faults for the New Madrid region (see below). It does not change any of the values at Memphis. Without the clipping, the $2 \% / 50$-year values were over $2 g$ for this limited area over the New Madrid "faults". With the clipping, the values are about $1.5 \mathrm{~g}$. The capping did not significantly alter the 0.3 - and $0.2-\mathrm{sec}$ values in this area. The PGA and spectral response values did not change in the Charleston region from this capping. Note that the capping was for the median values only. The variability (sigma) of the ground motions was still maintained in the hazard code, so that values larger than the median were allowed. We felt that the capping recognizes that values derived from point source simulations are not as reliable for M8.0 earthquakes at close-in distances $(<20 \mathrm{~km})$.

\section{Special Zones}

\section{New Madrid}

To calculate the hazard from large events in the New Madrid area we considered three parallel faults in an S-shaped pattern encompassing the area of highest historic seismicity (fig. 7 ). These are not meant to be actual faults; they are simply a way of expressing the uncertainty in the source locations of large earthquakes such as the 1811-12 sequence. The extent of these fictitious faults is similar to those used in Toro and others (1992). We assumed a characteristic rupture model with a characteristic moment magnitude $\mathbf{M}$ of 8.0 , similar to the estimated magnitudes of the largest events in 1811-12 (Johnston, 1996a, b). A recurrence time of 1000 years for such an event was used as an average value, considering the uncertainty in the magnitudes of prehistoric events. A recent compilation by Johnston and Schweig (1996) suggests a 500-year recurrence time for paleoliquefaction episodes (Johnston and Schweig, written commun., 1996). Tuttle and Schweig (1995) report two to three paleoliquefaction events over the past 5000-6000 years, but the earlier part of the record is likely incomplete. Of course, some of these events could have had magnitudes less than 8.0 .

Another possibility we tried was to use an exponential recurrence distribution starting at M7.5. We tried a run with such a distribution based on a cumulative recurrence time of 1500 years for events $>$ M7.5. This run produced substantially lower probabilistic ground motions than the characteristic run.

When applying the Toro and others (1993) and our attenuation tables to these finite faults, we measured distance to the closest point on the fault plane, with the shallowest part of the fault being at $10 \mathrm{~km}$ depth. We used the moment magnitude attenuation relations of and Toro and others (1993) and directly applied our tables based on moment magnitude.

In the June maps, we used an areal source zone for New Madrid for models 1-3, rather than the spatially smoothed historic seismicity. This area zone is shown in figure 8 and is bounded by the borders of the Reelfoot Rift. This zone accounts for the hazard from New Madrid events with moment magnitudes $<7.5$. The a-value for this zone was calculated from the rate of $\mathrm{mb}_{\mathrm{b}} 3.0$ and larger events observed since 1976. This $a$-value yields a recurrence time of 540 years for events with $\mathrm{mb}_{\mathrm{b}} \geq 6.5$, when added to the rate of $\mathbf{M} 8.0$ events in model 5 . 


\section{Charleston, South Carolina}

We used an areal source zone (fig. 9) to quantify the hazard from large earthquakes. This zone was drawn to encompass a narrow source zone defined by Pradeep Talwani (written commun., 1995; used in interim maps; see also, Talwani, 1982; Marple and others, 1994) and a larger zone drawn by S. Obermeier and R. Weems (written commun., 1996). The extent of the areal source zone was constrained by the areal distribution of paleoliquefaction locations, although the source zone does not encompass all the paleoliquefaction sites. We assumed a characteristic rupture model of moment magnitude 7.3 earthquakes, based on the estimated magnitude of the 1886 event (Johnston, 1996b). Note that we lowered the $\mathbf{M}_{\max }$ to $\mathbf{M} 7.2$ for models 1-3 for this areal source zone, to avoid double counting events. For the $\mathbf{M} 7.3$ events we used a recurrence time of 650 years, based on dates of paleoliquefaction events (Obermeier and others, 1990; Amick and Gelinas, 1991; Johnston and Schweig, written commun., 1996). We used vertical faults with random strikes distributed throughout the areal source zone when calculating the hazard. Each of these fictitious faults is centered on a grid cell within the source zone.

\section{Eastern Tennessee Seismic Zone}

Several participants in the Memphis workshop wanted a special source zone for the eastern Tennessee seismic zone. This is a linear trend of seismicity that is most obvious for smaller events with magnitudes around 2 (see Powell and others, 1994 ). The magnitude 3 and larger earthquakes tend to cluster in one part of this linear trend, so that hazard maps based just on smoothed $\mathrm{mb}^{3}$ and larger events tend to be high in one portion of the zone. Therefore, we used a source zone suggested by Martin Chapman based on the microseismicity (fig. 10). When calculating a-values for model 1 we counted the number of events $\left(m_{b} \geq 3\right.$ since 1976) that occurred within this zone to determine an a-value for this zone. This was the a-value used for grid cells within the zone for models 1-3. Using this areal zone elongates the contours of high hazard, corresponding to the trend of the source zone.

\section{Wabash Valley}

Recent work has identified several paleoearthquakes in the areas of southern Indiana and Illinois based on widespread paleoliquefaction features (Obermeier and others, 1992). We considered an areal zone with a higher $\mathbf{M}_{\max }$ of 7.5 to account for such large events (fig. 4). We did not use this zone to determine a-values for the hazard calculation; the gridded seismicity was used instead (models 1-3). The sum of the gridded a-values in this zone calculated from model 1 produce a recurrence time of 2600 years for events with $\mathrm{mb} \geq 6.5$. The recurrence rate of M6.5 and greater events is estimated to be about 4000 years from the paleoliquefaction dates ( $P$. Munson and S. Obermeier, oral commun., 1995), so it is not necessary to add additional large events to augment models 1-3. The Wabash Valley $\mathbf{M}_{\max }$ zone that we used in the maps is based on the Wabash Valley fault zone. Rus Wheeler drew the outline of the fault zone.

\section{Meers Fault}

We explicitly included the Meers fault in southwestern Oklahoma. We used the segment of the fault which has produced a Holocene scarp as described in Crone and Luza (1990). We considered a characteristic moment magnitude of 7.0 and a recurrence time of 4000 years based on the work of Crone and Luza (1990). Because of the long recurrence time, this fault has very little effect on the probabilistic grounds motions, event for the maps with $2 \%$ PE in 50 years. 


\section{Charlevoix, Quebec}

As mentioned above, a $40 \mathrm{~km}$ by $70 \mathrm{~km}$ region surrounding this seismicity cluster was assigned a b-value of 0.76 , based on the work of Adams, Halchuck and Weichert. This b-value was used in models $1-3$.

\section{Cheraw Fault}

The June 1996 maps contain this eastern Colorado fault with Holocene faulting, based on a study by Crone and others (1996). We determined the recurrence rate of this fault from a slip rate of $0.5 \mathrm{~mm} / \mathrm{yr}$. A maximum magnitude of 7.1 was found from the fault length using the relations of Wells and Coppersmith (1994). As with the WUS faults, we used characteristic and GutenbergRichter recurrence models (see below) with equal weighting. CEUS attenuation relations were applied to calculate the hazard from this fault.

\section{Background Source Zones (model 4)}

The background source zones are intended to quantify seismic hazard in areas that have not had 1 significant historic seismicity, but could very well produce sizeable earthquakes in the future. In essence, these zones address the possible non-stationarity of seismicity. Background source zones were largely agreed upon in the Memphis workshop and are shown in figure 11. They consist of a cratonic zone, an extended margin zone, a Rocky Mountain zone, and a Colorado Plateau zone. The latter zone was discussed at the Salt Lake City workshop. The Rocky Mountain zone was not discussed at any workshop, but is clearly defined by the Rocky Mountain front on the east and the areas of extensional tectonics to the west, north, and south. As stated above, the dividing line between the cratonic and extended margin zone was drawn by Rus Wheeler based on the westward and northern edge of rifting during the opening of the Iapetan ocean. One justification for having craton and extended crust zones is the work done by Johnston and others (1994). They compiled a global survey of earthquakes in cratonic and extended crust and found a higher seismicity rate (normalized by area) for the extended areas.

Some of the boundaries of the background zones are drawn along the international borders or along the coastline. Although these may seem arbitrary, we think it is valid to use the international borders since we want the hazard maps to reflect the area-normalized rates of seismicity in the broad area of interest for this set of maps, that is, the United States. The boundary along the coast is necessary because the catalog is obviously incomplete for offshore earthquakes.

The a-values for each background zone were determined by counting the number of $\mathrm{mb}_{\mathrm{b}} 3$ and larger events within the zone since 1924 and adjusting the rate to equal that since 1976 . The areanormalized $a$-value was then disaggregated into a set of grid cells, so that we could calculate the hazard using the same computer code used with the smoothed historic seismicity. A $b$-value of 0.95 was used for all the background zones, based on the $b$-value found for the entire CEUS.

\section{Combining the Models}

The inclusion of background zones lowers the probabilistic ground motions in areas of relatively high historic seismicity while raising the hazard to only low levels in areas with no historic seismicity. Figure 12 shows a hazard map (PGA 2\% PE in 50 years) without the background zones (using models $1-3$ and 5 with weights of $0.5,0.25,0.25,1$, respectively), while 
figure 13 contains a hazard map derived solely from the background zones (model 4 only). The probabilistic ground motions from the background zones are not small, relative to the values in much of the original map. In areas of low seismicity such as Iowa, Wisconsin, and Florida, the ground motions from the background zone are much higher than those from models $1-3$, and 5 (compare figs. 13 and 12). We combined the five models using weights of $0.4,0.2,0.2,0.2$, and 1.0 , respectively, to make the map in figure 14. Note that this decreases the values relative to Figure 12 in areas of higher seismicity such as eastern Tennessee, New York City, and the northern New York State-Ottawa region. Now the mapped values (fig. 14) are significantly higher in quiescent areas such as Florida, Texas, Iowa, and Wisconsin than the map without the background zones (fig. 12). This increase is at the expense of the more active areas, which are lower in figure 14 than in figure 12.

The effects of including the background zones can also be visualized from the hazard curves. Figure 15 displays two sets of hazard curves for six CEUS cities (Memphis, New York City, Chicago, Houston, St. Paul, and Miami): one set made with the background zones (models 1-5; dashed lines) and one set made without them (models 1-3,5; solid lines). Adding the background zones slightly lowers the hazard curves for Memphis and New York City, while substantially raising the hazard curves in Houston, St. Paul, and Miami. Although the hazard curves in the latter cities are still not high after including the background zones, their PE's are increased by a factor of 2-3 relative to the values found without the background zones. The hazard curve for Chicago is not significantly affected by the inclusion of the background zones. Note the difference in the slope of the hazard curves for St. Paul and Miami. This may be caused by the difference $\mathbf{M}_{\max }$ values, since St. Paul is in the craton zone and Miami is in the extensional zone.

\section{Adaptive Weighting for CEUS}

$\mathrm{T}$ he interim hazard maps of the CEUS did not incorporate the background zones, because they can lower the hazard in some locations from that calculated from the historic seismicity alone. The June 1996 versions of the maps do include the background zones using a weighting scheme that can vary locally depending on the level of historic seismicity in that cell of the a-value grid. Spatially varying weighting was suggested by Allin Cornell in the external review of the interim maps. Our "adaptive weighting" scheme avoids lowering the hazard in higher seismicity areas to raise the hazard in low seismicity areas. We implemented this by looping through the a-value grid and checking to see if the a-value for each cell from the historic seismicity was greater than the a-value from the background zone. For the CEUS the a-value from the historic seismicity was derived by weighting the rates from models 1,2 , and 3 by $0.5,0.25,0.25$ respectively. If this weighted sum was greater than the rate from the appropriate background zone, then the rate for that cell was determined by weighting the rates from models $1-3$ by $0.5, .25, .25$ (that is, historic seismicity only, no background zone). If the weighted sum from the historic seismicity was less than the rate of the background zone, then we used a weighting scheme of $0.4,0.2,0.2,0.2$ for models 1-4, respectively (including the background zone as model 4). This scheme does not make the rate for any cell lower than it would be from the historic seismicity (models 1-3). It also incorporates the background zones in areas of low historic seismicity. The total seismicity rate in the resulting a-value grid is only $10 \%$ larger than the observed rate of $\mathrm{mb}^{3}$ 's since 1976 . We think this is not a major difference. Of course, this scheme produces substantially higher ground motions (in terms of percentage increase) in the seismically quiet areas, than was found in the interim maps. These values are still quite low in an absolute sense.

Figure 16 shows a hazard map derived from the a-value grid made with this adaptive weighting method, plus model 5 . Note that areas of relatively high hazard have identical values between 
this map and the map using only historic seismicity plus model 5 (compare figs. 16 and 12; for example, eastern Tennessee, northern New York State to Ottawa). Areas of lower hazard (e.g., Minnesota, Wisconsin, Florida, eastern Texas, southwestern Pennsylvania) now have higher values than in the case with just the historic seismicity. These areas have values equal to those in the map made with the background zone and the historic seismicity (compare figs. 16 and 14).

It is useful to compare the CEUS hazard curves made with adaptive weighting (fig. 2) with those on figure 15 made with and without the background zones. For areas of higher hazard such as Memphis and New York City, the adaptive weighting hazard curves in Figure 2 are equivalent to those in figure 15 made without the background zones. For areas of lower hazard such as St. Paul, the adaptive weighting hazard curve in Figure 2 is equivalent to the hazard curve in figure 15 constructed with the background zone and the smoothed historic seismicity.

\section{Additional Notes for CEUS}

$\mathrm{O}_{\mathrm{s}}^{\mathrm{n}}$ ne criticism of the use of gridded historic seismicity is that it assumes that seismicity is stationary in time, so that areas of high activity in the past will remain so in the near-future. It has been suggested that using areal source zones based on geologic or geophysical criteria obviates the problem of nonstationary seismicity. We disagree. When a-values are determined for areal source zones they are necessarily based on the historic catalog. Therefore, they are still at the mercy of nonstationarity. This problem becomes even more severe as one tries to pick small source zones over localized features which may be tectonic. The more localized the source zone, the more likely you will not have a representative sampling of the a-value for this feature from the historic seismicity. This is one reason why we preferred to use large background source zones. This is one way to combat any nonstationarity in the seismicity by assuming that seismicity rates averaged over large areas are more stable in time.

It is useful to compare our maps to the source zones used in the EPRI (1986) study. For the areas to the north and west of New Madrid, most of the six EPRI teams had three source zones in common: (1) the Nemaha Ridge in Kansas and Nebraska, (2) the Colorado-Great Lakes lineament extending from Colorado to the western end of Lake Superior, and (3) a small fault zone in northern Illinois, west of Chicago. Each of these source zones are apparent as higher hazard areas in the our maps. The Nemaha Ridge is outlined in the maps because of magnitude 4 and 5 events occurring in the vicinity. Portions of the Colorado-Great Lakes lineament show higher hazard on the map, particularly the portion in South Dakota and western Minnesota. The portion of the lineament in eastern Minnesota has been historically inactive, so is not apparent on the our maps. The area in western Minnesota shows some hazard because of the occurrence of a few magnitude 4 events since 1860. A recent paper by Chandler (1995), argues that the locations and focal mechanisms of these earthquakes are not compatible with them being on the lineament, which is expressed as the Morris Fault in this region. The area in northern Illinois has relatively high hazard in the our maps because of M4-5 events that have occurred there.

Frankel (1995) found good agreement in the mean PE's and hazard curves derived from models 1-3 and 4 and those produced by the EPRI (1986) study, when the same PGA attenuation relation s were used.

\section{Brief Comparison with Previous USGS Maps}

ne of the major outcomes of the new maps for the CEUS is that the ground motions are about a factor of 2-3 times lower, on average, than the PGA values in Algermissen and others (1990) and the spectral values in Algermissen and others (1991) and Leyendecker and others (1995). We discussed this difference at the workshops. The primary cause of this difference is 
the magnitudes assigned to pre-instrumental earthquakes in the catalog. Magnitudes of historic events used by Algermissen and others were based on I max (maximum observed intensity), using magnitude-I $\max$ relations derived from WUS earthquakes. This overestimates the magnitudes of these events and, in turn, overestimates the rates of M4.9 and larger events. The magnitudes of historic events used in the new maps were primarily derived by Seeber and Armbruster (1991) from either felt area or I max using relations derived from CEUS earthquakes (Sibol and others, 1987). Thus, rates of M4.9 and larger events are much lower in the new catalog, compared to those used for the previous USGS maps.

\section{WESTERN UNITED STATES}

Note: The California portion of the hazard maps was produced jointly by us and Mark Petersen, Chris Cramer and Bill Bryant of the California Division of Mines and Geology (CDMG).

\section{Basic Procedure}

The scheme for mapping hazard in the WUS is shown in figure 17. On the left side we consider most of the WUS, we used two alternative models: 1) smoothed historical seismicity (weight of 0.67 ) and 2) large background zones (weight 0.33 ) based on broad geologic criteria and workshop input. Model 1 used a $0.1^{\circ}$ source grid to count number of events. We changed the determination of a-value somewhat from the CEUS, to incorporate different completeness times for different magnitude ranges. The a-value for each grid cell was calculated from the maximum likelihood method of Weichert (1980), based on events with magnitudes of 4.0 and larger. We used M4.0-5.0 since 1963, M5.0-6.0 since 1930, and M6.0 and larger since 1850. For the first two categories, completeness time was derived from plots of cumulative number of events versus time. The catalogs are probably not complete for all magnitude 6 events since 1850, but we felt it was important to include these events in the a-value calculation. It is important to note that the calculation of a-value counts one magnitude 6 event the same as one magnitude 4 event (this is also true for the CEUS). We did not use M3 events in the WUS hazard calculations since they are only complete since about 1976 for most areas and may not even be complete after 1976 for some areas. For California we used M4.0-5.0 since 1933, M5.0-6.0 since 1900, and M6.0 and larger since 1850 . The catalog for California is complete to earlier dates compared to the catalogs for the rest of the WUS (see below).

Another difference with the CEUS is that we did not use multiple models with different minimum magnitudes for the a-value estimates (such as models 1-3 for the CEUS). The use of such multiple models in the CEUS was partially motivated by the observation that some $\mathrm{mb}^{4}$ and $\mathrm{mb}_{\mathrm{b}} 5$ events in the CEUS occurred in areas with few mb3 events since 1924 (for example, Nemaha Ridge events and western Minnesota events). We wanted to be able to give such $\mathrm{mb}_{\mathrm{b}}$ and $\mathrm{mb}_{\mathrm{b}} 5$ events extra weight in the hazard calculation over what they would have in one run with a minimum magnitude of 3 . In contrast it appears that virtually all M5 and M6 events in the WUS have occurred in areas with numerous M4 events since 1965 . We also were reluctant to use a WUS model with a-values based on a minimum magnitude of 6.0 , since this would tend to double count events that have occurred on mapped faults included on figure 17 right.

For model 1, the gridded a-values were smoothed with a Gaussian with a correlation distance of $50 \mathrm{~km}$, as in model 1 for the CEUS. The hazard calculation from the gridded a-values differed from that in the CEUS, because we considered fault finiteness in the WUS calculations. For each 
source grid cell, we used a fictitious fault for magnitudes of 6.0 and larger. The fault was centered on the center of the grid cell. The strike of the fault was random and was varied for each magnitude increment. The length of the fault was determined from the relations of Wells and Coppersmith (1994). The fictitious faults were taken to be vertical.

A maximum moment magnitude of 7.0 was used for models 1 and 2, except for four shear zones in northeastern California and western Nevada described below. Of course, larger moment magnitudes are included in the specific faults (fig. 17 right; see below). A minimum moment magnitude of 5.0 were used for models 1 and 2. For each WUS site, the hazard calculation was done for source-site distances of $200 \mathrm{~km}$ and less, except for the Cascadia subduction zone, where the maximum distance was $1000 \mathrm{~km}$. The $200 \mathrm{~km}$ maximum distance may actually be too large in the sense that some of the attenuation relations used were based on data up to about 100 $\mathrm{km}$ (see below).

We did separate hazard calculations for deep events $(>35 \mathrm{~km})$. These events were culled from the catalogs. Their $a$-values were calculated separately from the shallow events. Different attenuation relations were used (see below).

We calculated regional b-values based on the method of Weichert (1980), using events with magnitudes of 4 and larger and using varying completeness times for different magnitudes. We found a $b$-value of $0.80 \pm 0.03$ for the Western United States without California. Accordingly, a regional $b$-value of 0.8 was used in models 1 and 2 for the WUS runs based on shallow events. For the deep events $(>35 \mathrm{~km})$, we found an average $b$-value of 0.65 . We used this low $b$-value in the hazard calculations for the deep events.

We used a $b$-value of 0.9 for most of California, except for the easternmost portion of California in our basin and range background zone (see below). This $b$-value was derived by CDMG.

\section{Catalogs}

Tor the WUS, except for California, we used the Stover and Coffman (1993), Stover, Reagor, 7 and Algermissen (1984), PDE, and DNAG catalogs (with the addition of Alan Sanford's catalog for New Mexico). For Califomia, we used a catalog compiled by Mark Petersen of California Division of Mines and Geology (CDMG). Mueller and others (1996) describes the processing of the catalogs, the removal of aftershocks, and the assignment of magnitudes. We removed Utah coal-mining events from the catalog (see Mueller and others, 1996). Explosions at NTS and their aftershocks were also removed from the catalog.

As in the CEUS, the treatment of magnitudes is crucial to the hazard maps and is somewhat problematic. The magnitudes in the catalogs were converted to moment magnitudes using the scheme described in Mueller and others (1996).

\section{Background Source Zones}

The background source zones for the WUS (model 2) were based on broad geologic criteria 1 and were developed by discussion at the Salt Lake City (SLC) workshop (except for the Cascades source zone). These zones are shown in figure 18. Note that we do not have background source zones west of the Cascades and west of the Basin and Range province. For those areas, we simply used model 1 with a weight of 1 . 
At the SLC workshop, we started with one large source zone encompassing the Basin and Range Province as well as other areas of extensional tectonics and the region of compressional tectonics in eastern Washington. Then we asked workshop participants to choose areas that they thought should be separate source zones because of their tectonic uniqueness. There was substantial sentiment for a Yellowstone Parabola source zone (see, for example, Anders and others, 1989) that would join up seismically-active areas in western Wyoming with the source areas of the Borah Peak and Hebgen Lake earthquakes. It was felt that the relatively seismically-quiescent areas consisting of the Snake River Plain and Colorado Plateau should be separate source zones because of the geologic characteristics. An area of southwest Arizona was suggested as a separate source zone by Bruce Schell, based partly on differences in the age and length of geologic structures compared with the Basin and Range Province (see Euge and others, 1992). We have since added a Cascades source zone since we felt that was a geologically distinct area.

The remaining background source zone includes the Basin and Range Province, the Rio Grande Rift, areas of Arizona and New Mexico, portions of west Texas, and areas of eastern Washington and northern Idaho and Montana. The northern border of this zone follows the international border. As stated above, we think this is a valid approach since we are interested in basing the hazard maps on the seismicity rate in the area of interest.

This large background zone is intended to address the possibility of having large earthquakes (M6 and larger) in areas with relatively low rates of seismicity in the brief historic record. It is important to have a large zone that contains areas of high seismicity in order to quantify the hazard in relatively quiescent areas such as eastern Oregon and Washington, central Arizona, parts of New Mexico, and west Texas. One can see the effect of this large background zone by noting the contours on the hazard maps in these areas. Of course the prominence of the background zones in the maps is determined by the weighting of models 1 and 2 .

The a-values were determined for each background zone by counting the number of events with $\mathbf{M} \geq 4.0$ since 1963 in each zone. As with the CEUS, the area-normalized $a$-values were distributed into a set of grid cells. The hazard was calculated directly from these gridded avalues. Fictitious finite faults centered on each grid cell were used for $\mathbf{M} \geq 6.0$.

In Figures 19-21, we show the effect of adding the background zones to one of the hazard maps made from the WUS runs. Figure 19 is the hazard map made from model 1 (the gridded seismicity), not including faults. Figure 20 contains the hazard map constructed just from model 2 , the background zones. The combination map (using weights of 0.67 and 0.33 for models 1 and 2 , respectively) is shown on figure 21 . The combined map significantly raises the hazard in eastern Washington and Oregon. The map exhibits a zones of higher hazard crossing Arizona from the northwest to southeast. It also tends to emphasize the hazard along the Rio Grande Rift in New Mexico and southern Colorado. It displays a zone of higher hazard that extends past El Paso into west Texas, including the sites of the 1931 Valentine and 1995 Alpine earthquakes. The combined map also shows somehat higher hazard along the Yellowstone Parabola than the map based on just the gridded seismicity.

The combined hazard map (fig. 21) does lower the hazard somewhat in areas of high seismicity such as western Nevada and central Utah. This is the price to be paid for raising the hazard in areas of low seismicity, while maintaining the total seismicity rate. This is essentially insurance for possible nonstationarity in earthquake occurrence.

Figure 22 shows the mean hazard curves for several Western cities (Salt Lake City, Reno, Las Vegas, Phoenix and El Paso) for the cases with and without the background zones (both cases include the hazard from the faults). The hazard curve for Reno is the highest of this group and it decreases somewhat when the background zones are included. The hazard curves for Salt Lake City and Las Vegas are barely affected by the inclusion of the background zones. The curve for 
Phoenix is raised substantially by the background zones, since it is in an area of relatively low historic seismicity. The curve for El Paso is raised the most by the background zones. El Paso is in an area of relatively low seismicity, but certainly has the potential for large earthquakes with active faults nearby. The peculiar shape of the hazard curve for El Paso for the case without the background zones is caused by its proximity to Quaternary faults with relatively long recurrence times.

\section{Adaptive Weighting for the WUS}

For the June 1996 maps, we used the adaptive weighting scheme to include the background 7 zones in the WUS without lowering the hazard values in the high seismicity areas. As with the CEUS, we checked the $a$-value for each source cell to see whether the rate from the historic seismicity exceeded that from the appropriate background zone. If it did, we just used the a-value from the historic seismicity. If the historic seismicity $a$-value was below the background value, then we used a rate derived from using 0.67 times the historic rate plus 0.33 times the background rate. This does not lower the a-value in any cell lower than the value from the historic seismicity. The total seismicity rate in this portion of the WUS in the new $a$-value grid is $16 \%$ above the historic rate (derived from M4 and greater events since 1963). Figure 23 is a map based on the adaptive weighting. Note that the areas of higher hazard in the Intermountain west have the same ground motions as the map with only historic seismicity and faults (compare figs. 23 and 19). Areas of low seismicity have the same probabilistic ground motions as the map made from models 1 and 2 (compare figs. 23 and 21).

\section{Faults}

Zor the June maps we explicitly calculated the hazard from about 500 Quaternary faults or fault 7 segments. We consioicred faults where geologic slip rates have been determined or estimates of recurrence times have been made from trenching studies. We have compiled a table of the parameters used in the hazard calculations, along with references (see our Internet Web site). Figures 24 and 25 are maps of the faults used in the June maps.

Below we cite individuals who worked on compilations of fault data for the maps or who provided their data for the maps. Complete references for the fault parameters are contained in the fault table on our Website.

Jim Lienkaemper developed a comprehensive table of consensus slip rate and magnitude information for northern California faults (Lienkaemper, written commun. 1995, 1996). He enlisted a set of USGS and non-USGS geologists to evaluate and compile slip rates and other fault information. Dave Schwartz was also essential to this process. These slip rates were used in the determination of recurrence times.

Pat McCrory spearheaded another effort to compile slip rate information for faults in the Humboldt Bay region of northern California. She convened a panel of experts to collect these critical data (McCrory, 1996).

Mark Petersen, Chris Cramer, and Bill Bryant (CDMG) developed a slip-rate table for southern California which is an extension of Petersen and Wesnousky (1994). This table was modified after extensive consultation with geologists working on southern California tectonics. The slip rates and segmentation for the San Jacinto and Elsinore faults were taken from consensus values derived under the auspices of the Southern California Earthquake Center (Working Group on California Earthquake Probabilities [WGCEP], 1995). Slip rates and recurrence times of some other southern California faults were from WGCEP (1995). 
Petersen, Cramer, and Bryant assembled a database containing recurrence times, a-values and maximum magnitudes for California faults, with the recurrence times usually based on the consensus slip rates described above. For California, the maximum magnitudes were determined from the fault area. We used the CDMG database directly in our hazard maps.

Craig dePolo provided us with slip rates he has derived for Nevada faults (from dePolo, 1996) using geomorphologic criteria. We have included Nevada faults with slip rates of $\geq 0.1 \mathrm{~mm} / \mathrm{yr}$ in the maps. We judged that these were the more reliable slip rates. We found that including Nevada faults with lower slip rate estimates made little difference to the hazard maps.

For Oregon, we used fault information from Pezzopane (1993) and the compilation of Geomatrix (1995), who produced seismic hazard maps for that State. We based our recurrence calculations on the slip rates given in Geomatrix (1995).

\section{Recurrence Models for Faults}

Now we add the hazard from specific faults. This is the right side of figure 17 . We divided the 1 faults into types A and B, roughly following the nomenclature of WGCEP (1995). We classify a fault as A-type if there have been sufficient studies of it to produce models of fault segmentation. In California, the A-type faults are: San Andreas, San Jacinto, Elsinore, Hayward, Rodgers Creek, and Imperial (M. Petersen, C. Cramer, and W. Bryant, written commun., 1996). The only fault outside of California that we classified as A-type is the Wasatch Fault. We assumed single-segment ruptures on the Wasatch Fault (see below). Note that we have not included uncertainty in segment boundaries for these hazard maps.

For California, we followed the rupture scenarios specified by Petersen, Cramer and Bryant of CDMG, with input from Lienkaemper of USGS for northern California. We assumed singlesegment, characteristic rupture for the San Jacinto and Elsinore faults. For the San Andreas fault, multiple-segment ruptures were included in the hazard calculation, including repeats of the 1906 and 1857 rupture zones, and a scenario with the southern San Andreas fault rupturing from San Bernardino through the Coachella segment. Both single-segment and double-segment ruptures of the Hayward Fault were included.

For California faults, we used characteristic magnitudes derived by CDMG from the fault area using the relations in Wells and Coppersmith (1994). For the remainder of the WUS, we determined characteristic magnitude from the fault length using the relations of Wells and Coppersmith (1994) appropriate for that fault type.

For the B-type faults, we felt there were insufficient studies to warrant specific segmentation boundaries. For these faults, we followed the scheme of Petersen and others (1996) and used both characteristic and Gutenberg-Richter (GR; exponential) models of earthquake occurrence. These recurrence models were weighted equally. The G-R model basically accounts for the possibility that a fault is segmented and may rupture only part of its length. We assume that the G-R distribution applies from a minimum moment magnitude of 6.5 up to a moment magnitude corresponding to rupture of the entire fault length. In the Pasadena workshop, we showed that without the M6.5 minimum, southern California faults would produce far too many M4-5 events compared to the historic record. For this comparison we determined the predicted rates of M4-5 events using fault slip rates and the equation for a-value given next.

Given a geologic slip rate $\dot{u}$ and a characteristic magnitude of $\mathrm{M}_{\mathrm{C}}$ we solve for the $a$-value for a fault by requiring that the calculated annual moment sum of earthquakes equals the geologic 
moment rate $\dot{M}_{0}$, where the recurrence rate is determined from the G-R relation. We do not use the observed rate of earthquakes near the fault to determine the $a$-value. Using the geologic moment rate produces

$$
\dot{M}_{0}=\mu \dot{u} L W=\sum_{M=6.5}^{M=M_{c}} N(M) M_{0}=\sum_{M=6.5}^{M=M_{C}} 10^{a-b M} 10^{1.5 M+16.1}
$$

where $\mu$ is shear modulus, $N(M)$ is the annual number of events in a magnitude bin from $\mathrm{M}-0.05$ to $M+0.05, L$ is fault length and $W$ is fault width. Equation (1) is rearranged to determine the $a$ value for each fault. We used a $b$-value of 0.8 for all of the faults (except for California faults where we used $b=0.9$ ), based on the $b$-value derived from the regional seismicity (see above). Equation (1) is a discrete version of similar equations to find a-values by Anderson (1979).

The procedure for calculating hazard using the G-R model involves looping through magnitude increments. For each magnitude we calculate a rupture length using Wells and Coppersmith (1994). Then a rupture zone of this length is floated along the fault trace. For each site, we find the appropriate distance to the floating ruptures and calculate the frequency of exceedance (FE). The FE's are then added for all the floating rupture zones. Of course, we normalize the rate of occurrence of the floating rupture zones to maintain the proper overall rate.

As we apply it, the characteristic earthquake model (Schwartz and Coppersmith, 1984) is actually the maximum magnitude model of Wesnousky (1986) Here we assume that the fault only generates earthquakes that rupture the entire fault. Smaller events along the fault would be incorporated by models 1 and 2 with the distributed seismicity or by the G-R model described above. Following Wesnousky (1986) we find a recurrence rate for the characteristic event with moment $M_{O c}$ as

$$
\text { rate }=\mu \dot{u} L W / M_{O C}
$$

It should be noted that using the G-R model generally produces higher probabilistic ground motions than the characteristic earthquake model, because of the more frequent occurrence of earthquakes with magnitudes of about 6.5 .

Fault widths (except for California)were determined by assuming a seismogenic depth of $15 \mathrm{~km}$ and then using the dip, so that the width equaled $15 \mathrm{~km}$ divided by the sine of the dip. For most normal faults we assumed a dip of $60^{\circ}$. Dip directions were taken from the literature. For the Wasatch, Lost River, Beaverhead, Lemhi, and Hebgen Lake faults, the dip angles were taken from the literature (see fault parameter table on Website). Strike-slip faults were assigned a dip of $90^{\circ}$. For California faults, widths were often defined using the depth of seismicity (J. Lienkaemper, writterı commun., 1996; M. Petersen, C. Cramer, and W. Bryant, written commun., 1996). Fault length was calculated from the total length of the digitized fault trace.

There are a number of special cases which need to be described.

1. Blind thrusts in the Los Angeles area. Following Petersen and others (1996) and as discussed at the Pasadena workshop, we assigned 0.5 weight to blind thrusts in the L.A. region, because of the uncertainty in their slip rates and in whether they were indeed seismically active. These faults are the Elysian Park thrust, the Compton thrust. The Santa Barbara Channel thrust (Shaw and Suppe, 1994) also has partial weight, based on the weighting scheme developed by CDMG. 
2. Offshore faults in Oregon. We assigned 0.05 weight to three offshore faults in Oregon identified by Goldfinger and others (in press) and tabulated by Geomatrix (1995): the Wecoma, Daisy Bank and Alvin Canyon faults. We felt the uncertainty in the seismic activity of these faults warranted a low weight, and we used the 0.05 probability of activity decided in Geomatrix (1995). We assigned a 0.5 weight to the Cape Blanco blind thrust.

3. Lost River, Lemhi and Beaverhead faults in Idaho. Here we assumed that the magnitude of the Borah Peak event (M7.0) represented a maximum magnitude for these faults. As with (3), the characteristic model floated a M7.0 along each fault. The G-R model considered magnitudes between 6.5 and 7.0. Note that using a larger maximum magnitude would lower the probabilistic ground motions, because it would increase the recurrence time.

4. Hurricane and Sevier-Torroweap Faults in Utah and Arizona. The long lengths of these faults (about $250 \mathrm{~km}$ ) implied a maximum magnitude too large compared to historical events in the region. Therefore we chose a maximum magnitude of M7.5. The characteristic and G-R models were implemented as in case (3). Other faults (outside of California) where the $\mathbf{M}_{\mathbf{m a x}}$ was determined to be greater than $\mathbf{7 . 5}$ based on the fault length were assigned a maximum magnitude of 7.5.

5. Wasatch Fault in Utah. We did not use slip rate to determine recurrence rates. We used recurrence times derived from dates of paleoearthquakes by Black and others (1995) and the compilation of McCalpin and Nishenko (1996).

6. Hebgen Lake Fault in Montana. We used a characteristic moment magnitude of 7.3 based on the 1959 event (Doser, 1985).

7. All short faults with characteristic magnitudes of less than 6.5 were treated with the characteristic recurrence model only (weight $=1$ ). No G-R relation was used. If a fault had a characteristic magnitude less than 6.0 , it was not used.

8. For the Seattle Fault, we fixed the characteristic recurrence time at 5000 years, which is the minimum recurrence time apparent from paleoseismology (R. Bucknam, pers. commun., 1996). Using the characteristic magnitude of 7.1 derived from the length and a $0.5 \mathrm{~mm} / \mathrm{yr}$ slip rate yielded a characteristic recurrence time of about 3000 years.

9. For the Eglington fault near Las Vegas, we fixed the recurrence time at 14,000 years, similar to the recurrence noted in Wyman and others (1993).

10. For a few faults, we determined the maximum magnitude from the magnitude of historic events (see fault table).

\section{Shear Zones in Eastern California and Western Nevada.}

We added areal shear zones along the western border of Nevada extending from the northern Wend of the Death Valley fault through the Tahoe-Reno area through northeast California ending at the latitude of Klamath Falls, Oregon (see fig. 26). We assigned a shear rate of 4 $\mathrm{mm} / \mathrm{yr}$ to zone 1 , and $2 \mathrm{~mm} / \mathrm{yr}$ to zones 2 and 3 . The shear rate in zone 1 is comparable to the shear rate observed on the Death Valley fault, but which is not observed in mapped faults north of the Death Valley fault (C. dePolo and J. Anderson, pers. commun., 1996). For the Foothills Fault system (zone 4) we used a shear rate of $0.05 \mathrm{~mm} / \mathrm{yr}$. $a$-values were determined for these zones in the manner described in Ward(1994). For zones 1-3, we used a magnitude range of 6.5 to 7.3. For zone 4 , we used a magnitude range of 6.0 to 7.0. The maximum magnitude for the 
calculation of hazard from the smoothed historic seismicity was lowered in these zones so that it did not overlap with these magnitude ranges. Fictitious faults with a fixed strike were used in the hazard calculation for these zones. Again, use of these areal zones in California was agreed upon after consultation with CDMG personnel.

\section{Cascadia Subduction Zone}

$\mathrm{W}$ e considered two alternative scenarios for great earthquakes on the Cascadia subduction zone. For both scenarios we assumed that the recurrence time of rupture at any point along the subduction zone was 500 years. This time is in or near most of the average intervals estimated from coastal and offshore evidence (see Atwater and Hemphill-Haley, 1996; Geomatrix, 1995; B. Atwater, written commun., 1996). Individual intervals, however, range from a few hundred years to about 1000 years (Atwater and others, 1995).

The first scenario is for moment magnitude 8.3 earthquakes to fill the subduction zone every 500 years. Based on a rupture length of $250 \mathrm{~km}$ (see Geomatrix, 1995) for an M8.3 event and the $1100 \mathrm{~km}$ length of the entire subduction zone, this requires a repeat time of about 110 years for an M8.3 event. However, no such event has been observed in the historic record of about 150 years. This M8.3 scenario is similar to what was used in the 1994 edition of the USGS maps (see Leyendecker and others, 1995) and it is comparable to the highest weighted scenario in Geomatrix (1995). We floated a M8.3 rupture zone along strike of the subduction zone to calculate the hazard. We assign a weight of 0.67 for this scenario in the maps.

It was suggested (B. Atwater, written commun., 1996) that another plausible scenario was to have a succession of M8 earthquakes rupturing the entire subduction zone in a few decades. Of course, such a scenario is non-Poissonian. Implementing such a scenario in the probabilistic hazard maps would require judgments on where we were in the earthquake cycle. We felt this scenario needed more study and did not use it in the June maps.

The second scenario we used is for a moment magnitude 9.0 earthquake to rupture the entire Cascadia subduction zolie every 500 years on average. We see no compelling reason to rule out such a scenario. This scenario would explain the lack of M8's in the historic record. It is also consistent with a recent interpretation of Japanese tsunami records by Satake and others (1996). By ruling out alternative source regions, Satake and others (1996) reported that a tsunami in 1700 could have been produced by a M9.0 earthquake along the Cascadia subduction zone. We assign a weight of 0.33 to the M9.0 scenario in the maps.

The subduction zone was specified as a dipping plane striking north-south from about Cape Mendocino to $50^{\circ} \mathrm{N}$. (fig. 27). We assumed that the plane reached $20 \mathrm{~km}$ depth at a longitude of $123.8^{\circ} \mathrm{W}$., just east of the coastline. This corresponds roughly to the $20-\mathrm{km}$-depth contour drawn by Hyndman and Wang (1995) and is consistent with the depth and location of the Petrolia earthquake in northern California. We assigned a dip of $10^{\circ}$ to the plane and a width of $90 \mathrm{~km}$. We assumed the seismogenic portion of the plane extended to a depth of $20 \mathrm{~km}$.

\section{WUS Attenuation Relations}

Crustal Events. For peak ground acceleration (PGA) we used three, equally-weighted attenuation relations: (1) Boore, Joyner, and Fumal (BJF; 1993, 1994a) with later modifications to differentiate thrust and strike-slip faulting (Boore and others, 1994b), (2) Sadigh and others (1993), and (3) Campbell and Bozorgnia (1994). When calculating spectral response values, we used BJF (1993) and Sadigh and others (1993). For (1) we calculated ground motions for a site with average shear-wave velocity of $760 \mathrm{~m} / \mathrm{sec}$ in the top $30 \mathrm{~m}$, using the relations between shear-wave velocity ana site amplification in Boore and others (1994a). For (2) and (3) we used 
their "rock" values. Joyner (1995) reported velocity profiles compiled by W. Silva and by D. Boore showing that WUS rock sites basically spanned the NEHRP B/C boundary. When calculating ground motions for each fault, we used the relations appropriate for that fault type (for example, thrust). All of the relations found higher ground motions for thrust faults compared with strike slip faults.

For all calculations we included the variability of ground motions. For (1) we used the sigma values reported in BJF (1994b). For (2) and (3) we used the magnitude-dependent sigmas found in those studies. Our hazard code incorporates magnitude-dependent variability.

Of course, the distance measure from fault to site varies with the attenuation relation and this was accounted for in the hazard codes

Deep events (>35 km). Most of these events occurred beneath the Puget Sound region. although some were in northwestern California. For these deep events, we used only one attenuation relation by Geomatrix (1993; with recent modification for depth dependence provided by $\mathrm{R}$. Youngs, written commun., 1996) which is based on empirical data of deep events recorded on rock sites. We did not use the relations of Crouse (1991), because they were for soil sites. We have found that the ground motions from Geomatrix (1993) are somewhat smaller than those from Crouse (1991), by an amount consistent with soil amplification. These events were placed at a depth of $40 \mathrm{~km}$ for calculation of ground motions.

Cascadia subduction zone. For M8.3 events on the subduction zone we used two attenuation relations (with equal weights) following the lead of Geomatrix (1993): (1) Sadigh and others (1993) for crustal thrust earthquakes and (2) Geomatrix (1993) for interface earthquakes. For the M9.0 scenario we could not use Sadigh and others (1993) formulas, since they are invalid over M8.5. Therefore, we used only Geomatrix (1993). Again the values from Geomatrix (1993) were somewhat smaller than the soil values in Crouse (1991).

\section{ACKNOWLEDGMENTS}

$\mathrm{W}$ e thank Dave Boore and Bill Joyner for many discussions about reference site conditions and attenuation. Dave Boore ran the stochastic simulations for the CEUS ground motions, based on parameters that we specified. Paul Thenhaus worked on the initial stages of this effort. He organized the northeast workshop, co-convened the Seattle workshop, and provided substantial insights on hazard mapping. We thank all of the participants in the regional workshops for their valuable insights and feedback. We thank Mark Petersen, Chris Cramer, Bill Bryant, and Mike Reichle of CDMG for assembling the fault files for California. We thank the reviewers for providing many useful comments on the maps and the documentation: Walter Arabasz, Allin Cornell, Klaus Jacob, Arch Johnston, Mark Petersen, Ivan Wong, Brian Atwater, Tom Hanks, Jim Mori, Dave Schwartz, and Buddy Schweig. Rus Wheeler gave us invaluable advice on sources in the CEUS, drew some of the boundaries of the background CEUS source zones, and carefully reviewed the text. John Adams, Gail Atkinson, Jim Zollweg, Jeff Munsey, and Jim Pechmann provided valuable comments on our methodology. We thank Bob Smith, Diane Doser, Martin Chapman, Arch Johnston, Jim Case, Mike Stickney, and Pradeep Talwani for providing us additional information. Many others sent us written comments on the maps, which were very helpful. The hazard maps were produced using the GMT plotting package (Wessel and Smith, 1991), which was essential to the success of the project. Eleanor Omdahl provided invaluable editorial assistance. 


\section{REFERENCES}

Adams, J., D.H. Weichert, S. Halchuk, and P.W. Basham (1996).Trial seismic hazard maps of Canada-1995: final values for selected Canadian cities, Geological Survey of Canada, Open File 3283.

Algermissen, S.T., D.M. Perkins, P.C. Thenhaus, S.L. Hanson, and B.L. Bender (1990). Probabilistic earthquake acceleration and velocity maps for the United States and Puerto Rico, U.S. Geological Survey, Misc. Field Studies Map MF-2120.

Algermissen, S.T., E.V. Leyendecker, G.A. Bollinger, N.C. Donovan, J.E. Ebel, W.B. Joyner, R.W. Luft, and J.P. Singh (1991). Probabilistic ground-motion hazard maps of response - spectral ordinates for the United States, in Proceedings of Fourth International Conference on Seismic Ordinates for the United States, Stanford Univ., v. II, p. 687-694.

Amick , D. and R. Gelinas (1991). The search for evidence of large prehistoric earthquakes along the Atlantic Seaboard, Science, v. 251, p. 655-658.

Anders, M.H., J.W. Geissman, L.A. Piety and J.T. Sullivan (1989). Parabolic distribution of circumeastern Snake River Plain seismicity and latest Quaternary faulting: migratory pattern and association with the Yellowstone Hotspot, J. Geophys. Res., v. 94, p. 15891621.

Anderson, J. G. (1979). Estimating the seismicity from geological structures for seismic-risk studies, Bull. Seism. Soc. Am., v. 69, p. 135-158.

Atwater, B.F. and E. Hemphill-Haley (1996). Preliminary estimates of recurrence intervals for great earthquakes of the past 3500 years at northeastern Willapa Bay, Washington, U.S. Geological Survey, Open-file report 96-001, 88p.

Atwater, B., A. Nelson, J. Clague, G. Carver, D. Yamaguchi, P. Bobrowsky, J. Bourgeois, M. Darienzo, W. Grant, S. Palmer, C. Peterson, and M. Reinhart (1995), Summary of coastal geologic evidence for past great earthquakes at the Cascadia subduction zone, Earthquake Spectra, v. 11, p. 1-18.

Black, B.D., W.R. Lund, and B.H. Mayes (1995). Large earthquakes on the Salt Lake City segment of the Wasatch Fault Zone--summary of new information from the South Fork Dry Creek site, Salt Lake County, Utah, in Environmental and Engineering Geology of the Wasatch Front Region, W.R. Lund (ed.), Utah Geological Association Publication 24, 1995.

Bollinger, G.A., F.C. Davison, M.S. Sibol, and J.B. Birch (1989). Magnitude recurrence relations for the southeastern United States and its subdivisions, J. Geophys. Res. ,v. 94, p. 28572873.

Boore, D.M. and G.M. Atkinson (1987). Stochastic prediction of ground motion and spectral response parameters at hard-rock sites in eastern North America, Bull. Seism. Soc. Am., v. 77, p. 440-467.

Boore, D.M., W.B. Joyner, and T.E. Fumal (1993). Estimation of response spectra and peak accelerations from western North American earthquakes: an interim report, U.S. Geological Survey open-file report 93-509.

Boore, D.M., W.B. Joyner, and T.E. Fumal (1994a). Estimation of response spectra and peak accelerations from western North American earthquakes: an interim report Part 2, U.S. Geological Survey open-file report 94-127.

Boore, D.M., W.B. Joyner and T.E. Fumal (1994b). Ground motion estimates for strike- and reverse-slip faults (pre-print).

Campbell, K.W. and Y. Bozorgnia (1994). Near-source attenuation of peak acceleration from worldwide accelerograms recorded from 1957 to 1993, in Proceedings of Fifth U.S. National Conference on Earthquake Engineering, Earthquake Engineering Research Institute, vol. 3, p. 283-292. 
Chandler, V.W. (1995). The west-central Minnesota earthquake of June 5, 1993: an opportunity to re-examine seismicity near the Morris Fault, Seism. Res. Letts, v. 66, no. 6, p. 113121.

Crone, A.J. and K.V. Luza (1990). Style and timing of Holocene surface faulting on the Meers fault, southwestern Oklahoma, Geol. Soc. Am. Bull., v. 102, p. 1-17.

Crone, A., M. Machette, L. Bradley and S. Mahan (1996). Holocene surface faulting on the Cheraw Fault, southeastern Colorado, U.S. Geological Survey, MF map, in press.

Crouse, C.B. (1991). Ground-motion attenuation equations for earthquakes on the Cascadia subduction zone, Earthquake Spectra, v. 7, p. 201 -.

Davis, S.D. and W.D. Pennington (1989). Induced seismicity in the Cogdell oil field of west Texas, Bull. Seism. Soc. Am., v. 79, p. 1477-1495.

dePolo, C. (1996). Fault slip rates for Quaternary and suspected Quaternary faults in Nevada, $\mathrm{PhD}$. thesis, University of Nevada, Reno.

Dolan, J.F., K. Sieh, T.K. Rockwell, R.S. Yeats, J. Shaw, J. Suppe, G.J. Huftile, and E.M. Gath (1994). Prospects for larger or more frequent earthquakes in the Los Angeles metropolitan region, Science, v. 267, p. 199-205.

Doser, D.I. (1985). Source parameters and faulting processes of the 1959 Hebgen Lake, Montana, earthquake sequence, J. Geophys. Res., v. 90, p. 4537-4556.

Electric Power Research Institute (1986). Seismic hazard methodology for the central and eastern United Statest, 10 volumes, EPRI report NP-4726, Electric Power Research Institute, Palo Alto.

Euge, K.M., B.A. Schell, and I. Po Lam (1992). Development of seismic maps for Arizona, Arizona Dept. of Transportation, report no. FHWA-AZ92-344.

Frankel, A. (1995). Mapping seismic hazard in the Central and Eastern United States, Seism. Res. Letts, v.,66, no. 4, p. 8-21.

Geomatrix Consultants (1993). Seismic margin earthquake for the Trojan site: final unpublished report prepared for Portland General Electric Trojan Nuclear Plant, Ranier, Oregon. Note: tables of these attenuation relationships are included in Geomatrix (1995).

Geomatrix Consultants (1995). Seismic design mapping state of Oregon, Final Report prepared for Oregon Department of Transportation, Salem, Oregon.

Goldfinger, C., L.D. Kulm. R.S. Yeats, B. Applegate, M. MacKay, and G.R. Cochrane (in press). Active strike-slip faulting and folding of the Cascadia plate boundary and forearc in central and northern Oregon, in Rogers, A.M., W.J. Kockelman, G. Priest, and T.J. Walsh (eds.), Assessing and reducing earthquake hazards in the Pacific northwest, U.S. Geological Survey Professional Paper 1560.

Hyndman, R.D. and K. Wang (1995). The rupture zone of Cascadia great earthquakes from current deformation and the thermal regime, J. Geophys. Res., v. 100, p. 22,133-22,154.

Jacob, K., J. Armbruster, N. Barstow, and S. Horton (1994). Probabilistic ground motion estimates for New York: comparison with design ground motions in national and local codes, in Proceedings of fifth U.S. National Conference on Earthquake Engineering, Chicago., v. iii, p. 119-128.

Johnston, A. (1994). Moment magnitude assessment of stable continental earthquakes, Part I: instrumental seismicity, pre-print (published with revised relations in Geophys. J. Int., [1996], v. 124, p. 381-414)

Johnston, A. (1996a). Moment magnitude assessment of stable continental earthquakes, Part 2: historical seismicity, Geophys. J. Int., v. 125, p. 639-678.

Johnston, A.(1996b). Seismic moment assessment of stable continental earthquakes, Part 3: 1811-1812 New Madrid, 1886 Charleston, and 1755 Lisbon, submitted to Geophys. J. Int.

Johnston, A.C. and S.J. Nava(1985). Recurrence rates and probability estimates for the New Madrid seismic zone, J. Geophys. Res., v. 90, p. 6737-6753.

Johnston, A.C., K.J. Coppersmith, L.R. Kanter, and C.A. Cornell (1994). The earthquakes of stable continental regions: assessment of large earthquake potential, EPRI TR-102261, J.F. Schneider, ed., Electric Power Research Institute, 309 p. 
Johnston, A.C. and E.S. Schweig (1996). The enigma of the New Madrid earthquakes of 1811 1812, Annual Review of Earth and Planetary Sciences, v. 24, p. 339-384.

Joyner, W.B. (1995). Advocacy Paper \#4, Soil is the most appropriate reference site condition, in ATC 35-2, Preprints: National Earthquake Ground Motion Mapping Workshop, Applied Technology Council.

Leyendecker, E.V., D.M. Perkins, S.T. Algermissen, P.C. Thenhaus, and S.L. Hanson (1995) USGS spectral response maps and their relationship with seismic design forces in building codes, U.S. Geological Survey, open-file report 95-596.

Lienkaemper, J.J. (1996). "Fault parameter compilation for northern California", in preparation.

Marple, R., P. Talwani, and N. Olson (1994). A postulated north-northeast trending fault system in the coastal plain of north and south Carolina, (abstract), in Programs and Abstracts for 66th Annual Meeting of Eastern Section, Seismological Society of America, p. 34.

Martin, G.R. and R. Dobry (1994). Earthquake site response and seismic code provisions, NCEER Bulletin, v. 8, p. 1-6.

McCalpin, J.P. and S.P. Nishenko (1996). Holocene paleoseismicity, temporal clustering, and probabilities of future large $(M>7)$ earthquakes on the Wasatch Fault Zone, Utah, preprint.

McCrory, P.A. (1996). Fault-hazard evaluation in the Humboldt area, northwestern California, submitted as U.S. Geological Survey Open-File Report.

Mueller, C., M. Hopper, and A. Frankel (1996). Preparation of earthquake catalogs for the 1996 national seismic hazard maps: documentation, U.S. Geological Survey Open-File Report, in review.

Obermeier, S.F., R.B. Jacobson, J.P. Smoote, R.E. Weems, G.S. Gohn. J.E. Monroe, and D.S. Powers (1990). Earthquake-induced liquefaction features in the coastal setting of South Carolina and in the fluvial setting of the New Madrid seismic zone, U.S. Geological Survey, Prof. Paper 1504, 44 p.

Obermeier, S.F., P.J. Munson, C.A. Munson, J.R. Martin, A.D. Frankel, T.L. Youd, and E.C. Pond (1992). Liquefaction evidence for strong Holocene earthquake(s) in the Wabash Valley of Indiana-Illinois, Seism. Res. Letts, v. 63, p. 321-336.

Petersen, M.D. and S.G. Wesnousky (1994). Fault slip rates and earthquake histories for active faults in southern California, Bull. Seism. Soc. Am., v. 84, p. 1608-1649.

Petersen, M.D., C.H. Cramer, W.A. Bryant, M.S. Reichle, and T.R. Toppozada (1996). Preliminary hazard assessment for Los Angeles, Ventura, and Orange counties, California, affected by the 17 January 1994 Northridge earthquake, Bull. Seism. Soc. Am., v. 86, p. S247-S261.

Pezzopane, S.K. (1993). Active faults and earthquake ground motions in Oregon, PhD. dissertation, University of Oregon, Eugene, 208 p.

Powell, C., G. Bollinger, M. Chapman, M. Sibol, A. Johnston, and R. Wheeler (1994). A seismotectonic model for the 300-kilometer-long eastern Tennessee seismic zone, Science, v. 264, p. 686-688.

Sadigh, K., C.Y. Chang, N.A. Abrahamson, S.J. Chiou, and M.S. Power (1993). Specification of long-period ground motions: updated attenuation relationships for rock site conditions and adjustment factors for near-fault effects, in Proceedings of ATC-17-1 Seminar on Seismic Isolation, Passive Energy Dissipation, and Active Control, Applied Technology Council, Redwood City. Note: tables of these attenuation relationships are included in Geomatrix (1995).

Satake, K., K. Shimazaki, Y. Tsuji, and K. Ueda (1996). Time and size of a giant earthquake in Cascadia inferred from Japanese tsunami record of January 1700 , Nature, v. 379, p. 246249.

Schwartz, D.P. and K.J. Coppersmith (1984). Fault behavior and characteristic earthquakes: examples from the Wasatch and San Andreas fault zones, J. Geophys. Res., v. 89, p. 5681-5698. 
Seeber, L. and J. G. Armbruster (1991). The NCEER-91 earthquake catalog: improved intensitybased magnitudes and recurrence relations for U.S. earthquakes east of New Madrid, National Center for Earthquake Engineering Research, NCEER-91-0021.

Senior Seismic Hazard Analysis Committee (1996?). Probabilistic seismic hazard analysis: a consensus methodology, supported by DOE, NRC, and EPRI.

Shaw, J.H. and J. Suppe (1994). Active faulting and growth faulting in the eastern Santa Barbara Channel, California, Geol. Soc. Am. Bul., 78, 700-721.

Sibol, M.S., G.A. Bollinger, and J.B. Birch (1987). Estimation of magnitudes in central and eastern North America using intensity and felt area, Bull. Seism. Soc. Am., v. 77, p. 1635-1654.

Stover, C.W. and J.L. Coffman (1993). Seismicity of the United States 1568-1989 (revised), U.S. Geological Survey Professional Paper 1527.

Stover, C.W., G. Reagor, and S.T. Algermissen (1984). United States earthquake data file, U.S. Geological Survey Open-File Report 84-225.

Taber, S. (1914). Seismic activity in the Atlantic Coastal Plain near Charleston, South Carolina, Bull. Seism. Soc. Am., v. 4, p. 108-160.

Talwani, P. (1982). Internally consistent pattern of seismicity near Charleston, South Carolina, Geology, v. 10, p. 654-658.

Toro, G.R., W.J. Silva, R.K. McGuire, and R.B.Herrmann (1992). Probabilsitic seismic hazard mapping of the Mississippi Embayment, Seism. Res. Letts, v. 63, p. 449-475.

Toro, G.R., N.A. Abrahamson, and J.F. Schneider (1993). Engineering model of strong ground motions from earthquakes in the central and eastern United States, in Guidelines for determining design basis ground motions, EPRI TR-102293, J.F. Schneider, ed., Electric Power Research Institute.

Tuttle, M.P. and E.S. Schweig (1995). Archeological and pedological evidence for large prehistoric earthquakes in the New Madrid seismic zone, central United States, Geology, v. 23, p. 253-256.

Veneziano, D. and J. Van Dyck (1986). Seismic parameter estimation methods, in Seismic Hazard Methodology for Nuclear Facilities in the Eastern United States, v. 2, Appendix A, EPRI NP-4726, Electric Power Research Institute.

Ward, S.N. (1994). A multidisciplinary approach to seismic hazard in southern California, Bull. Seism. Soc. Am., v.84, p. 1293-1309.

Weichert, D.H. (1980). Estimation of earthquake recurrence parameters for unequal observation periods for different magnitudes, Bull. Seism. Soc. Am., 70, p. 1337-1356.

Wells, D.L. and K.J. Coppersmith (1994). New empirical relationships among magnitude, rupture length, rupture width, and surface displacement, Bull. Seism. Soc. Am., v. 84, p. 974-1002.

Wesnousky, S.G. (1986). Earthquakes, Quaternary faults, and seismic hazard in California, J. Geophys. Res., v. 91, p. 12,587-12,631.

Wessel, P. and W.H.F. Smith (1991). Free software helps map and display data, EOS Trans. Amer. Geophys. U., v. 72, p. 441,445-446.

Wheeler, R.L. (1995). Earthquakes and the cratonward limit of Iapetan faulting in eastern North America, Geology, v. 23, p. 105-108.

Working Group on California Earthquake Probabilities (1995). Seismic hazards in southern California: probable earthquakes, 1994 to 2024, Bull. Seism. Soc. Am., v. 85, p. 379-439.

Wyman, R.V. M. Karakouzian, V. Bax-Valentine, D.B. Slemmons, L. Peterson, and S. Palmer (1993), Geology of Las Vegas, Nevada, Bull. Assoc. of Engineer. Geologists, v. XXX, p.33-78. 


\section{ILLUSTRATIONS}

\section{Figure}

1. Map showing attenuation boundary between WUS and CEUS.

2. Mean hazard curves used in the June 1996 maps for selected cities (using June 1996 values).

3. Scheme for producing hazard maps for the CEUS.

4. $\mathbf{M}_{\max }$ zones used in the CEUS (for models 1-4 only). Values are for moment magnitude. See text for description of magnitudes of large events used in model 5 for New Madrid and Charleston areas.

5. (a) Cumulative number of earthquakes versus time for the CEUS for magnitudes 3.0-3.5. Latitude and longitude ranges are shown to right. (b) Plot for area around New Madrid for same magnitude range.

6. $b$-value plot for CEUS events $\left(24.6^{\circ}-50^{\circ} \mathrm{N}\right.$. lat.; $65^{\circ}-105^{\circ} \mathrm{W}$. long.), excluding Charlevoix events. ML stands for fit from maximum likelihood method. LS denotes fit from leastsquares method. $b$-values determined from each method are shown to right.

7. Fictitious faults used to calculate hazard from large earthquakes in the New Madrid area (see text). Also shown are earthquakes from the Seeber and Armbruster (1992) catalog.

8. Area source zone for New Madrid

9. Area source zone used for M7.3 events in the Charleston area. Seismicity is from Seeber and Armbruster (1992)catalog.

10. Source zone used for the eastern Tennessee area, based on the linear trend of the microseismicty (Martin Chapman, written commun., 1995).

11. Background zones used for model 4 for the CEUS.

12. Seismic hazard map ( $2 \%$ PE in 50 years) for CEUS made without background zone model. Weights are $0.5,0.25,0.25,0 ., 1.0$ for models $1-5$, respectively.

13. Seismic hazard map (PGA; 2\% PE in 50 years) constructed from model 4 only (background zones on fig. 11).

14. Seismic hazard map (PGA; $2 \%$ PE in 50 years) constructed from models 1-5 (including background zone). Weights are $0.4,0.2,0.2,0.2,1.0$ for models $1-5$, respectively.

15. Mean hazard curves for selected CEUS cities, for cases without background zones (solid lines) and for cases with background zones (dashed lines). Symbols are keyed to cities. Weighting schemes are given in captions to figures 14 and 15.

16. Seismic hazard map (PGA; $2 \%$ PE in 50 years) constructed from adaptive weighting scheme using the historic seismicity, background zones, and model 5 (see text). 
17. Scheme used to make hazard calculations for WUS.

18. Background zones used for model 2 for the WUS.

19. Seismic hazard map constructed from model 1, not including faults (see left side of fig. 17) and without background zones. This map shows the ground motion values in only a limited portion of the WUS.

20. Seismic hazard map made from only the background zones (model 2; see fig. 18). Note the lower values in northeastern California caused by the lower $\mathbf{M}_{\max }$ values (see fig. 27 and text). This map shows the ground motion values in only a limited portion of the WUS.

21. Seismic hazard map made from model 1 (gridded seismicity; weight 0.67 ) and model 2 (background zones, weight 0.33 ), not including faults. This map shows the ground motion values in only a limited portion of the WUS.

22. Mean hazard curves for selected WUS cities, keyed by symbols. Solid lines are for case without background zones (gridded seismicity plus faults). Dashed lines are for case with background zones, (weight 0.33 ) gridded seismicity (weight 0.67 ), and faults.

23. Seismic hazard map using adaptive weighting scheme (see text), not including faults. This map shows the ground motion values in only a limited portion of the WUS.

24. Faults used in hazard maps.

25. Faults used in hazard maps, California and Nevada region.

26. Areal source zones used in WUS (see text). $a$-values in each zone were determined from shear rates.

27. Outline of fault plane used for Cascadia subduction zone. Maximum depth of plane is $20 \mathrm{~km}$. 


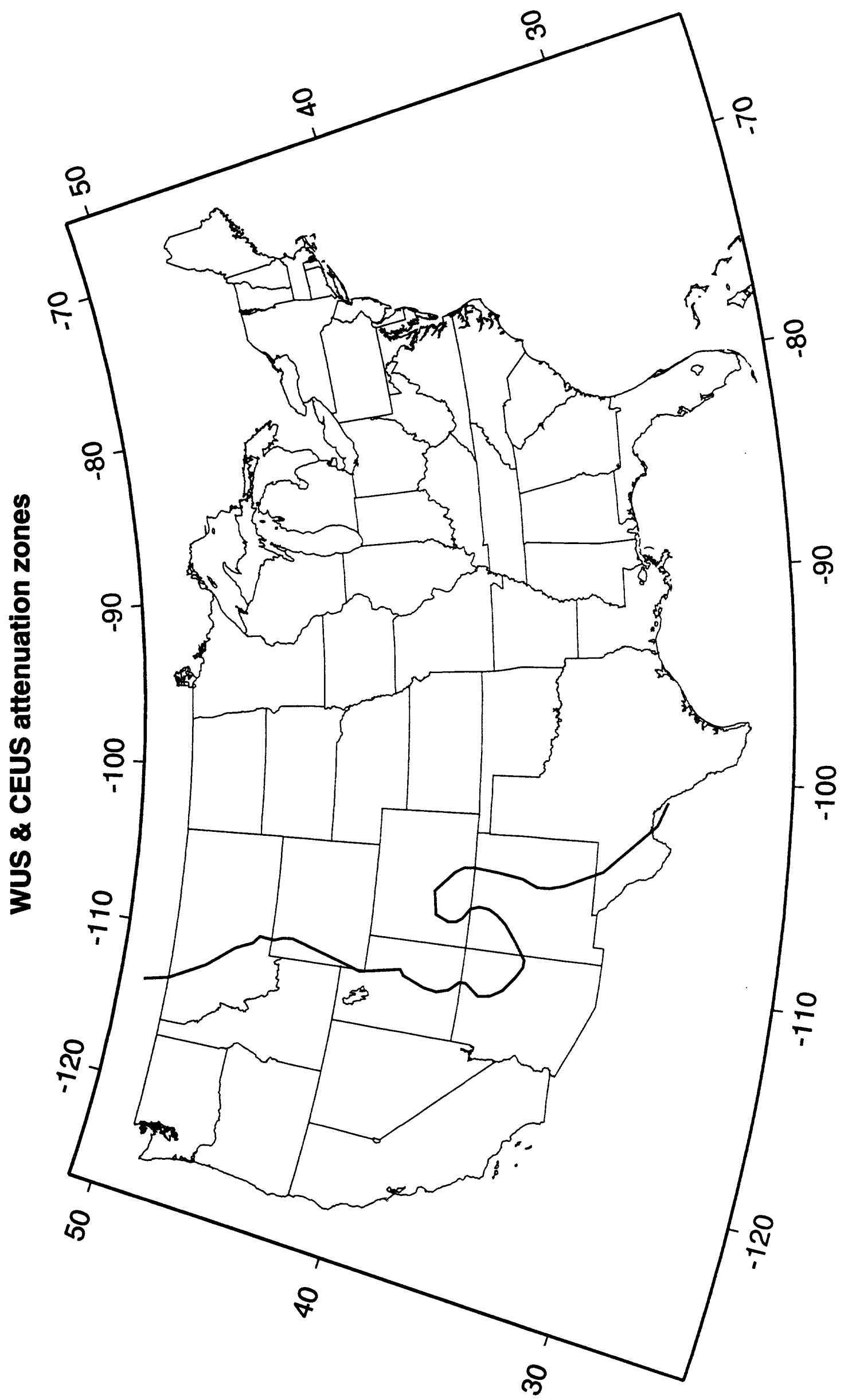




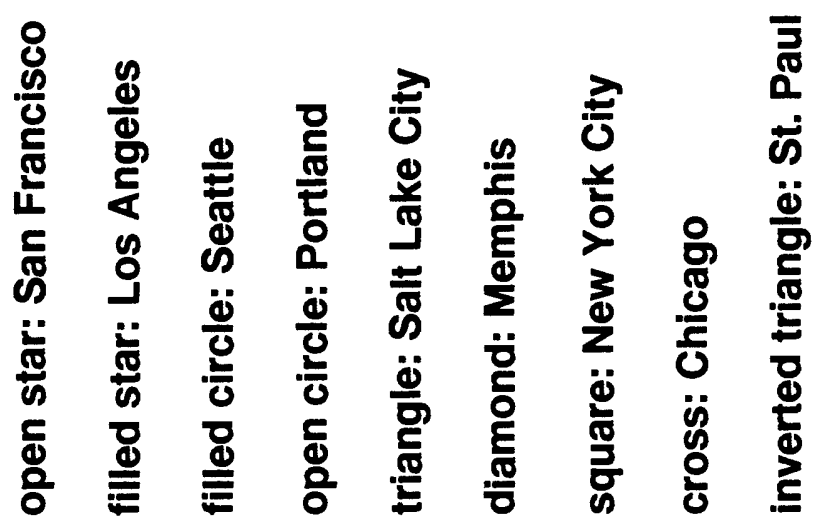

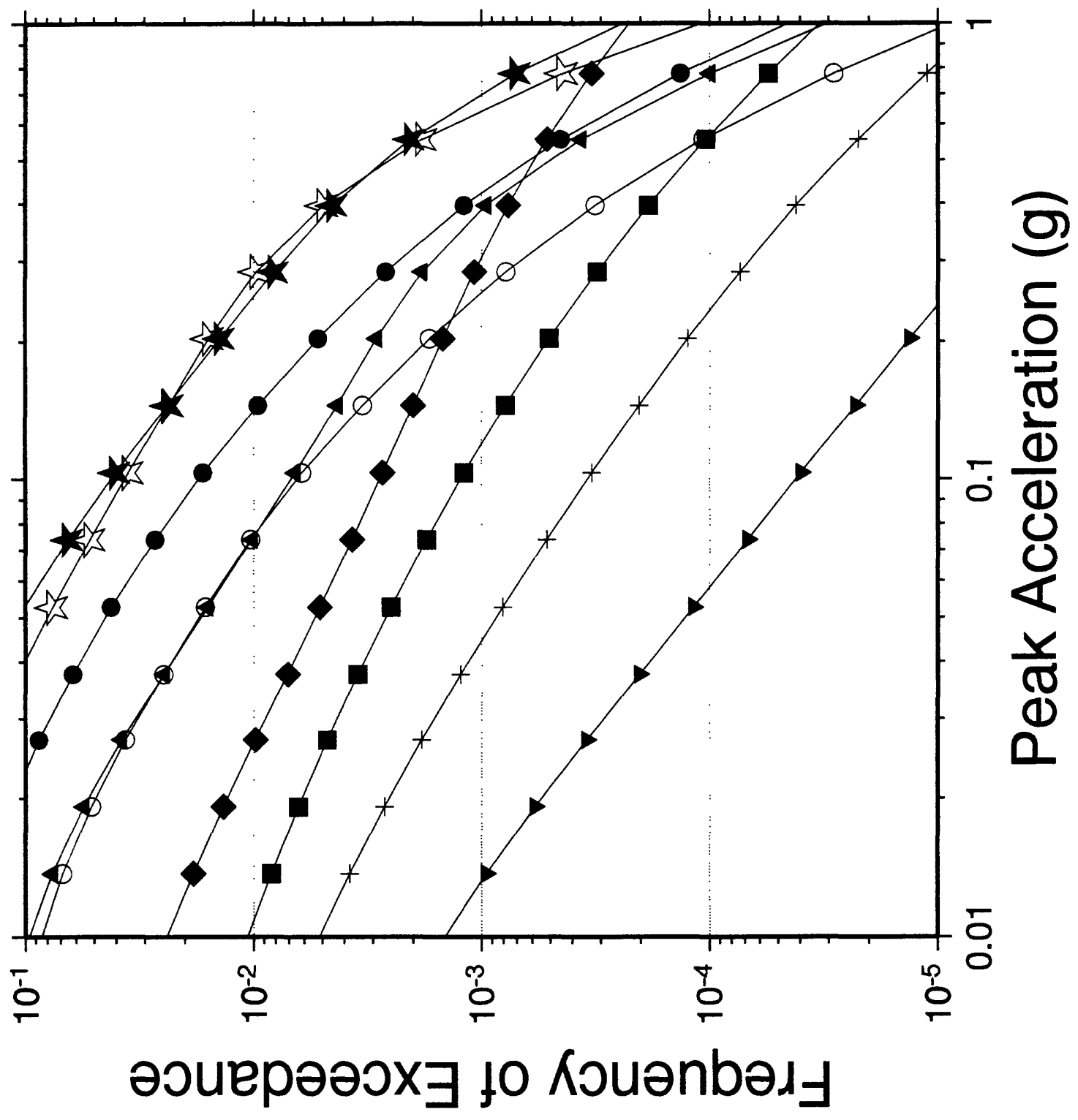



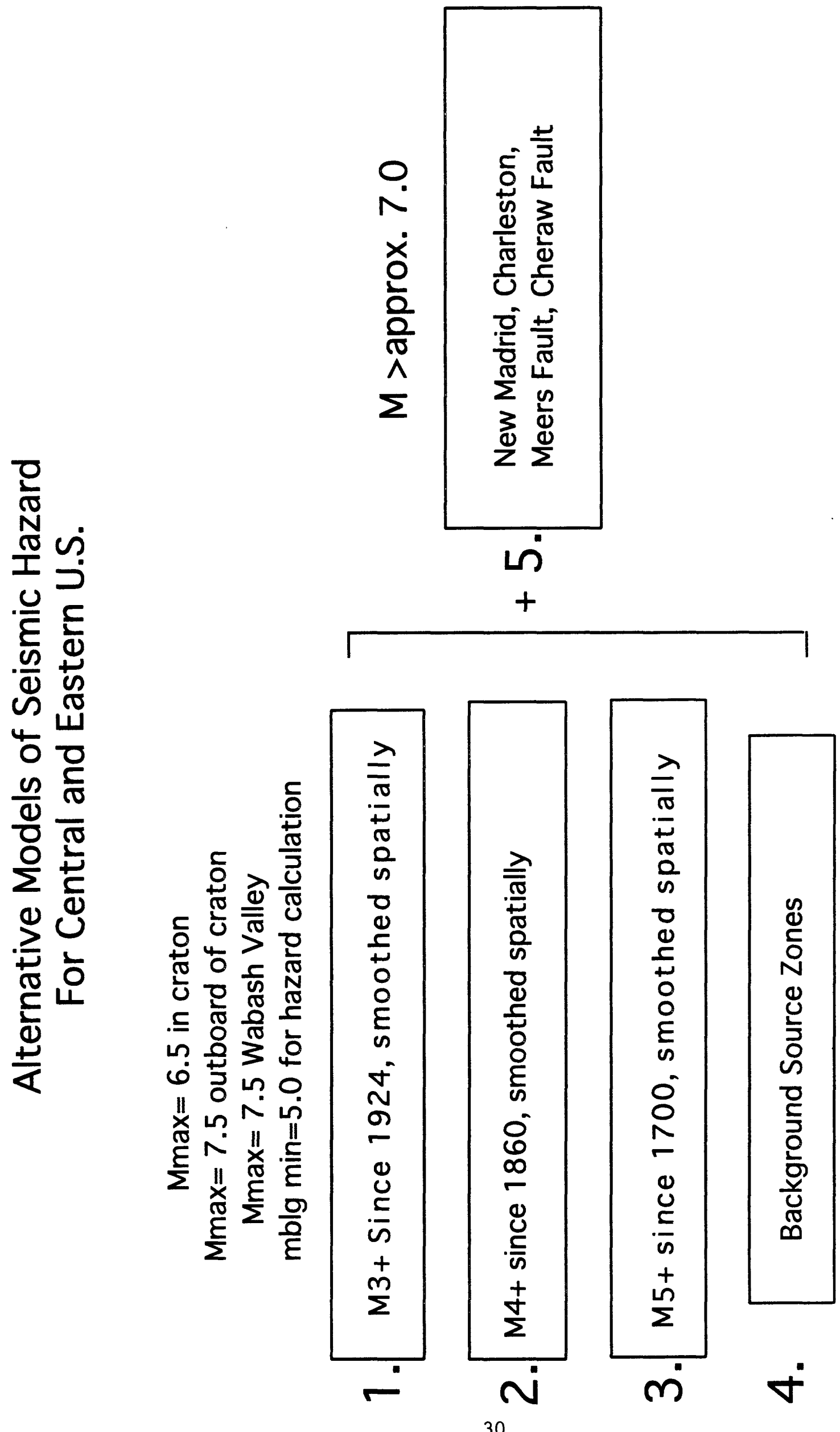

FIGURE 3 


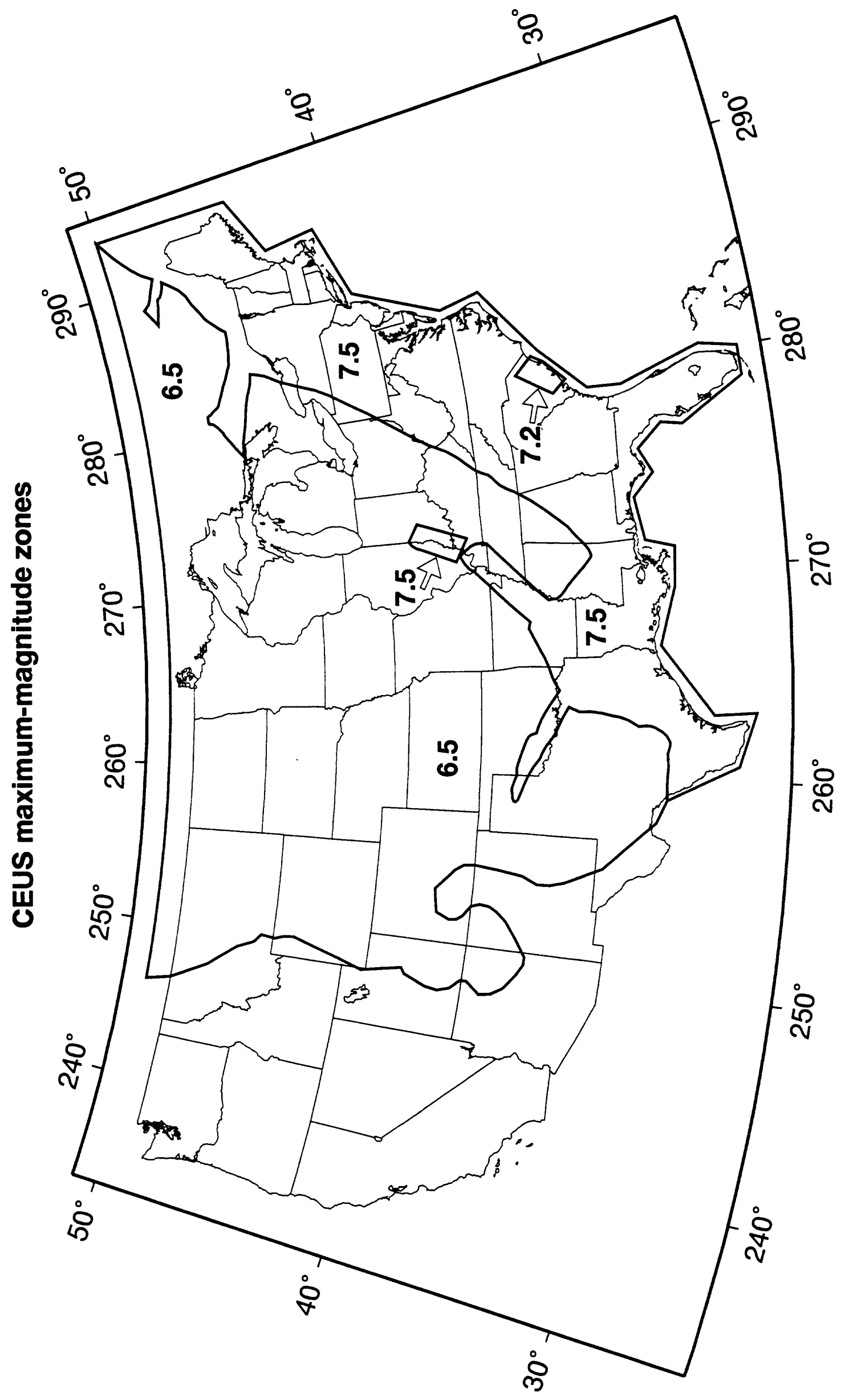




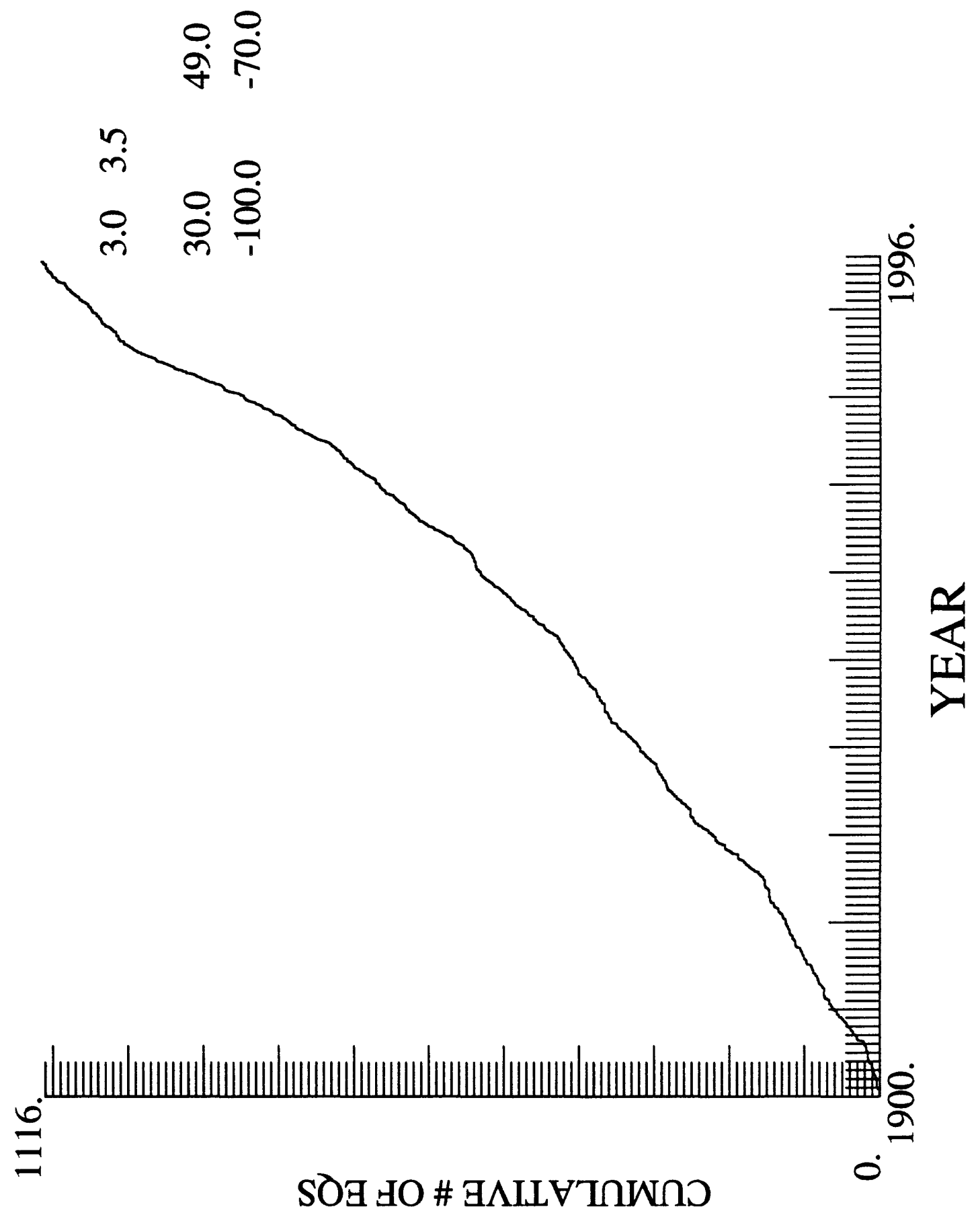




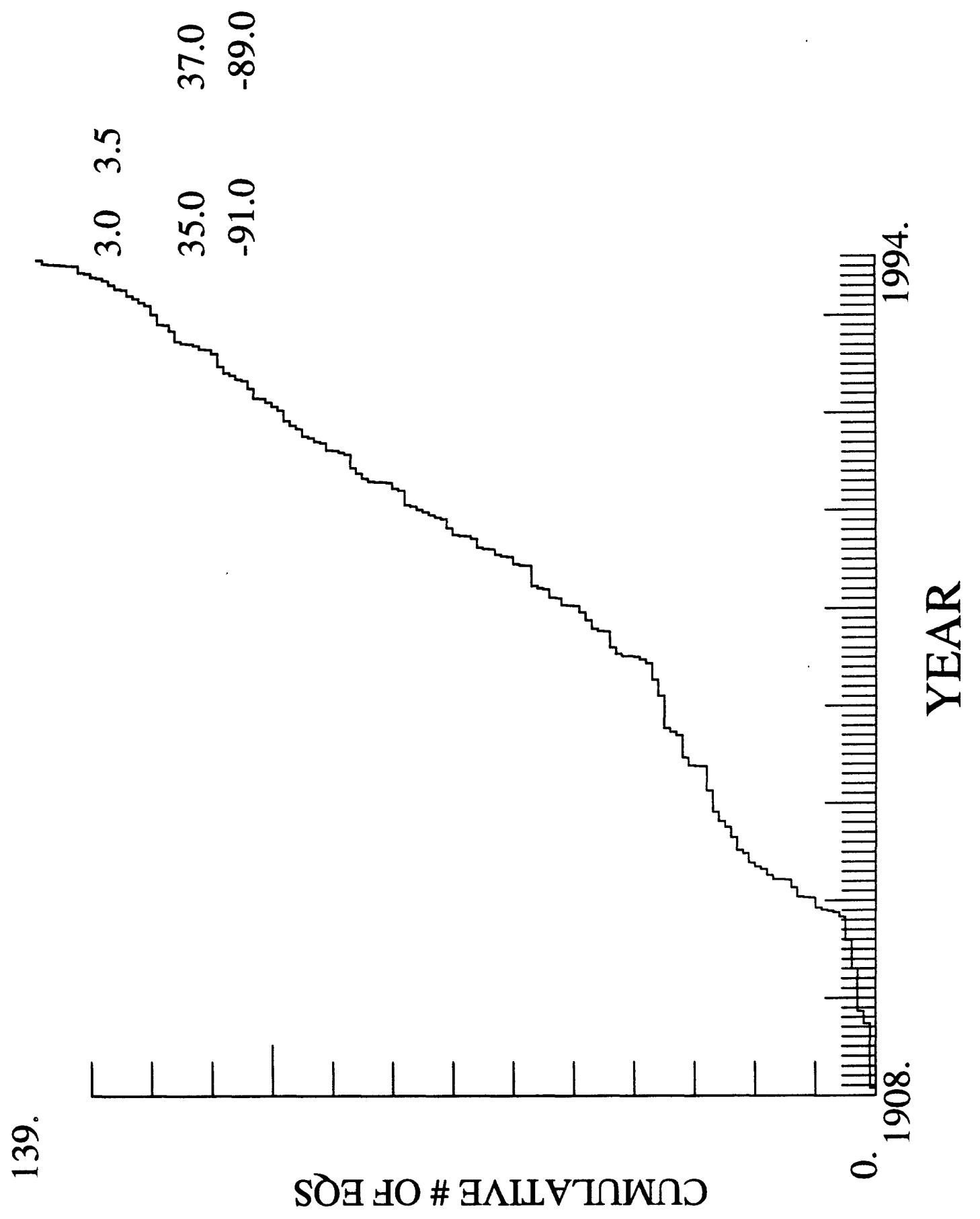




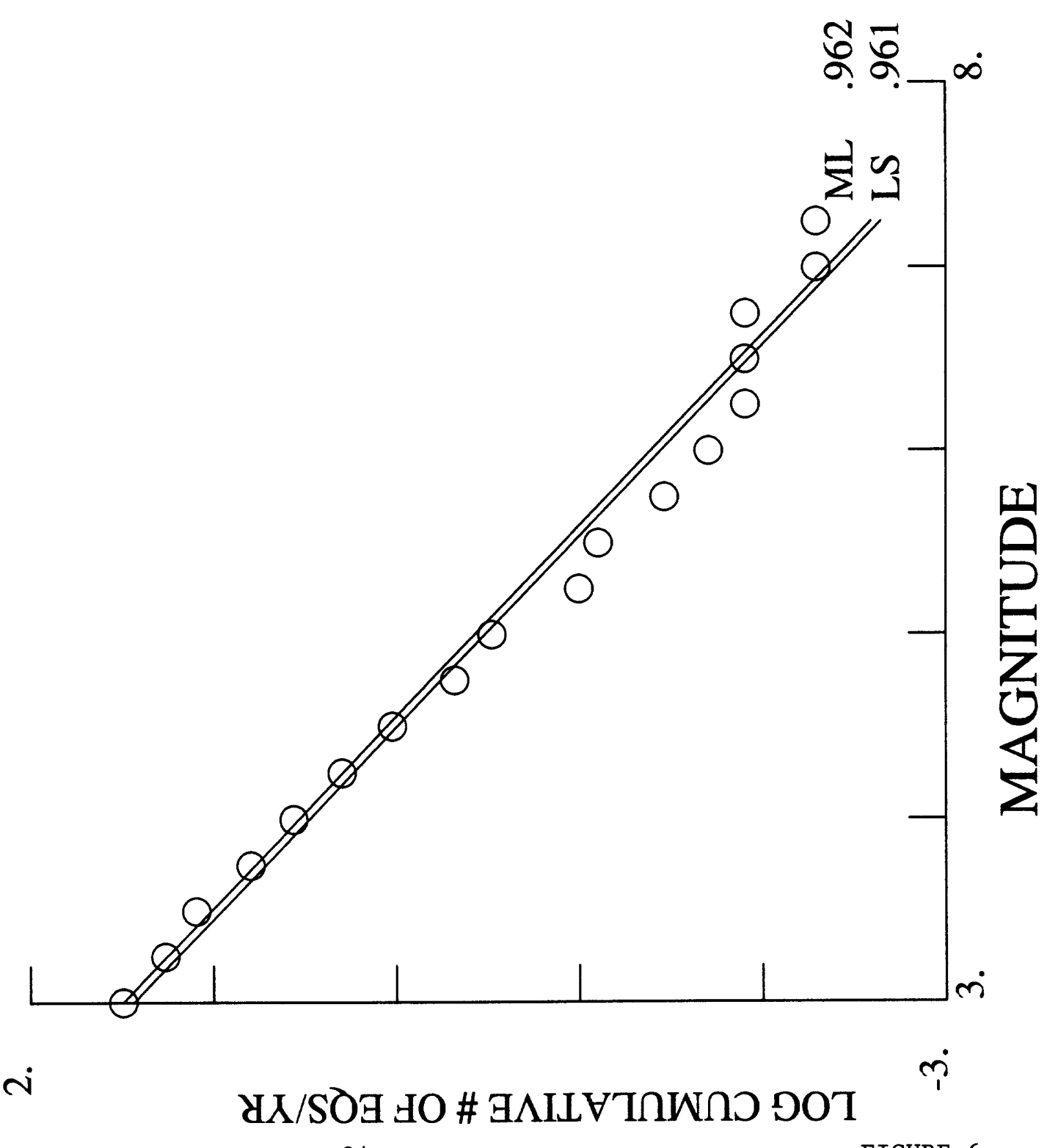




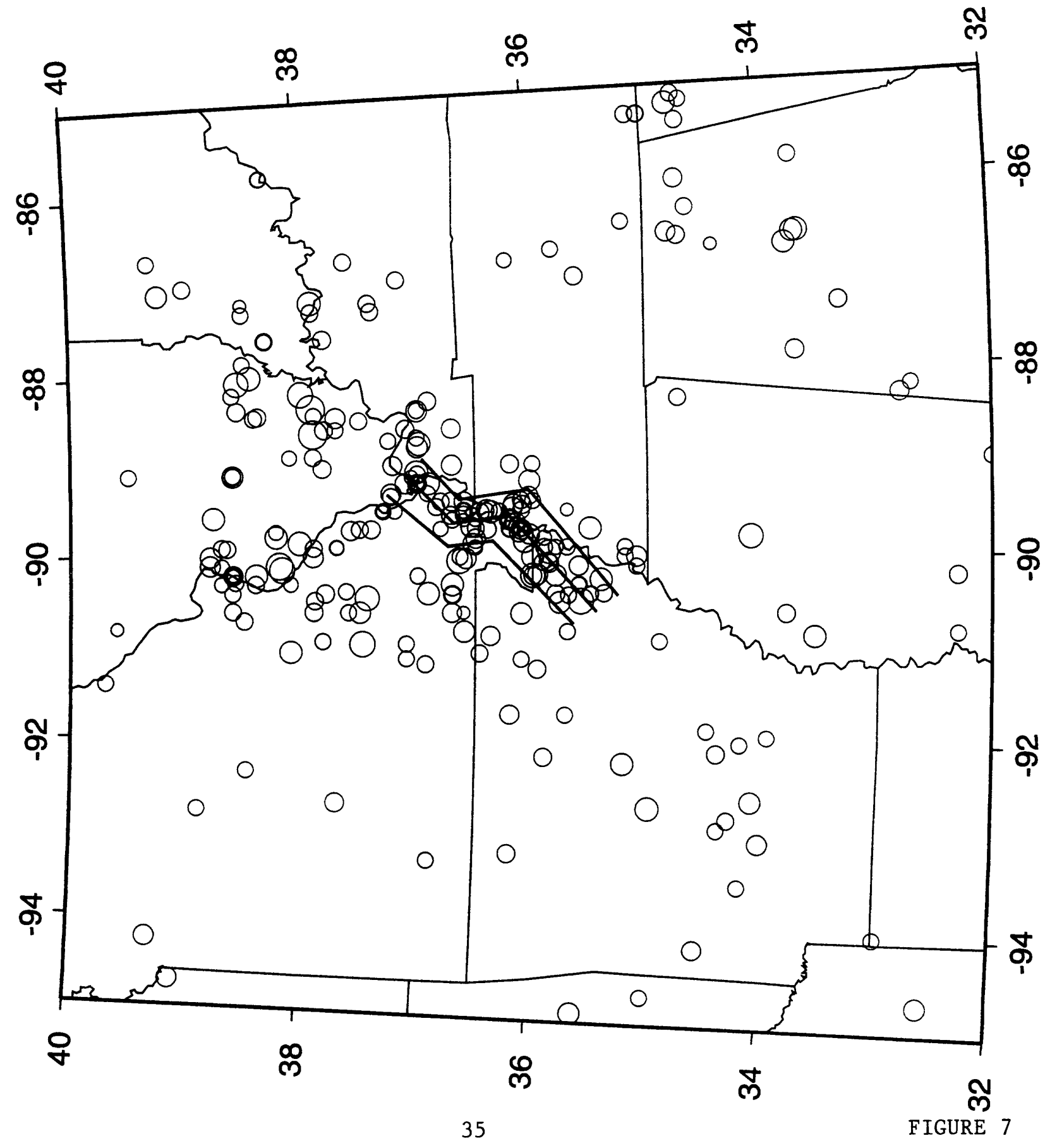




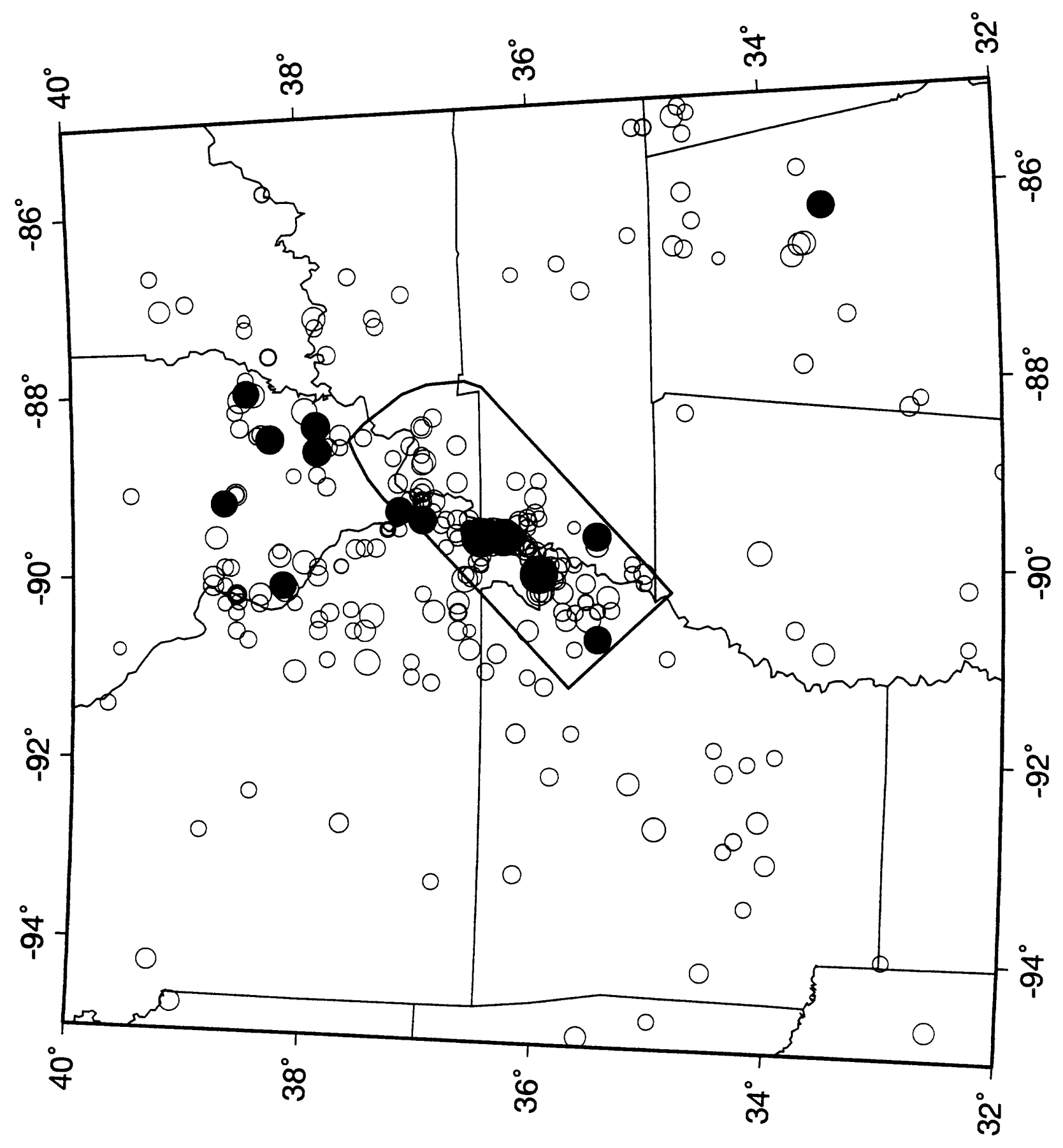




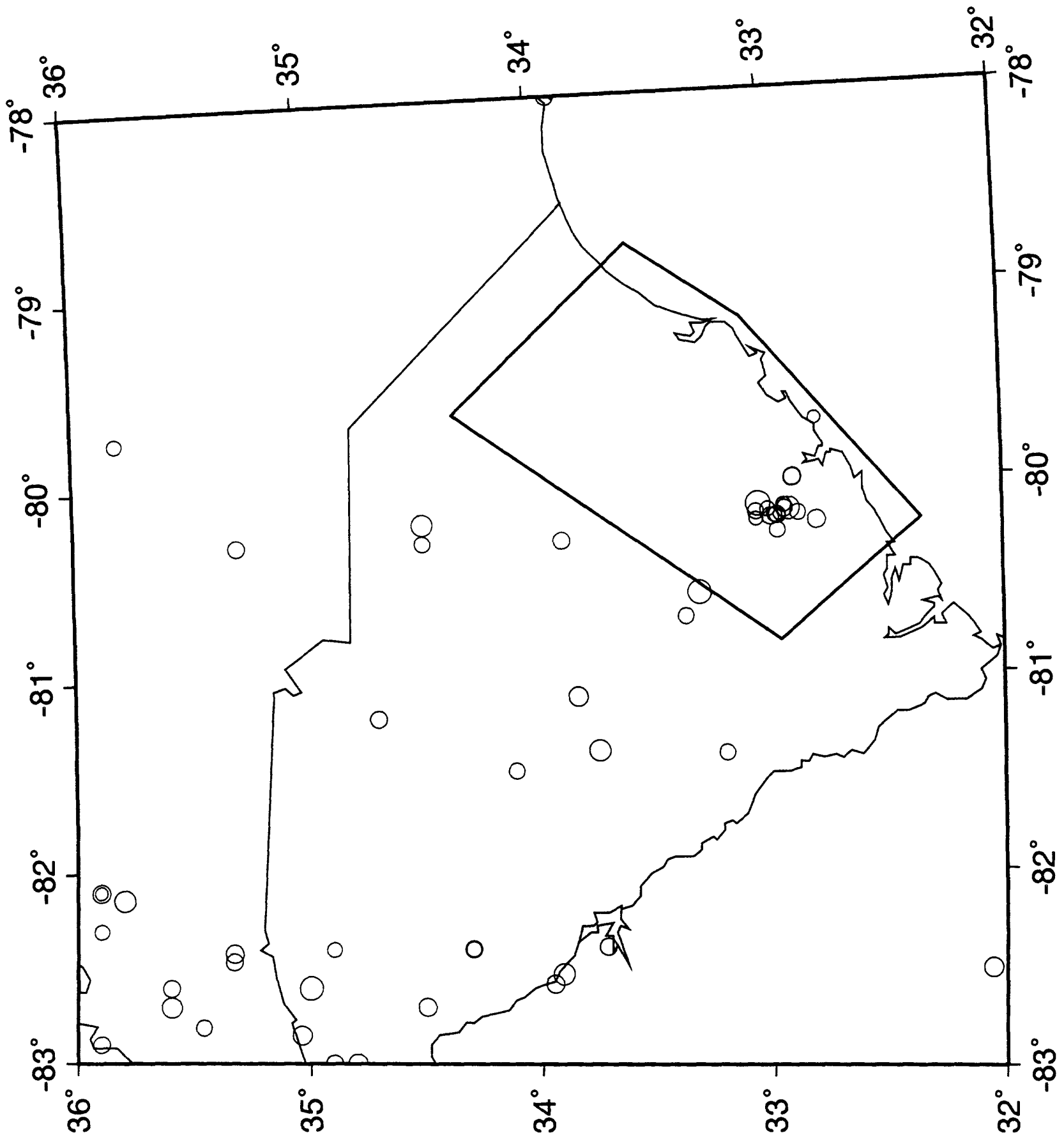

37

FIGURE 9 


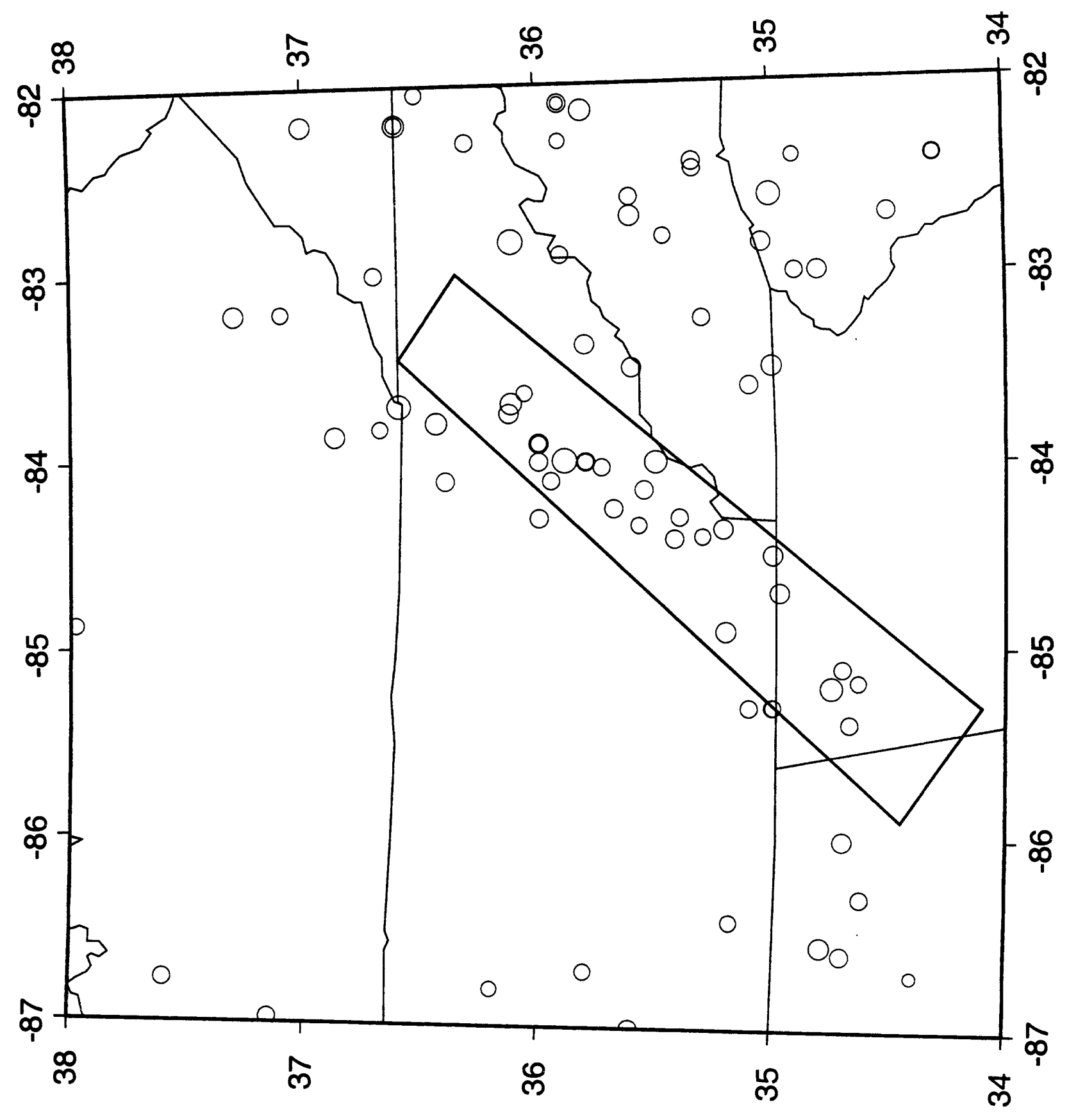




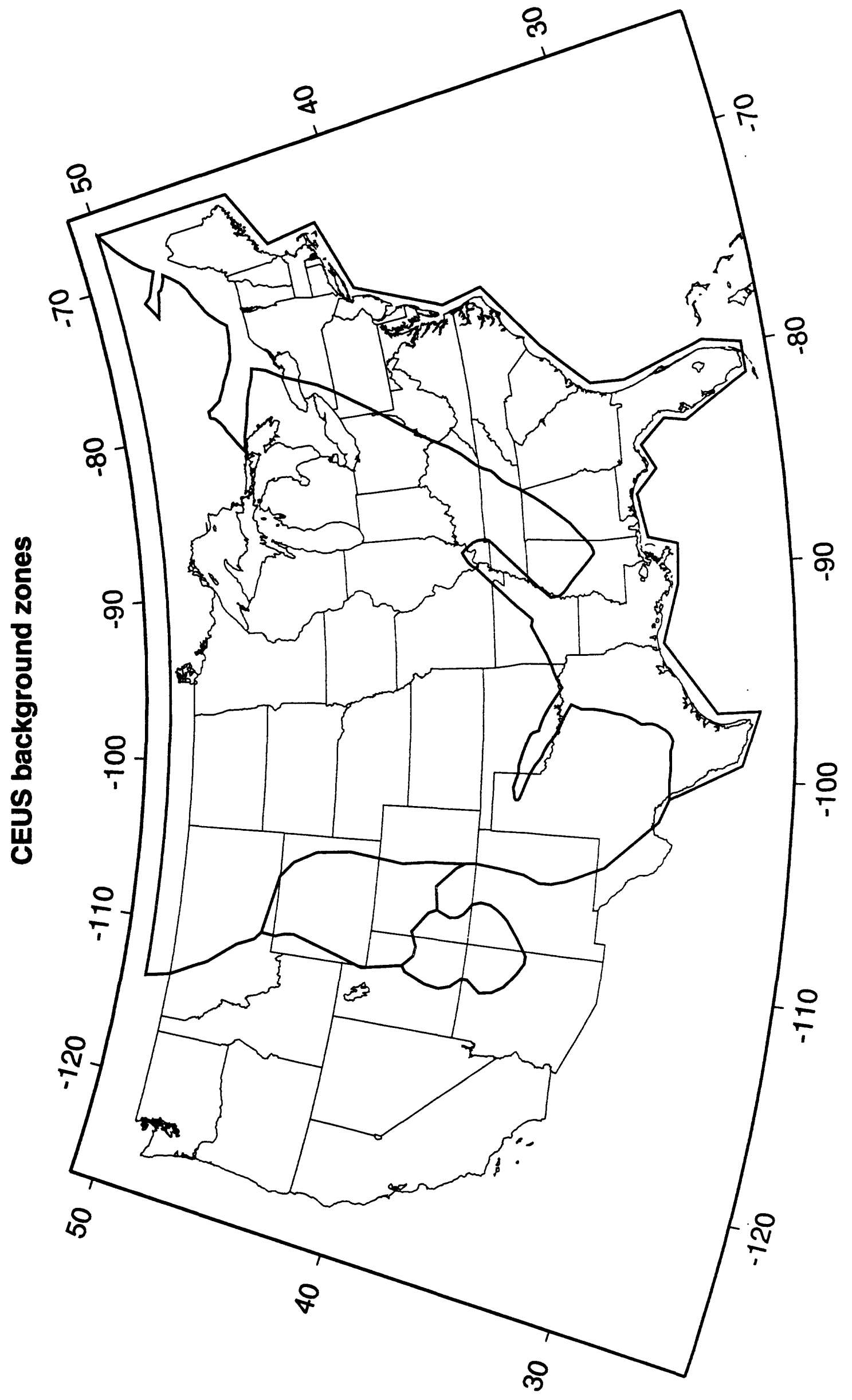




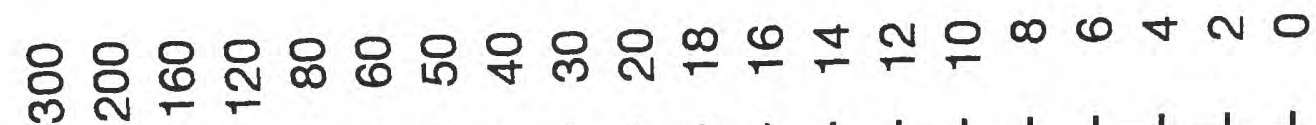

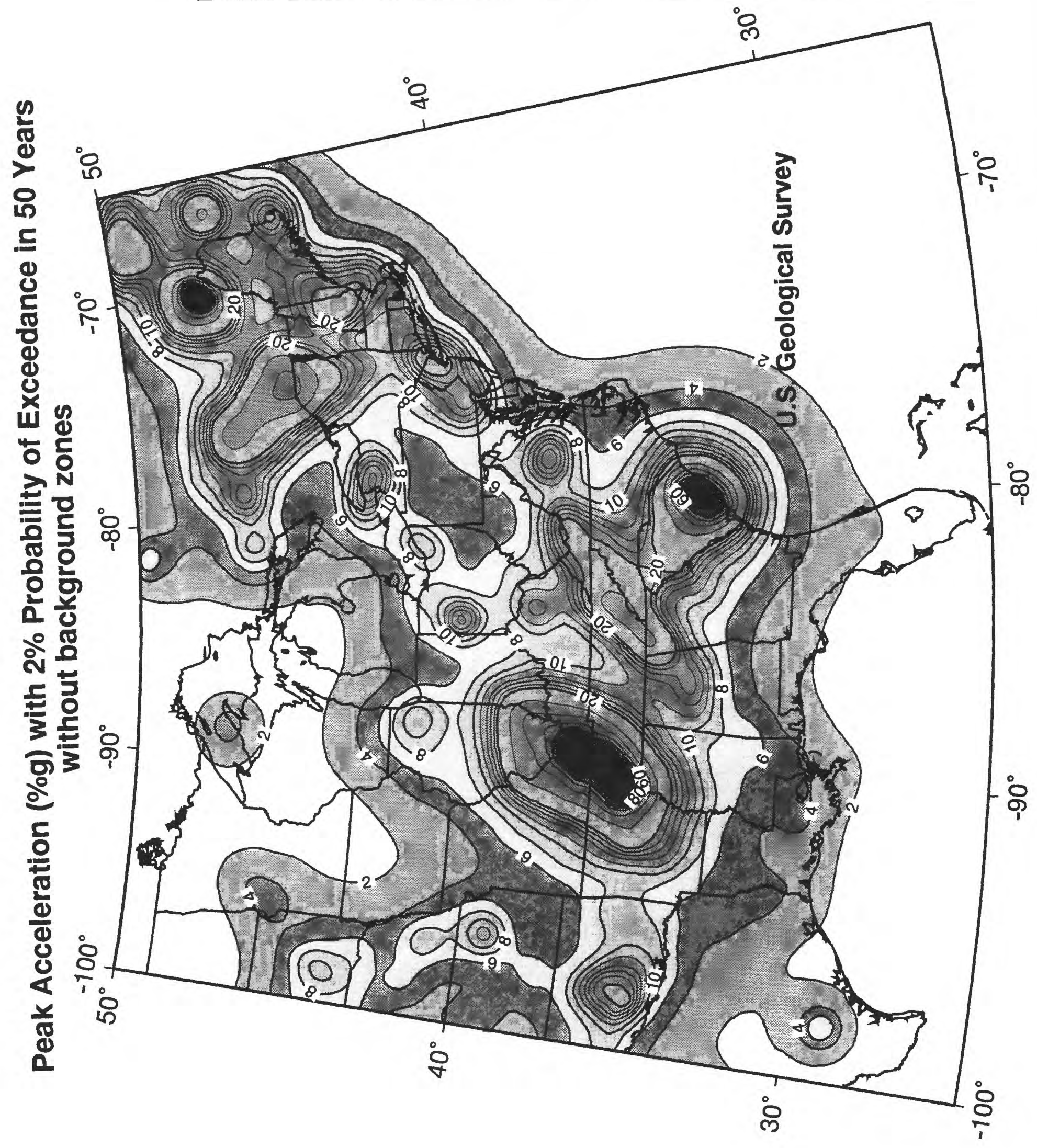




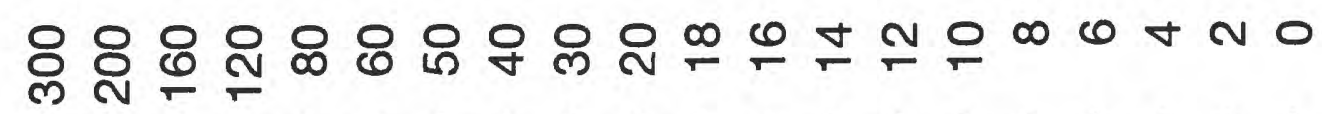

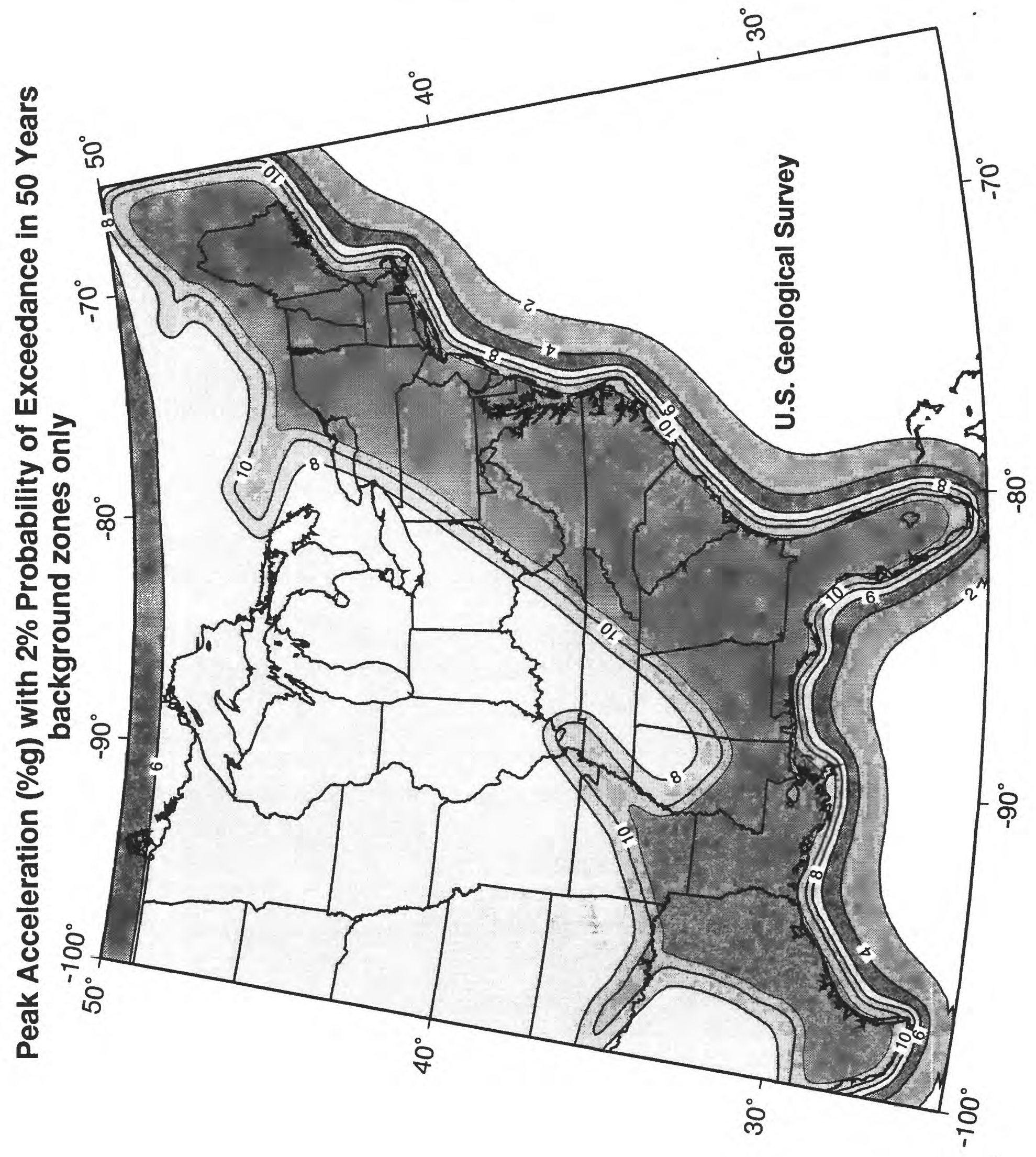




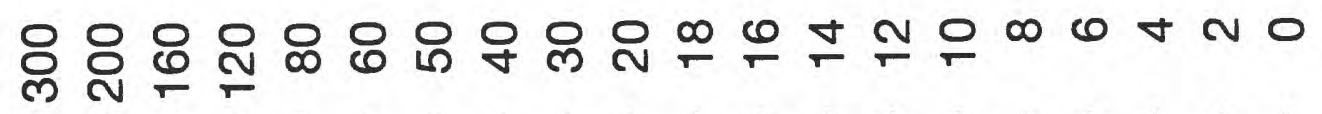

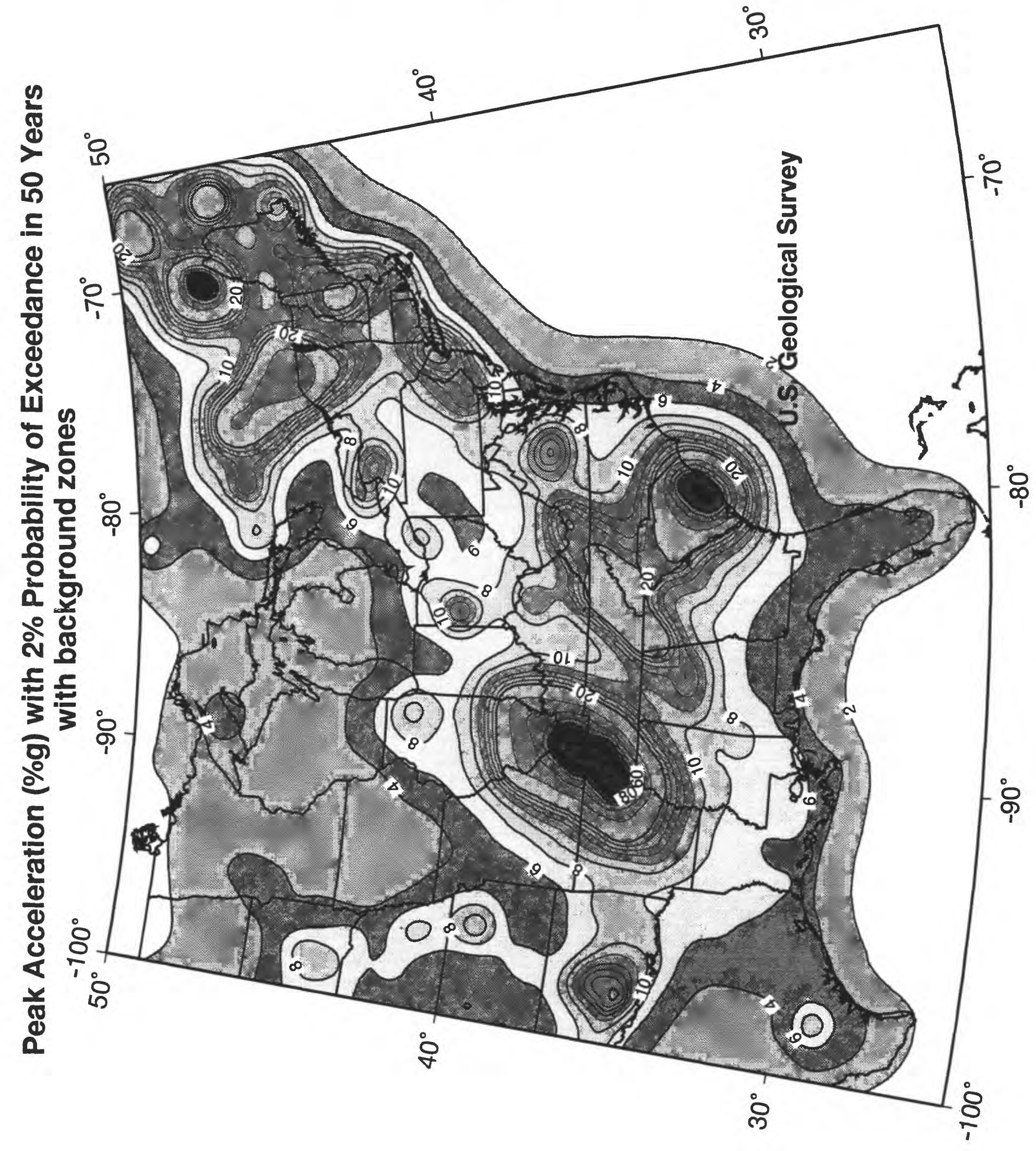




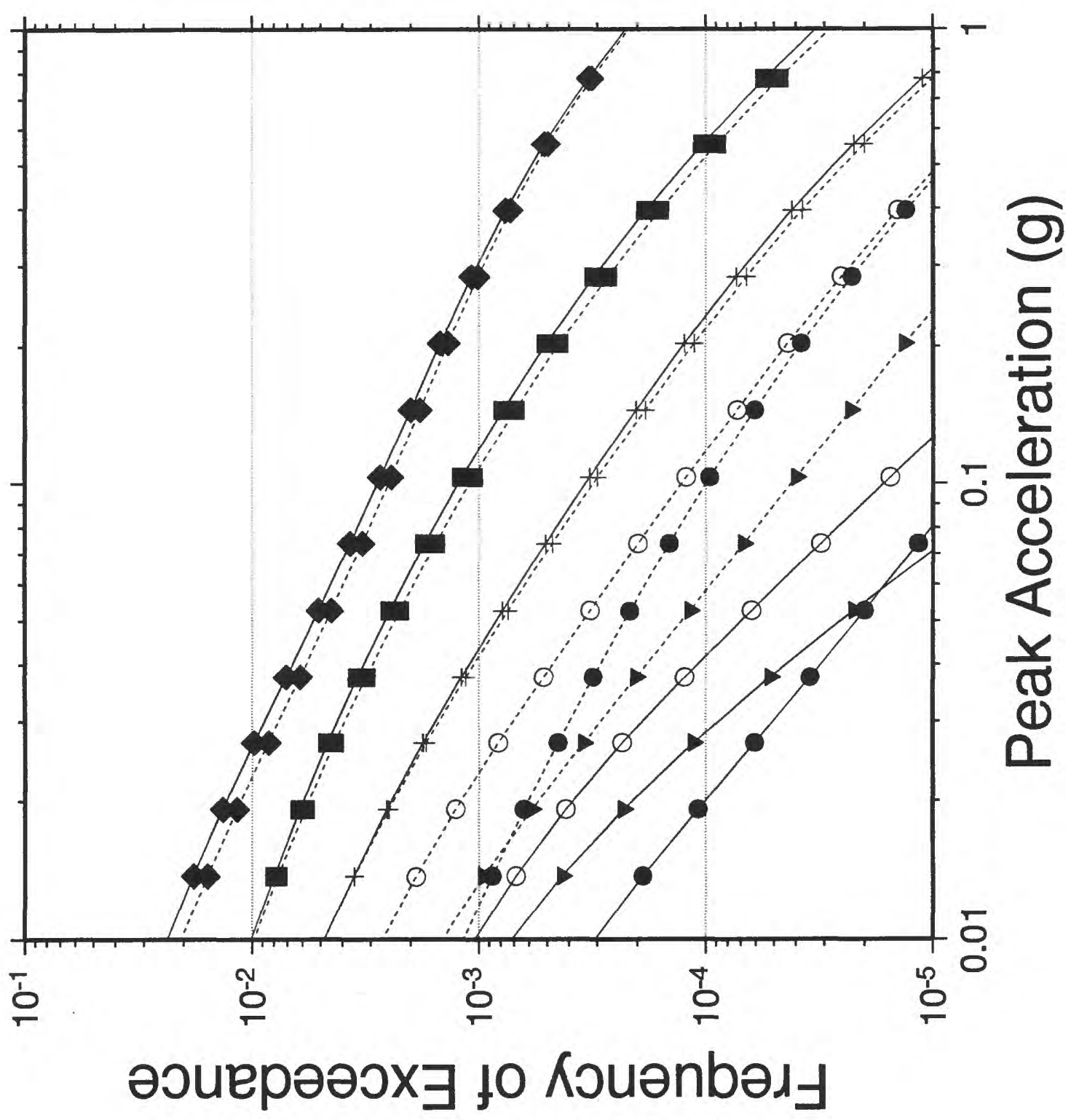




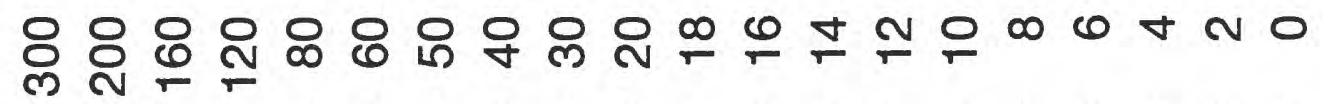

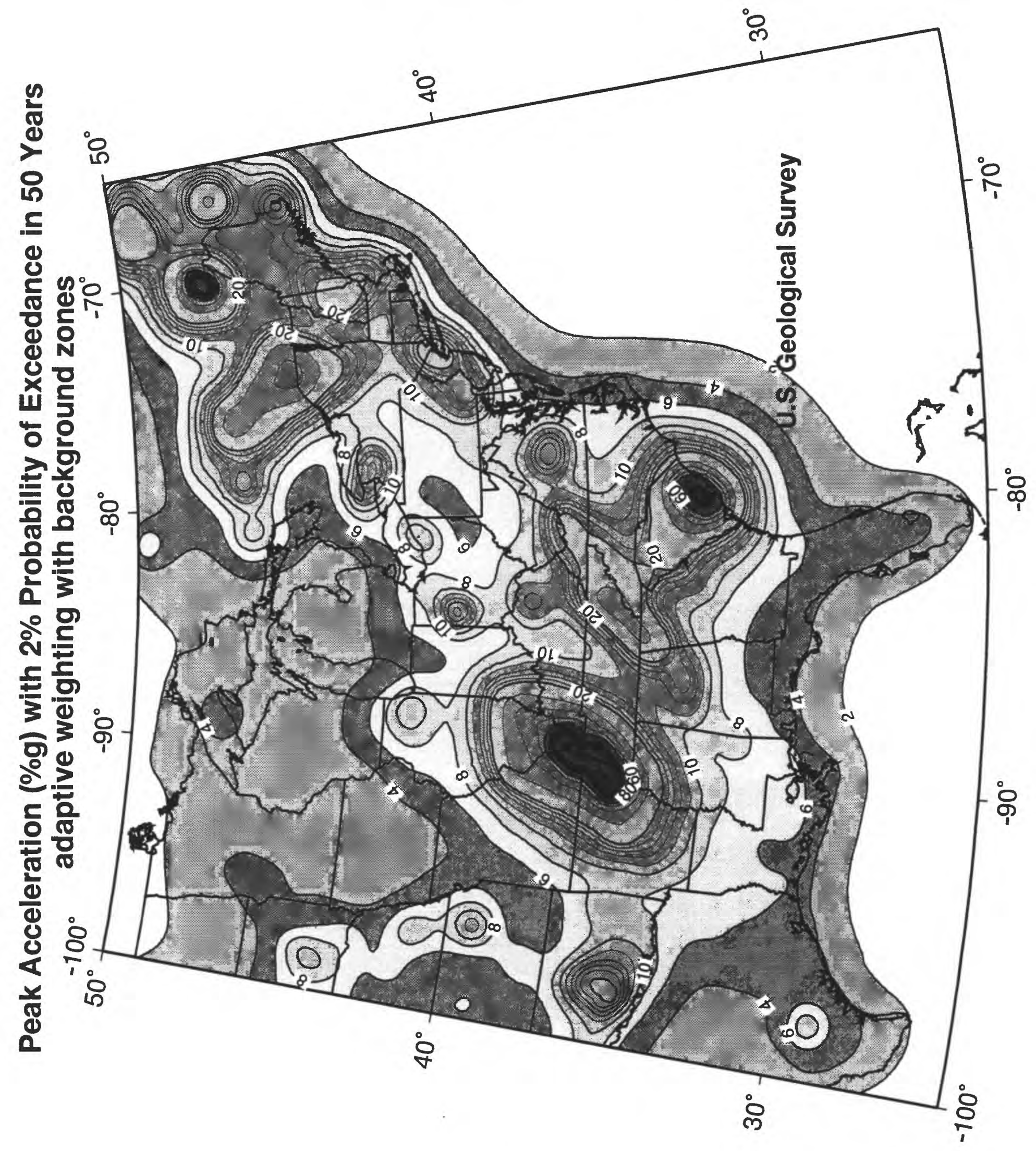




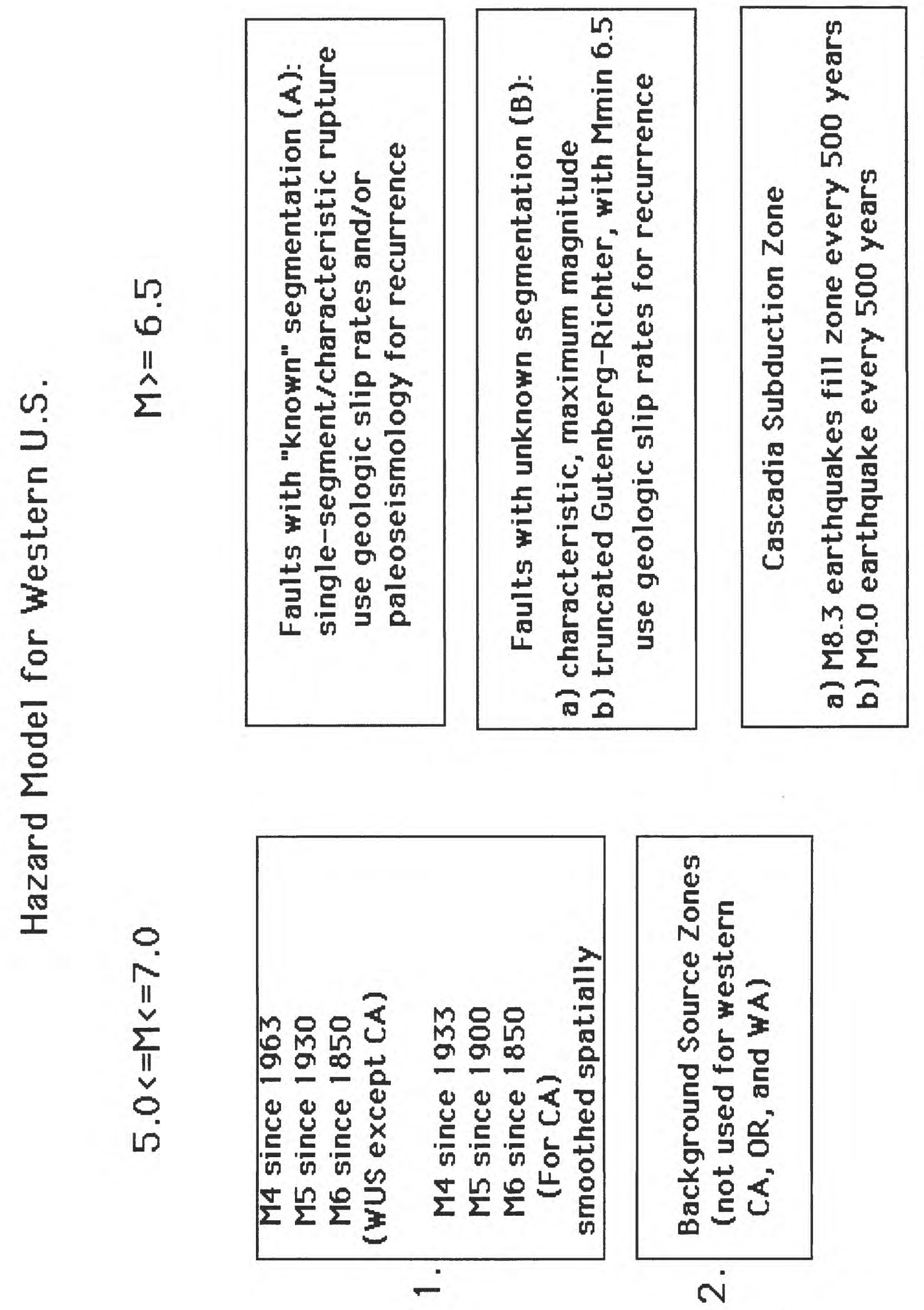




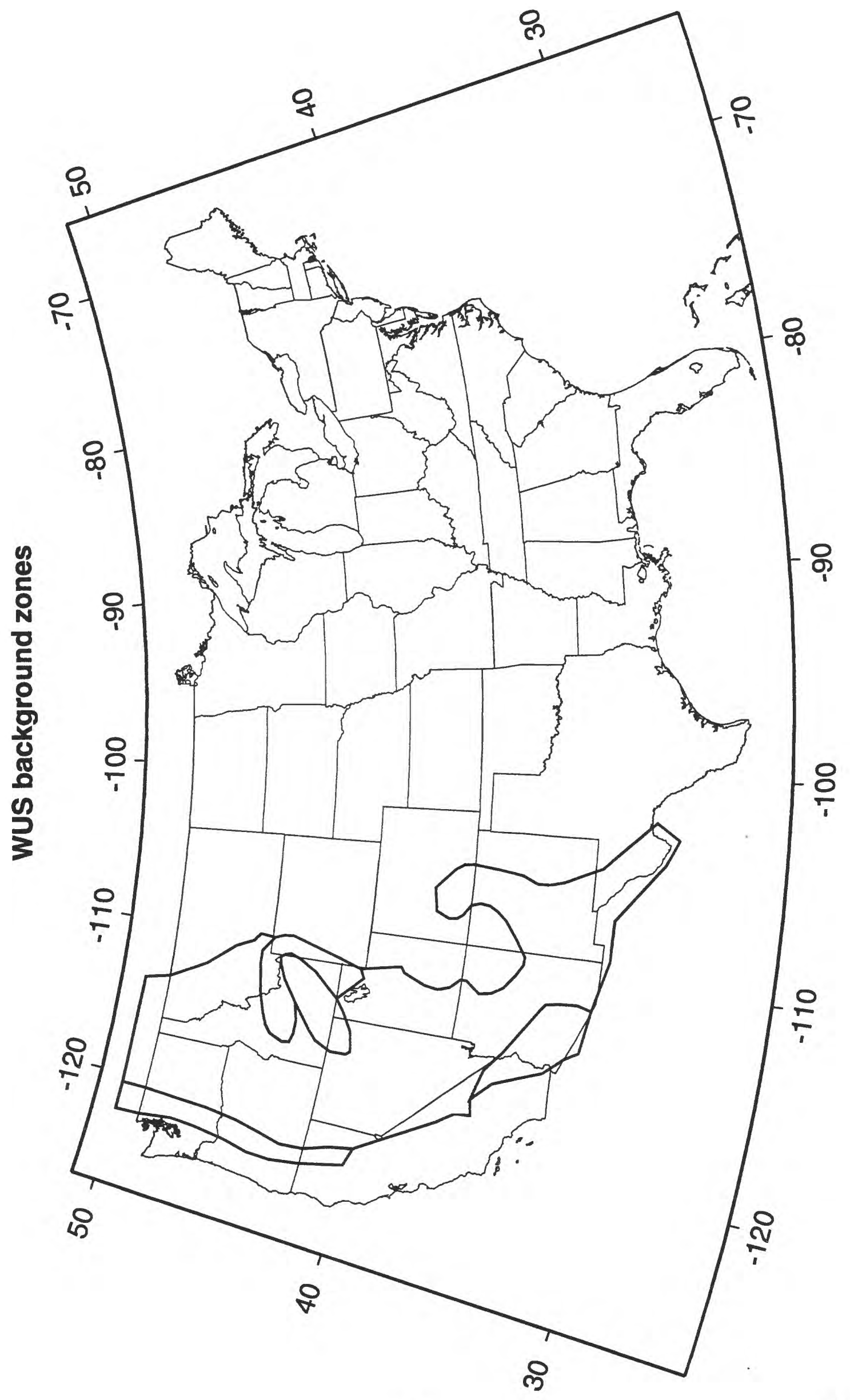



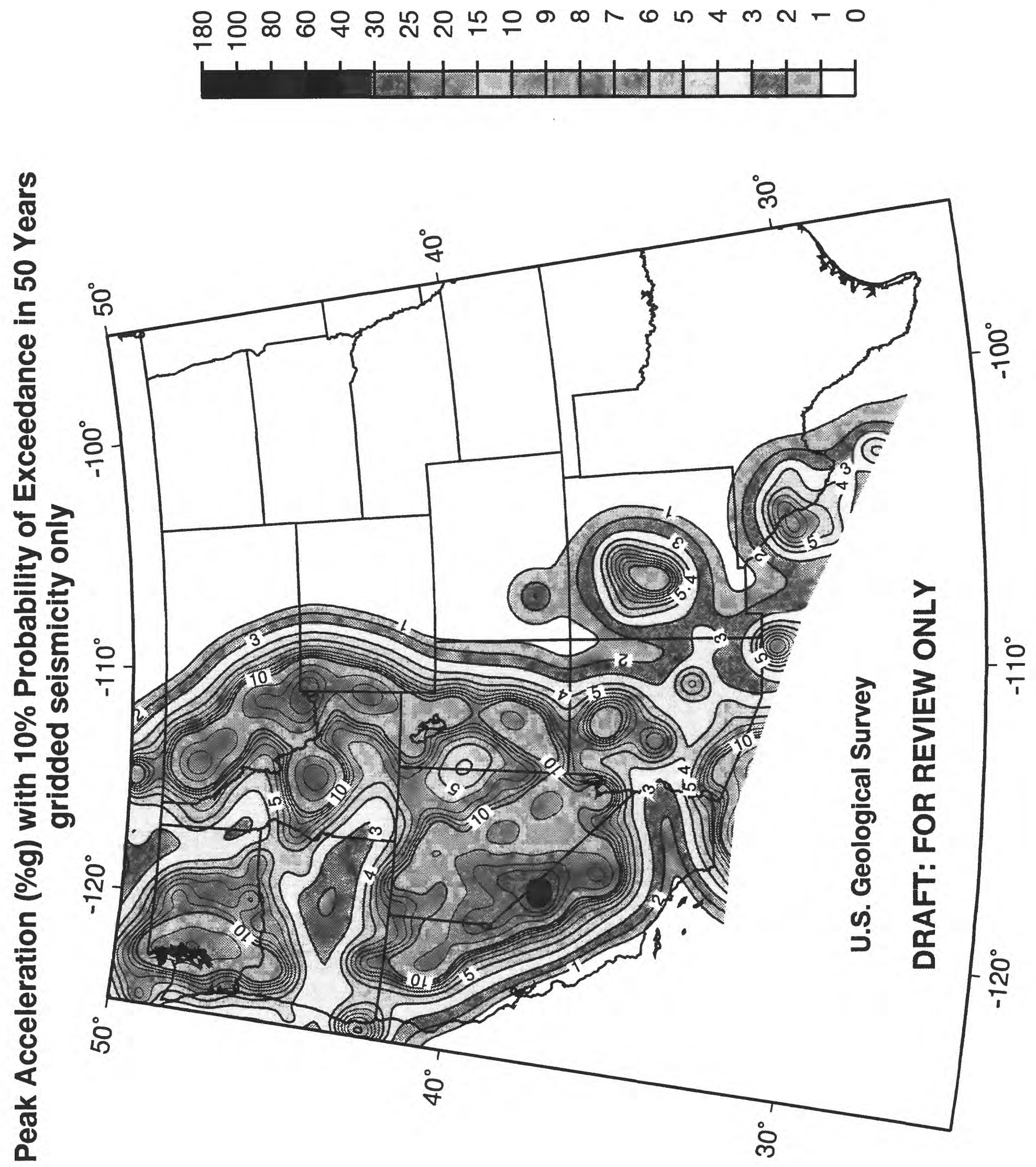


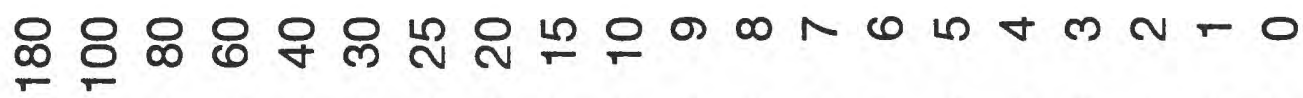

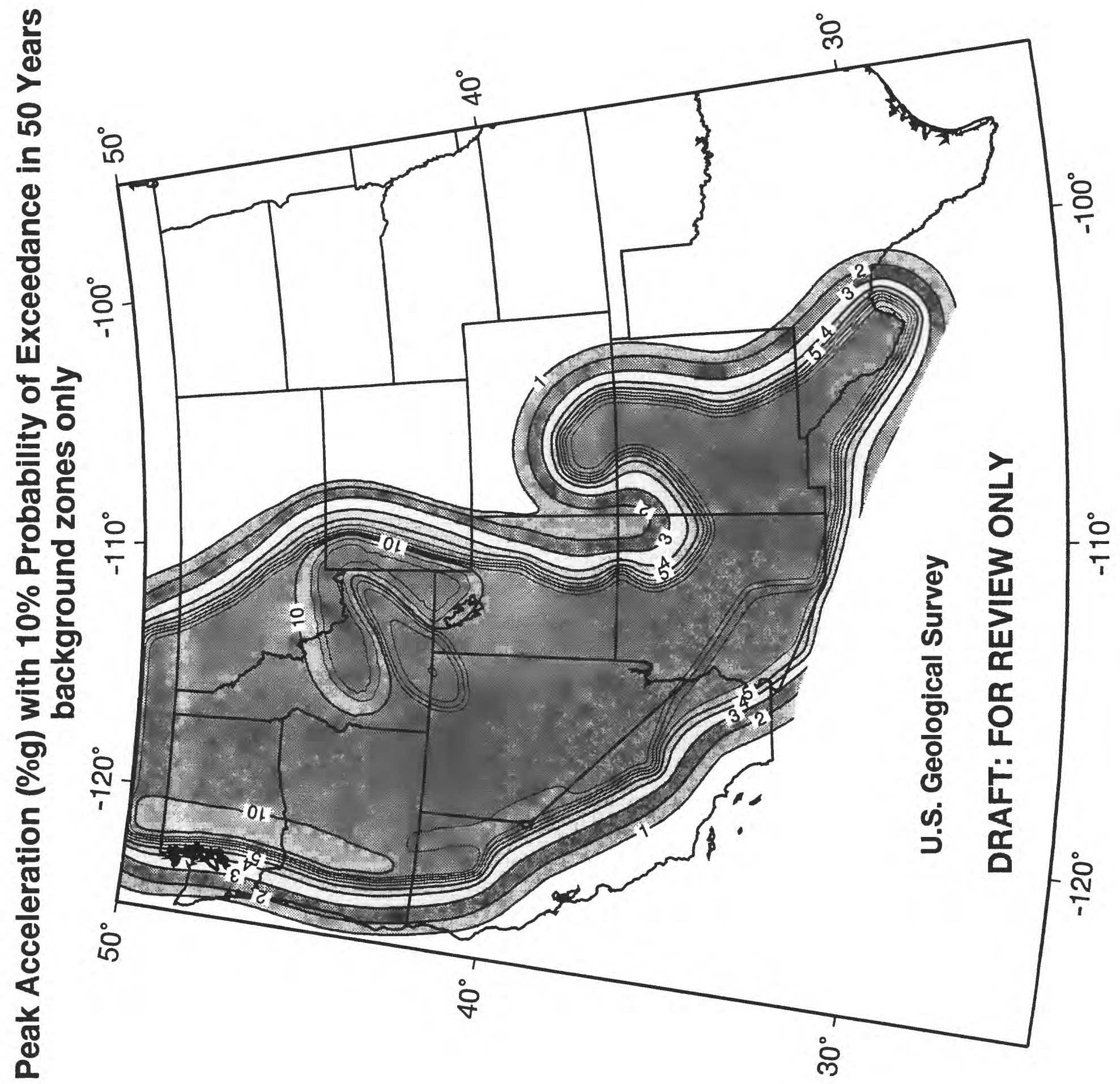




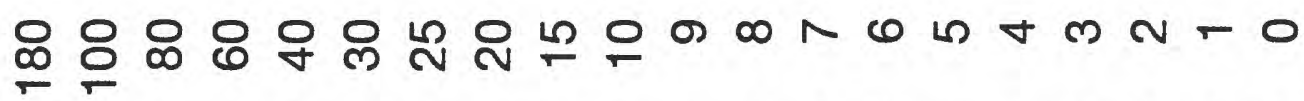

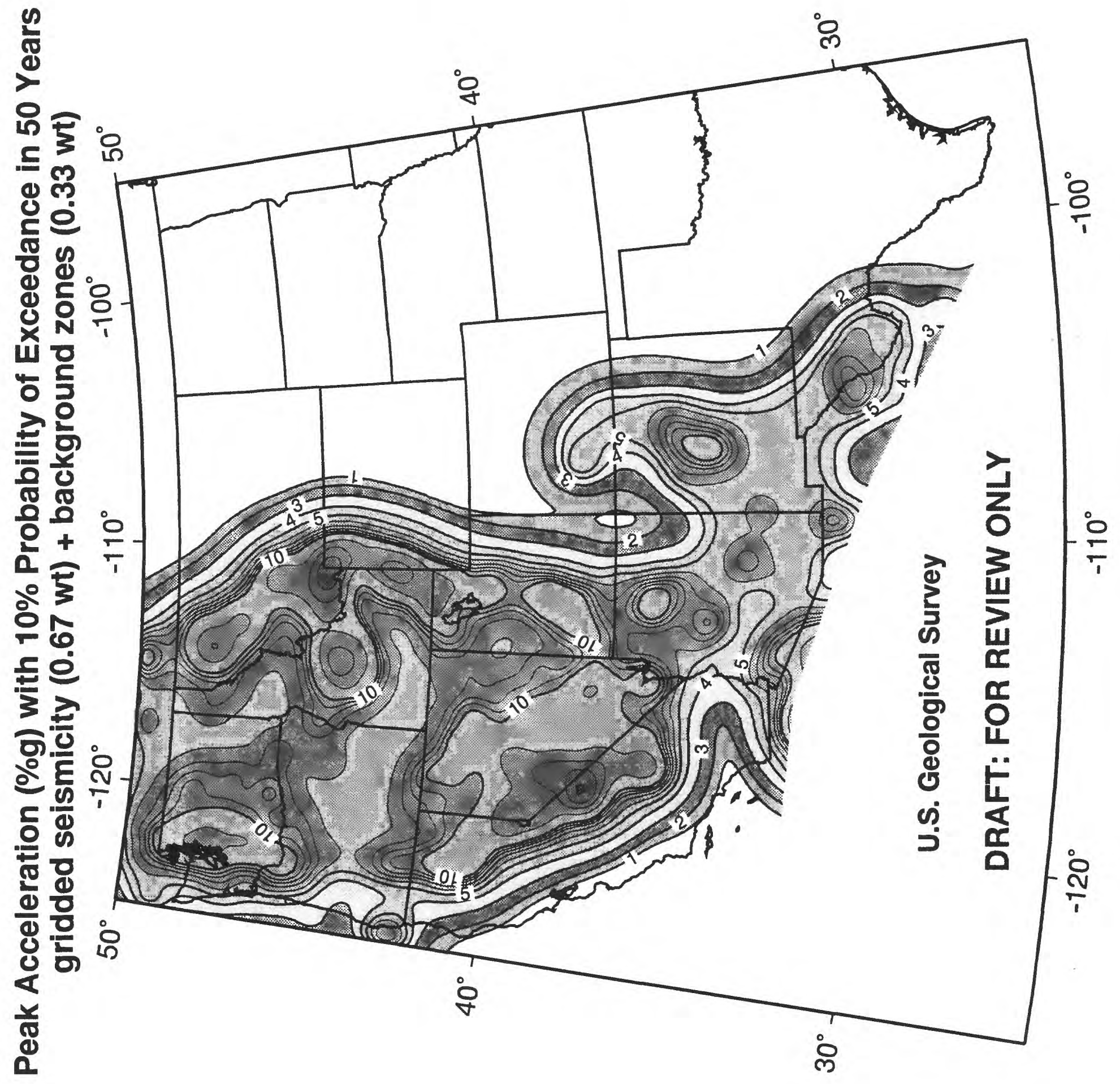




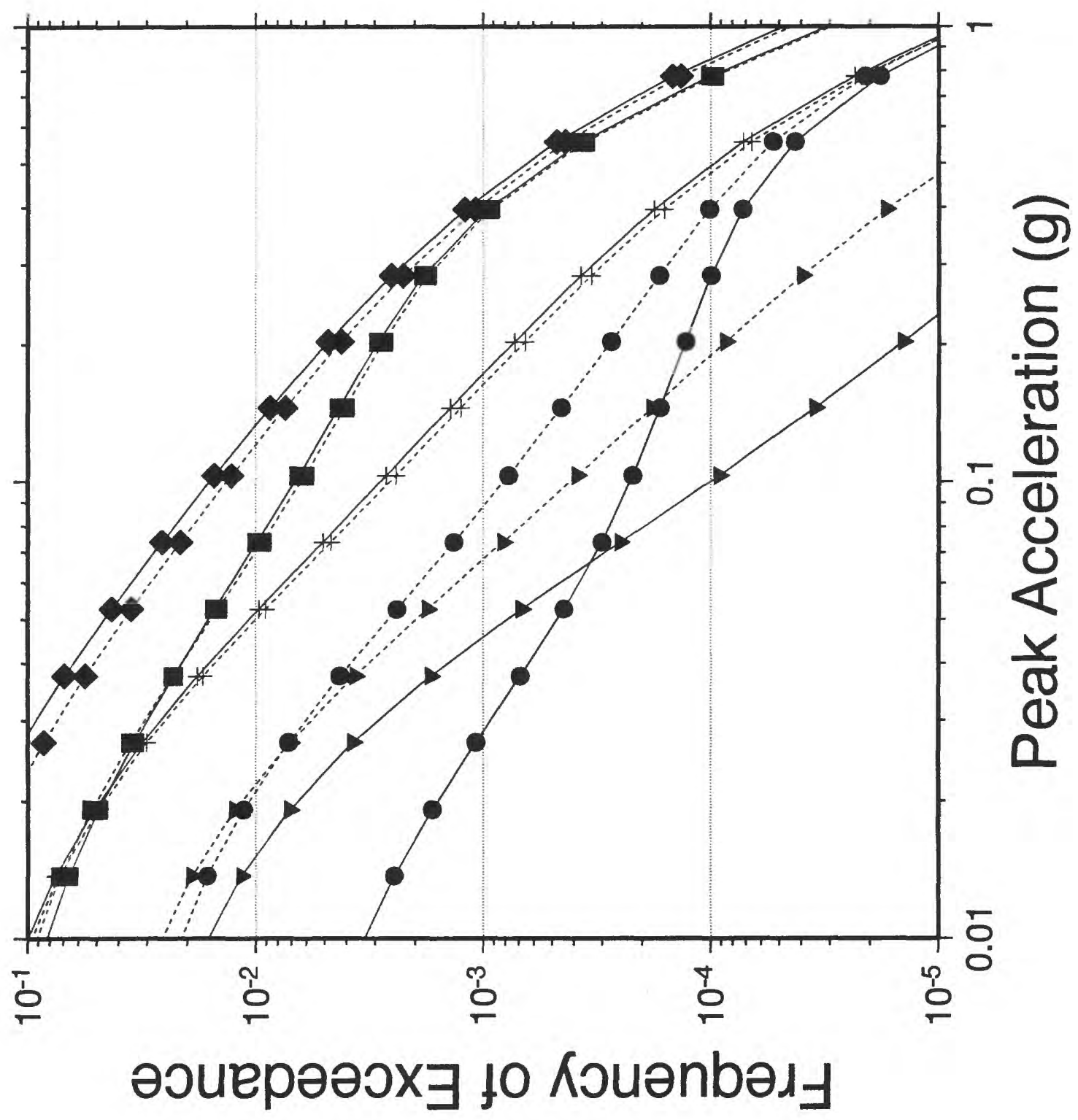




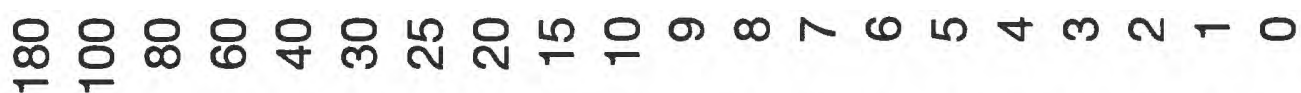

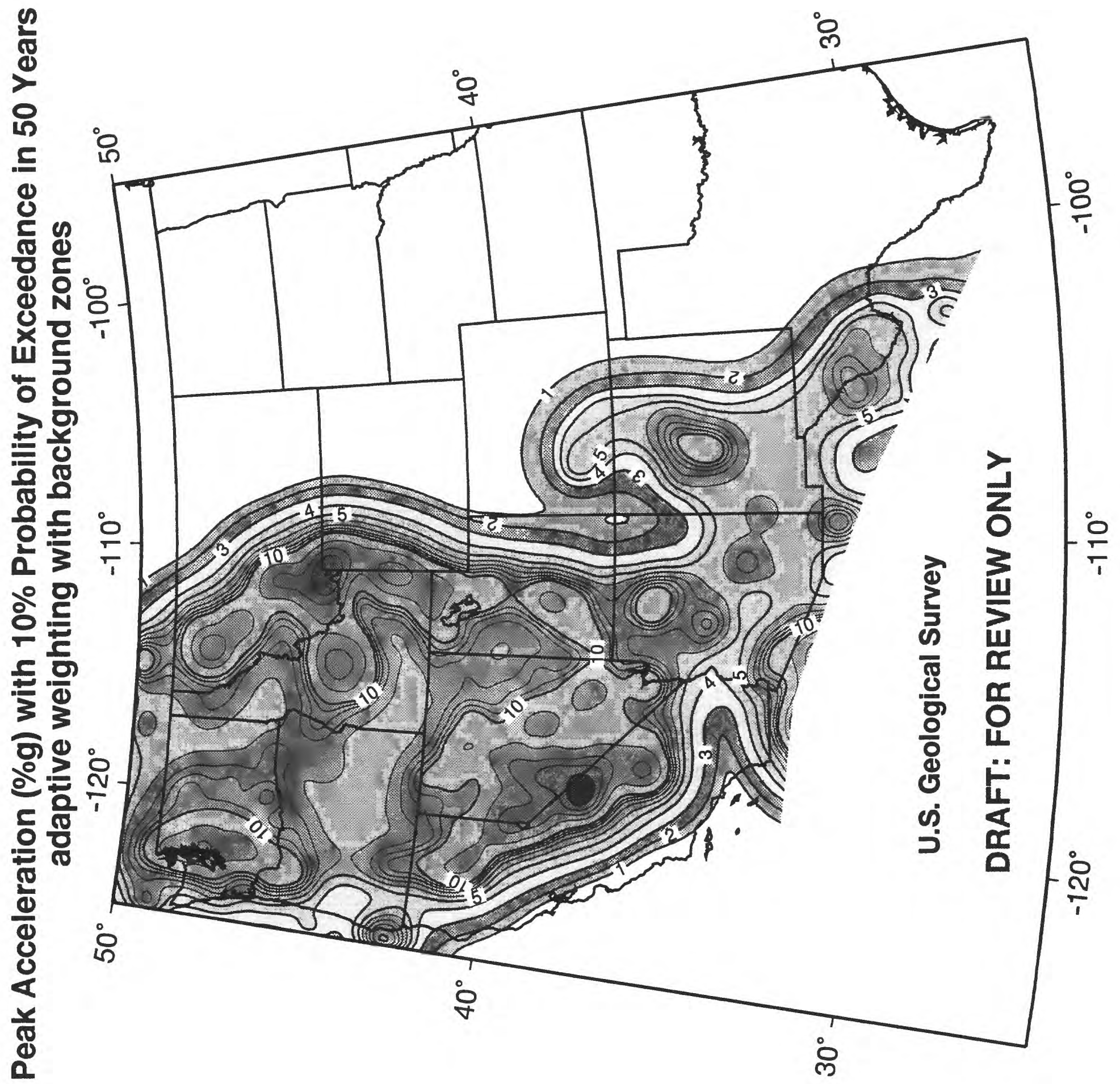




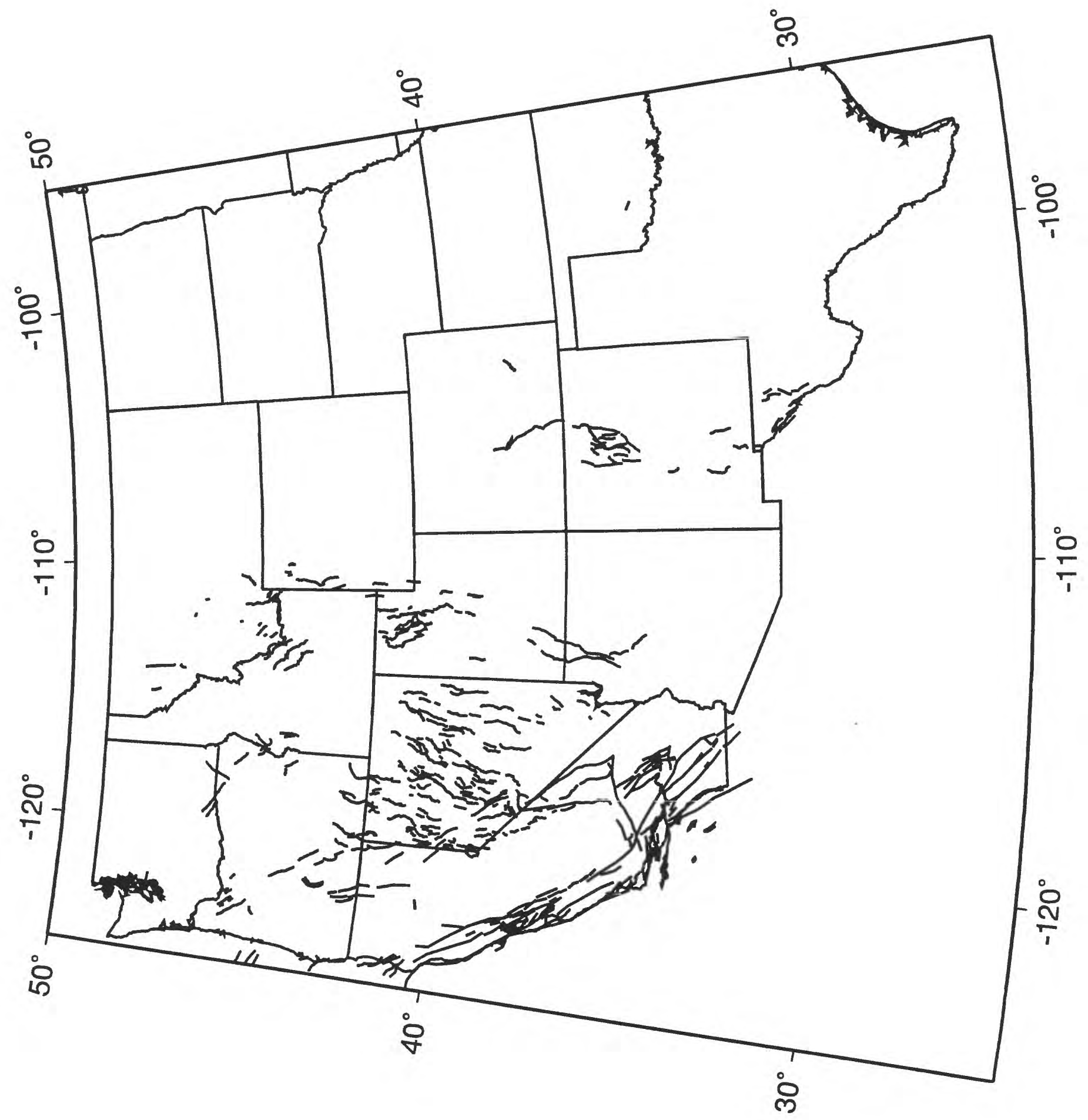




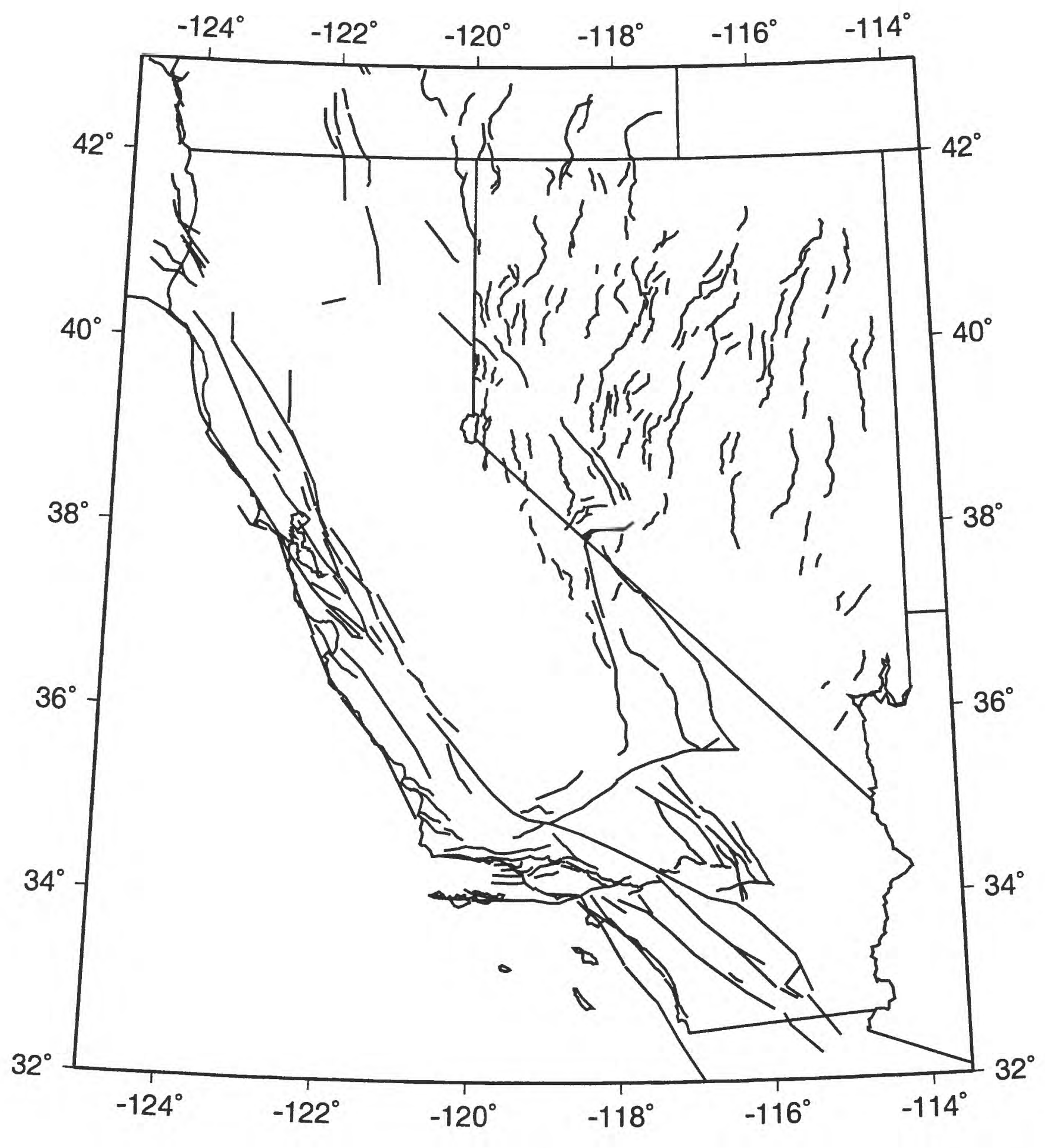




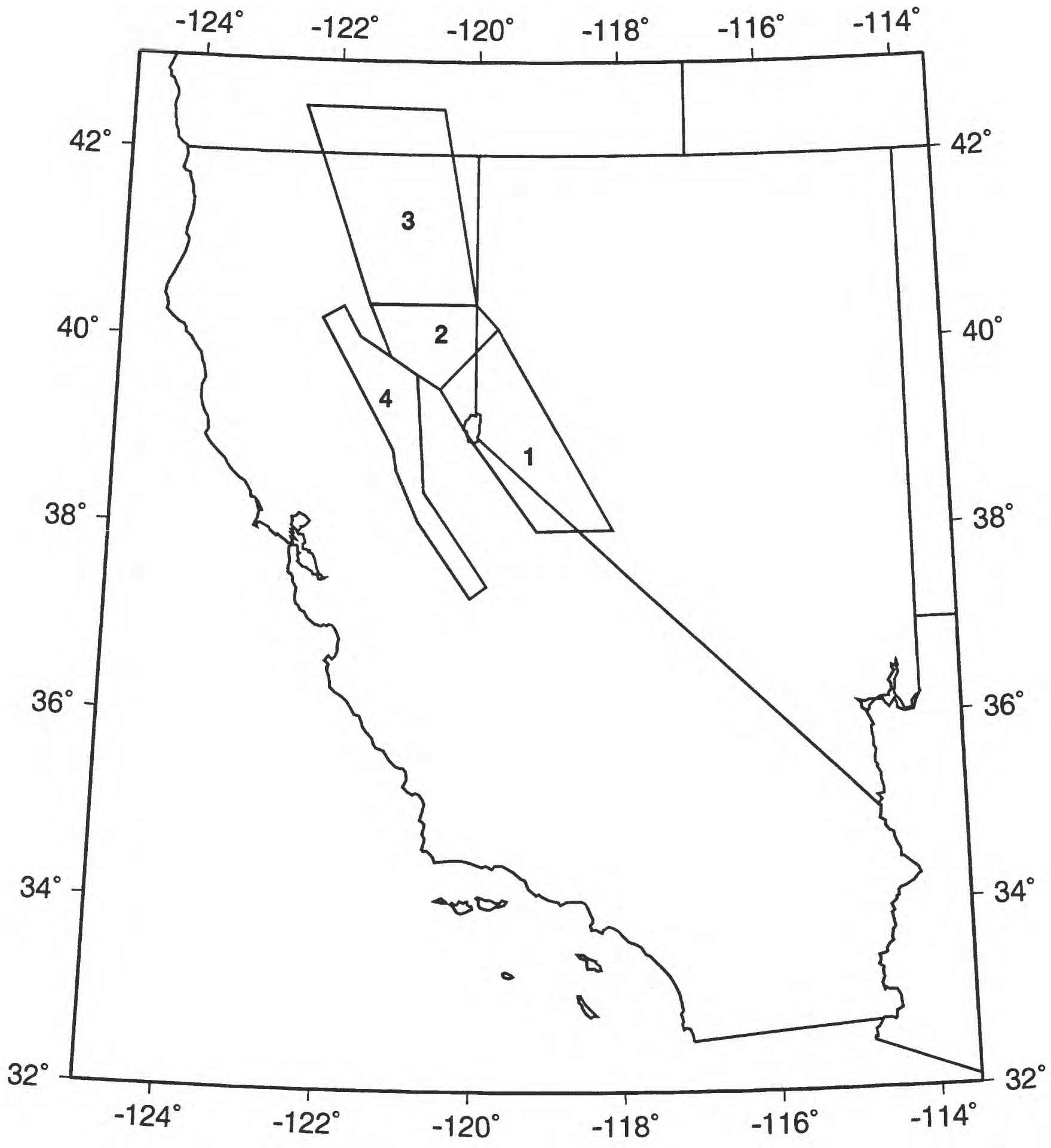




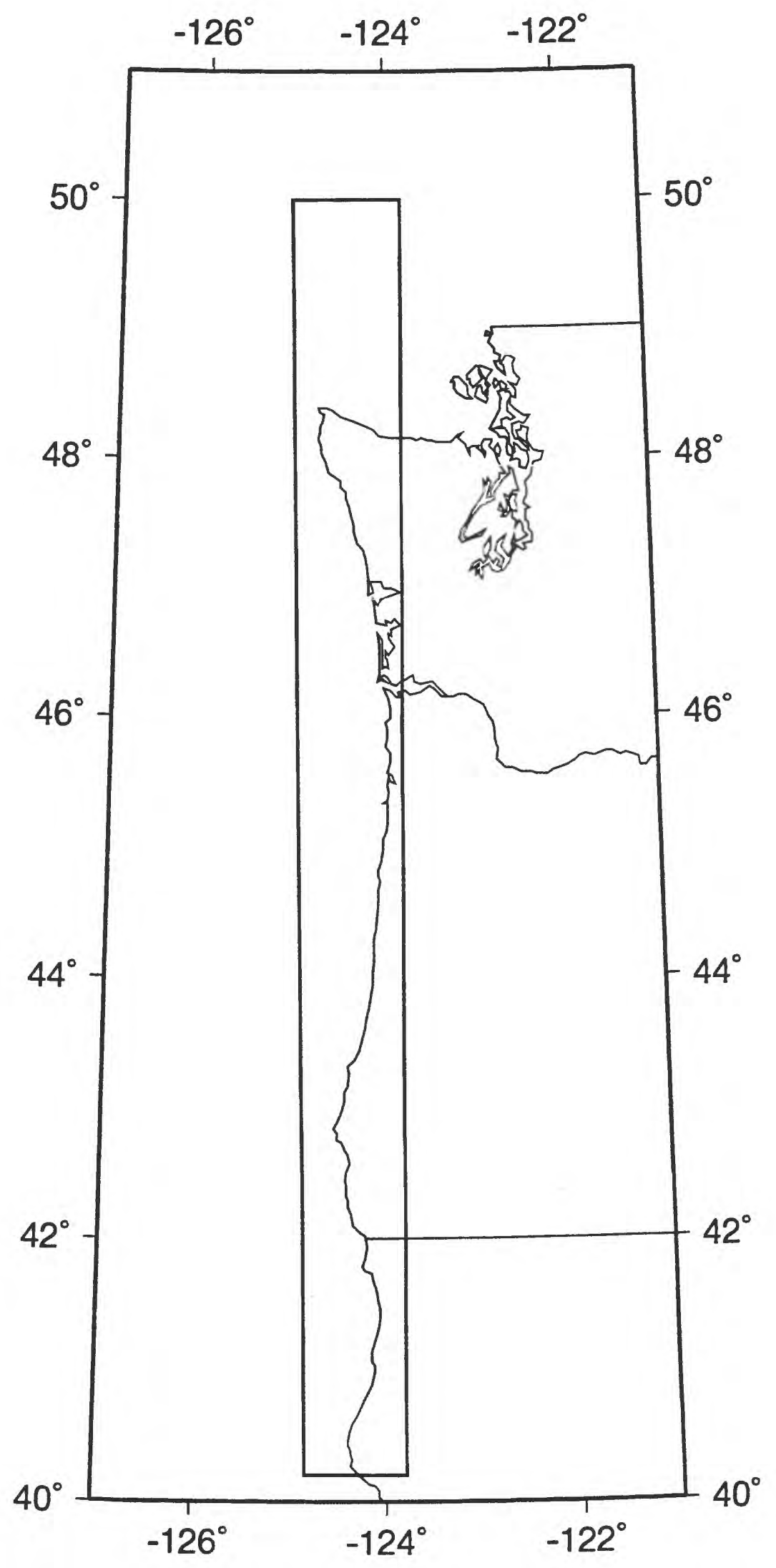




\section{APPENDIX $\underline{\mathrm{A}}$}

\section{Ground Motions For NEHRP B-C Boundary Sites In CEUS}

Two ground-motion attenuation relations were used in constructing the interim hazard maps for CEUS, one due to Toro and others (1993) with a modification for amplification by nearsurface materials, and the other constructed especially for this application. The purpose of this note is to document the new attenuation relation and the amplification factors applied to the Toro et al (1993) curves. The reference site condition is the boundary between NEHRP classes B and $C$, i.e, a site with an average shear wave velocity $\left(V_{S}\right)$ of $760 \mathrm{~m} / \mathrm{sec}$ in the top $30 \mathrm{~m}$. We refer to this site as "firm rock," differentiating it from "hard rock" with shear-wave velocities near 3.0 $\mathrm{km} / \mathrm{sec}$ at the surface.

The need for a new attenuation relation was apparent from discussion at our northeastern U.S. hazard workshop of August 1994 (see Frankel and others, 1995). Most workshop participants wanted an attenuation relation with a relatively high median stress drop of $150-200$ bars, to accommodate the possibility of occasional Saguenay events with very high stress drops of about 500 bars. Atkinson and Boore (1995) used a stress drop of 180 bars (albeit with a high shearwave velocity of $3.8 \mathrm{~km} / \mathrm{sec}$ ), higher than the 100 bars (with $\mathrm{Vs}=3.5 \mathrm{~km} / \mathrm{sec}$ ) used in Boore and Atkinson (1987) and the median stress drop of 120 bars used in Toro and others (1993). The workshop participants were not comfortable, however, with the two-corner frequency model advocated by Atkinson and Boore (1995) which dramatically decreases the intermediate-period (about $1.0 \mathrm{sec}$ ) spectral values compared to a single-corner frequency Brune model. Thus, we decided to construct a new set of attenuation relations based on a higher stress drop consistent with the high-frequency Fourier spectral levels specified in Atkinson and Boore (1995), but with a source model with a single corner frequency. These new attenuation relations also incorporate frequency-dependent amplification appropriate for a "firm-rock" CEUS site with a hypothetical shear-wave velocity profile at shallow depth $(<500 \mathrm{~m})$ and an average $V_{S}$ of $760 \mathrm{~m} / \mathrm{sec}$ in the top $30 \mathrm{~m}$.

\section{NEW MOTIONS FOR THIS APPLICATION}

The ground motions new to this application were based on the random-vibration implementation of the stochastic model, with parameters described below. The results are in the form of tables of ground motion for a set of moment magnitudes and hypocentral distances; there are separate tables for the various ground-motion parameters (peak acceleration and response spectra with 5\% critical damping). The tables used in the hazard maps are contained in Tables A1-A4. The input parameters for the stochastic model are given in Table A5, which is a listing of the inputparameter file. The meaning of the various parameters is explained in detail in Boore (1996). We discuss a few of these parameters here.

Source: The most important parameter affecting the source is the stress parameter. Atkinson finds that a single-corner-frequency spectrum with a stress parameter of 180 bars will fit the high-frequency spectral level data that she published in 1993 (Atkinson, personal communication, 1995, and Atkinson and Boore, 1996). Because of her data selection and her data reduction procedure, her stress parameter is appropriate for a hard-rock site with no nearsurface amplification and a source shear velocity of $3.8 \mathrm{~km} / \mathrm{s}$. On the other hand, we think that hard-rock sites should have some amplification, and we have used a source shear velocity of 3.6 $\mathrm{km} / \mathrm{s}$. For this reason, we have modified her stress parameter to account for these two effects (note that later we discuss the further amplification for a firm-rock site). The decreased source shear velocity and the near-surface amplification will increase high-frequency spectral levels for 
a given stress parameter; for this reason, the stress parameter in our model must be reduced in order to preserve the high-frequency spectral levels (we are assuming that Atkinson's source model gave an adequate fit to the observed spectral levels). With amplification the new highfrequency spectral level (i.e., the spectral level above the corner frequency, but not at frequencies so high as to be affected by diminution effects such as kappa or fmax) would be about equal to $\mathrm{A} *$ stress $(2 / 3)$ /beta, where the near-surface hard-rock amplification $\mathrm{A}$ is about sqrt(3.6/2.8) (the near-surface shear velocity at a hard-rock site is assumed to be $2.8 \mathrm{~km} / \mathrm{s}$ ). Equality of high-frequency spectral levels then requires stress $=180 *$ $[(3.6 / 3.8) * \operatorname{sqrt}(2.8 / 3.6)]^{(3 / 2)}$ or stress $=180 * 0.76=137$. We have conservatively chosen 150 bars rather than 137 bars as the stress parameter. Note that for long periods the spectra go as inverse shear velocity cubed, with no contribution from stress and little from amplification, so the spectral levels will be increased by $(3.8 / 3.6)^{3}=1.18$. Note that this only considers the Fourier spectra; the ground motion amplitudes are also influenced by the duration. Note also that we have used a single-corner-frequency model rather than the two-corner-frequency model used by Atkinson and Boore (1995); this will have the effect of increasing the ground motions at intermediate periods.

Signal Duration: The signal duration was specified as in Boore and Atkinson (1987). The duration (in sec) is equal to $1 / f_{C}+0.05 R$, where $R$ is distance and $f_{C}$ is the comer frequency.

Path: The geometrical spreading and attenuation are those used by Atkinson and Boore (1995). We used a tripartite geometrical spreading function consisting of $\mathrm{R}^{-1}$ from 10 to $70 \mathrm{~km}$, $\mathrm{R}^{0}$ from 70 to $130 \mathrm{~km}$, and $\mathrm{R}^{-0.5}$ for greater than $130 \mathrm{~km}$. Q was set equal to $680 \mathrm{f}^{0.36}$.

Site Amplification: The amplifications for Fourier spectral values are given in Table A5, and are intended to represent a hypothetical NEHRP B-C boundary site for the CEUS. They are obtained by converting an average velocity vs depth function to amplifications and frequencies using an approximate method discussed in Boore and Joyner (1991), as implemented by the program Site_Amp in Boore (1996). The underlying velocity vs. depth function was constructed by requiring the average velocity in the upper $30 \mathrm{~m}$ to be $760 \mathrm{~m} / \mathrm{s}$ (=NEHRP B-C boundary of 2500 $\mathrm{ft} / \mathrm{sec}$ ). Table A6 contains the velocity and density profiles used. Figure A1 shows the shallow velocity profile. A steep linear gradient was imposed from the surface down to $200 \mathrm{~m}$ depth. The velocity gradient was intended to be steeper than that for a typical WUS rock site. A less steep gradient was imposed below $200 \mathrm{~m}$, with the velocities approaching the hard-rock values at depth. The velocities and densities were chosen with consideration given to the gross differences in lithology and age of the rocks in ENA compared with those in coastal California (the source of much of the borehole data that can be used to constrain velocity--depth functions): we expect ENA rocks to be higher velocity and density than those in coastal California at any given depth below the surface. Figure A1 also shows the shallow velocities used in our simulations for hard-rock sites (see below). 


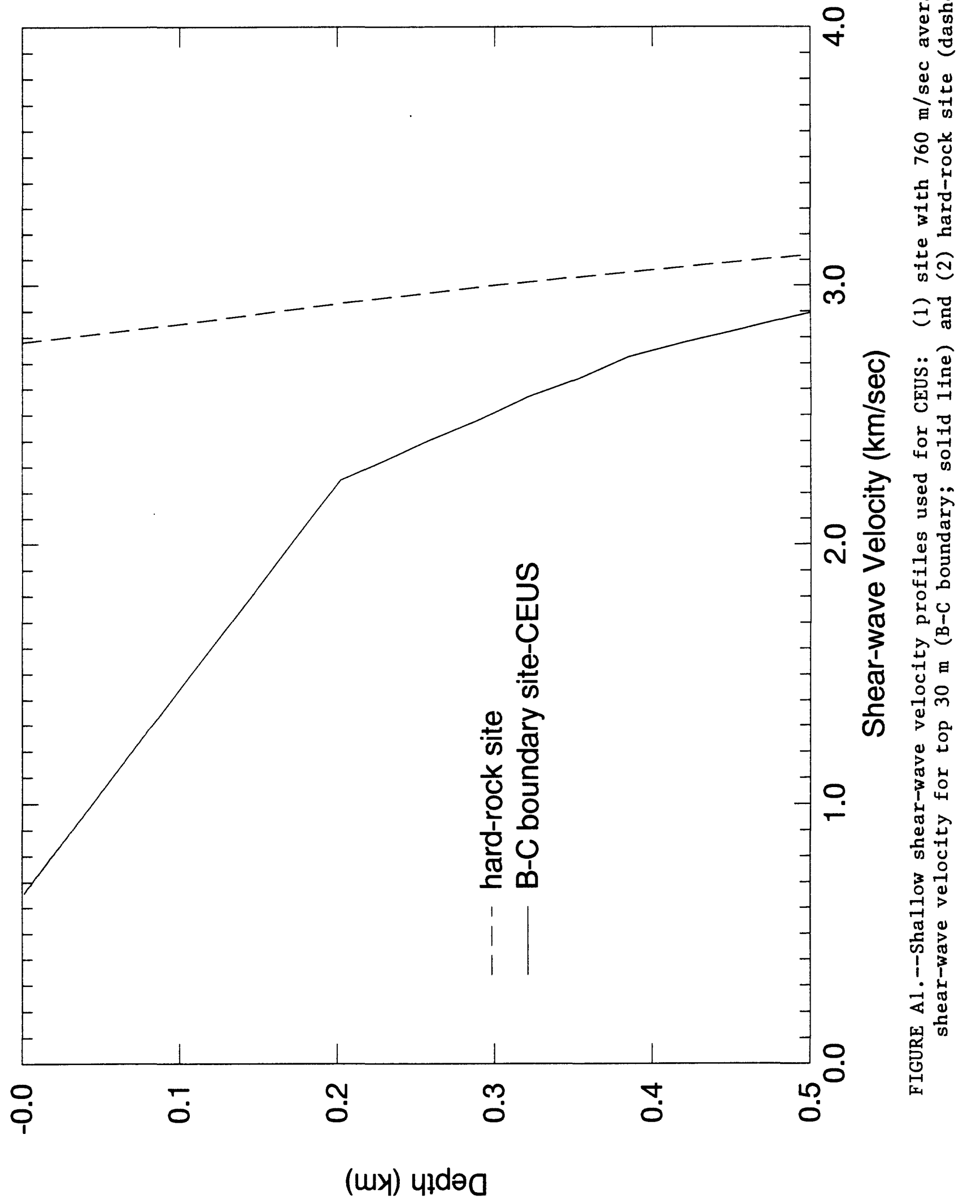


Diminution of High Frequencies: The parameter kappa controls the loss of high frequencies at close to moderate distances, and exerts a strong control on peak acceleration. The proper choice of this parameter gave us some difficulty. For very hard rock sites in ENA kappa seems to be considerably less than 0.01; for firm-rock sites in WNA it seems to be between 0.03 and 0.04 (Silva and Darragh, 1995; Boore and Joyner, 1996). Studies of shear waves recorded at various levels in a borehole in Savannah River, GA, suggest values near 0.01 (Fletcher, 1995), and this is the conservative choice that we have taken. For the velocity model in Table 2, a kappa of 0.01 corresponds to a shear-wave $Q$ of 43 and 72 if all the attenuation occurred within the upper 1 and $2 \mathrm{~km}$, respectively. These numbers do not seem unreasonable to us, although we have little or no information regarding shear-wave $\mathrm{Q}$ in the upper few kilometers for firmrock sites in eastern North America. To see the sensitivity of the ground motions to kappa, the ground motions have also been computed using kappa $=0.020$. In general, the ground-motion parameter most sensitive to kappa is pga, with the motions using kappa $=0.020$ being about 0.7 times those using kappa $=0.010$. The 0.3 and $1.0 \mathrm{sec}$ response spectra are reduced by factors of about 0.90 and 0.98 , respectively.

Note the cap on MEDIAN ground motions described in the documentation above (see

Attenuation Relations for CEUS).

\section{Toro And Others (1993) Motions}

The ground motions for Toro and others (1993) are for a hard-rock site, with kappa $=0.006$.

Modification factors to convert their values to a firm-rock site were developed by first computing motions using the stochastic model discussed above, but with hard-rock site amplifications and $\mathrm{kappa}=0.006$, and then forming the ratio of these motions with those from the firm-rock model discussed above at each magnitude, distance, and oscillator period. (The input parameters for the hard-rock calculations are given in table A7; the shallow shear-wave velocity profile is shown in fig. A1). For a given oscillator period these ratios are generally independent of magnitude and distance, and we have applied magnitude- and distance-independent factors to the Toro et al hard-rock values (see main text)

\section{References}

Atkinson, G. M. (1993). Earthquake source spectra in eastern North America, Bull. Seism. Soc. Am. 83, 1778--1798.

Atkinson, G. M. and D. M. Boore (1995). Ground motion relations for eastern North America, Bull. Seism. Soc. Am. 85, 17--30.

Atkinson, G.M. and D.M. Boore (1996). Empirically-based stochastic ground motion predictions for eastern North America, Earthquake Spectra, (submitted).

Boore, D.M. (1986). Short-period P- and S-wave radiation from large earthquakes: Implications for spectral scaling relations, Bull. Seism. Soc. Am. 76, 43--64.

Boore, D.M. (1996). SMSIM-- Fortran programs for simulating ground motions from earthquakes: version 1.0, U.S. Geol. Survey Open-File Report (in internal review).

Boore, D. M. and W. B. Joyner (1991). Estimation of ground motion at deep-soil sites in eastern North America, Bull. Seism. Soc. Am. 81, 2167--2185.

Boore, D.M. and W.B. Joyner (1996). Site-amplifications for generic rock sites, Bull. Seism. Soc. Am. (in internal review).

Fletcher, J.B. (1995). Source parameters and crustal Q for four earthquakes in South Carolina, Seism. Res. Letters 66, 44--58.

Frankel, A., P. Thenhaus, and K. Jacob (1995). Seismic hazard mapping in the northeastern United States, NCEER Bulletin, v. 9, number 1, 13-16. 
Silva, W. J., and R. B. Darragh (1995). Engineering Characterization of Strong Ground Motion Recorded at Rock Sites, Electric Power Research Institute, Palo Alto, Calif., Report No. TR-102262.

Toro, G.R., N.A. Abrahamson, and J.F. Schneider (1993). Engineering model of strong ground motions from earthquakes in the central and eastern United States, in Guidelines fo determining design basis ground motions, EPRI TR-102293, J.F. Schneider, ed., Electric Power Research Institute. 


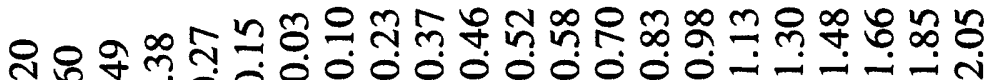

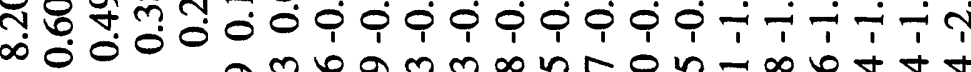
छ் 8 ษ

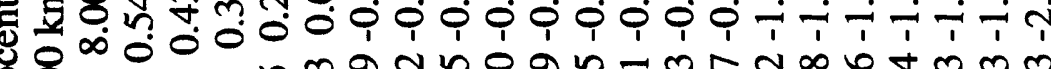

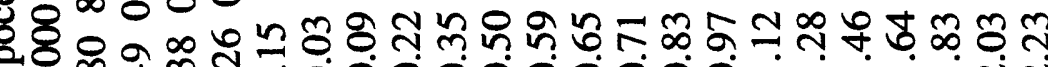
ख̃

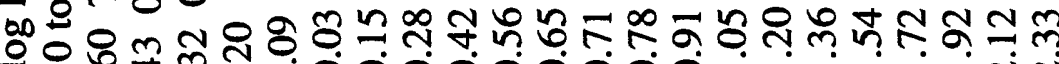
పี n

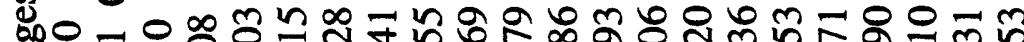

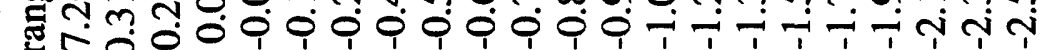
은

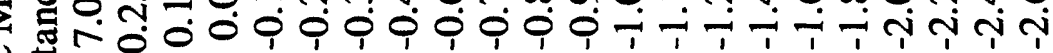

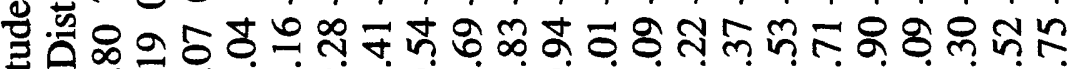
告

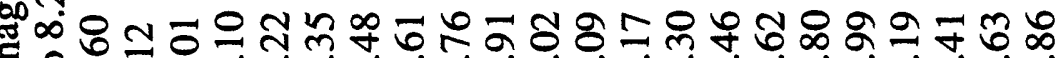
E 0 o Zี

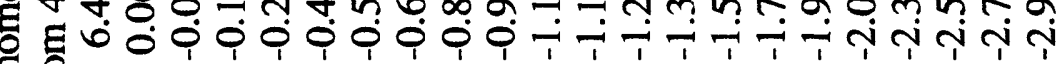

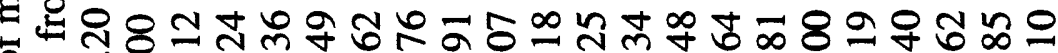

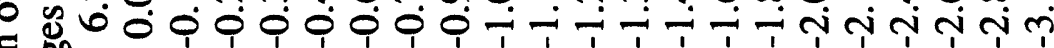

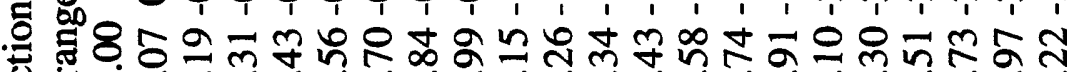

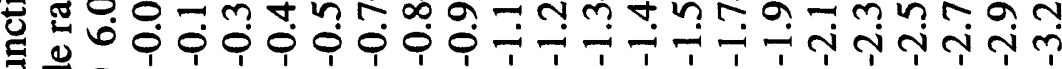

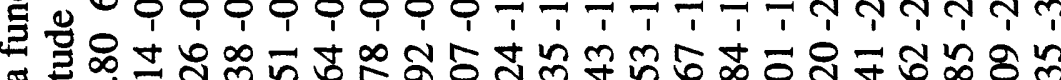
* z

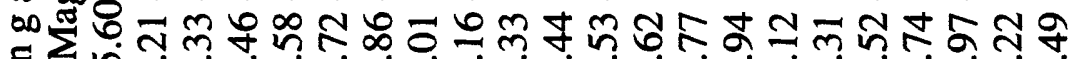
I 일워 元

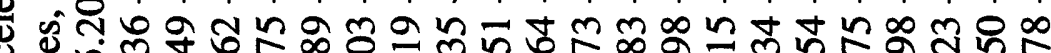

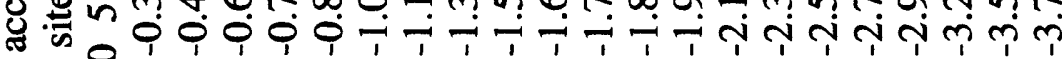

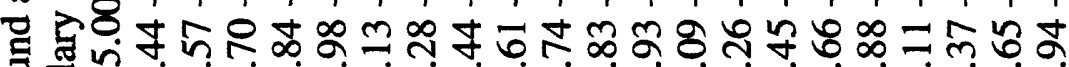

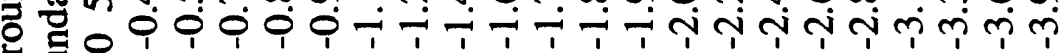
แ

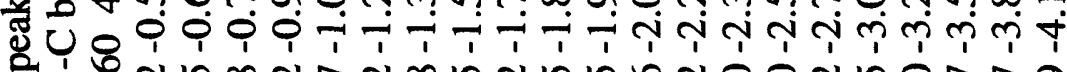

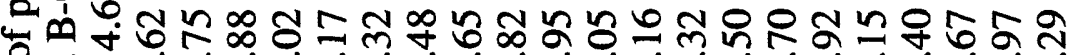
舟金耐

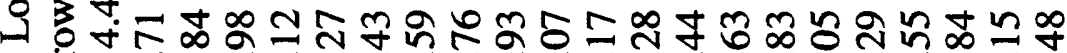

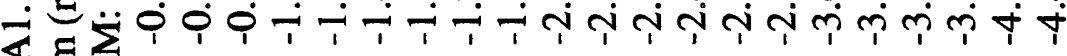

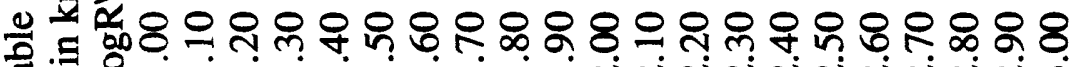

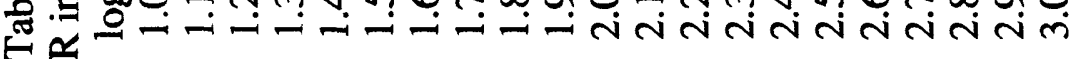




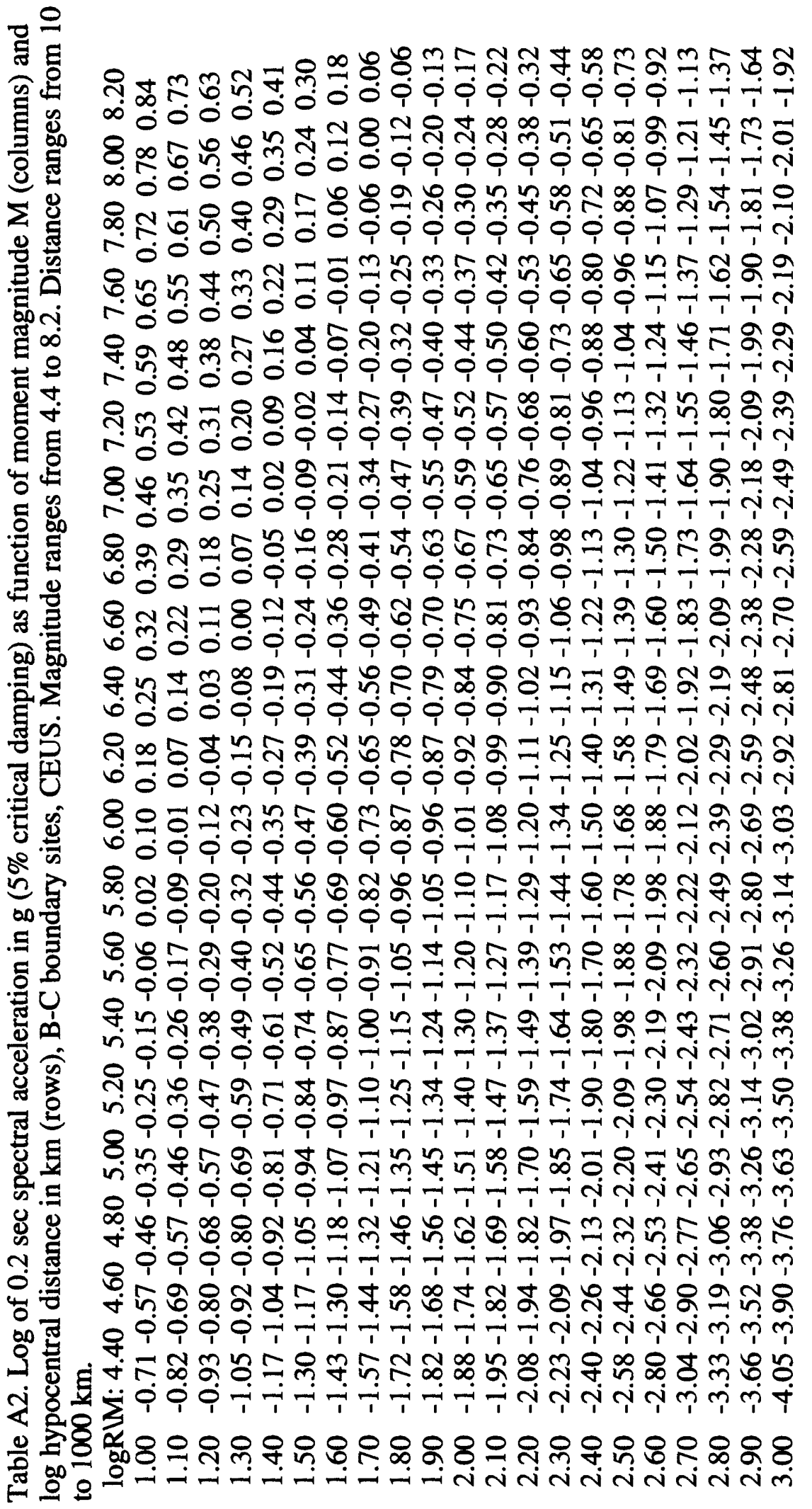




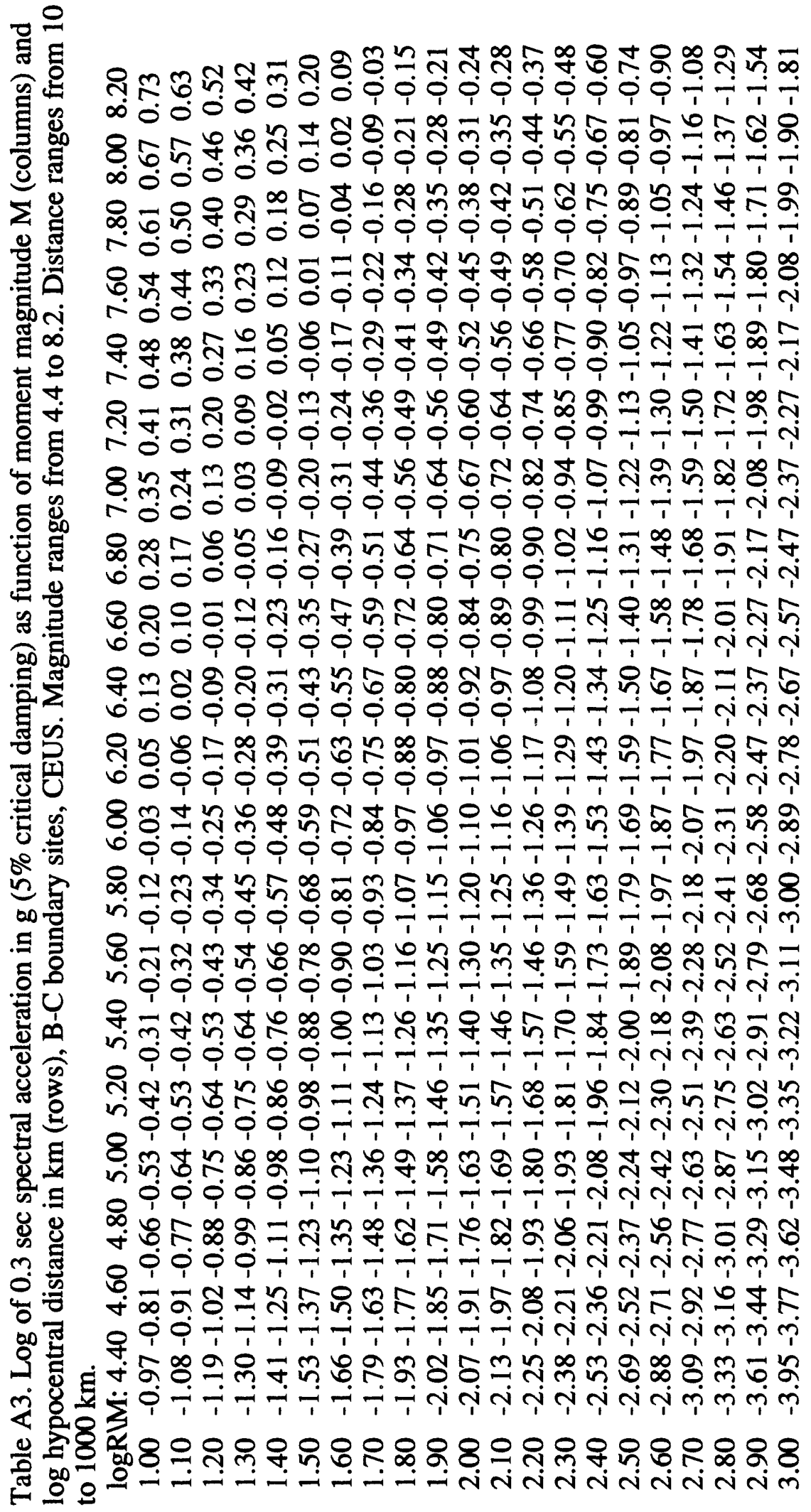




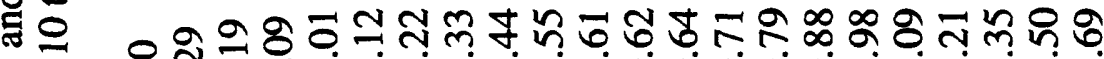

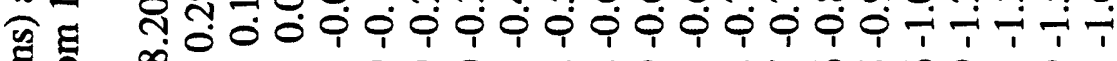

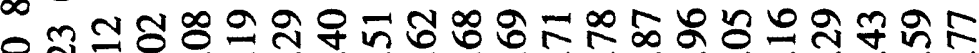

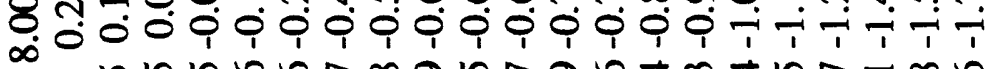

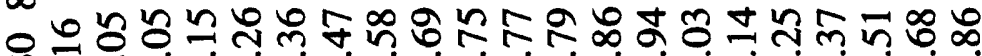
ه

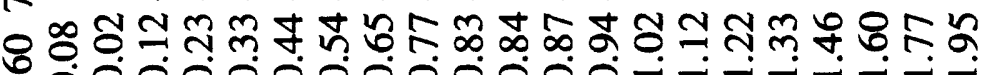

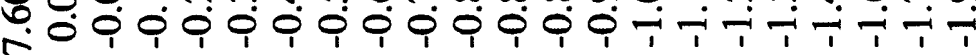
잉유유

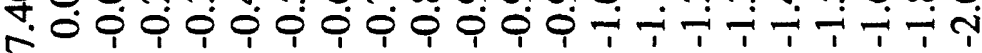

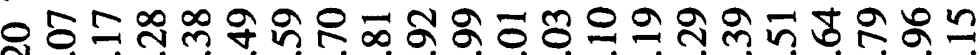
กัب

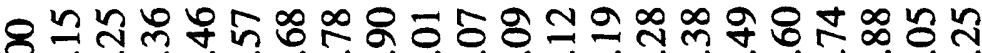

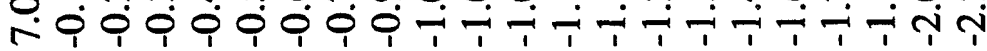

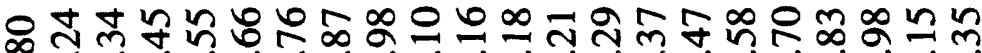
ن

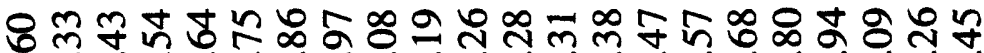
ó0 윤휴 ט 0 0

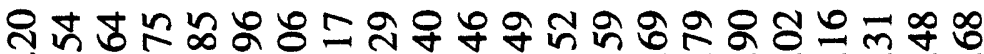
ט

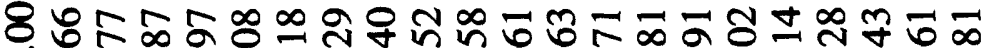
0 இ

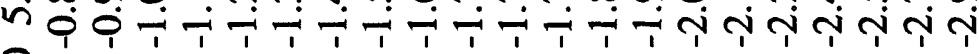

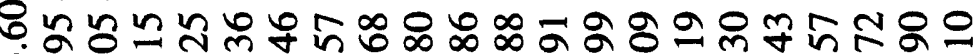
vị

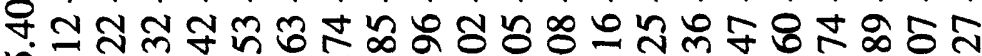

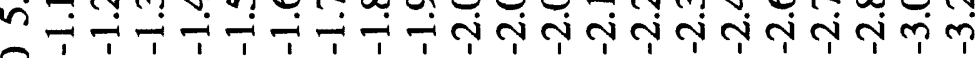
กิ่ 两

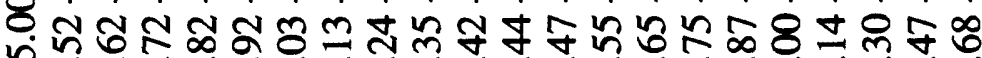

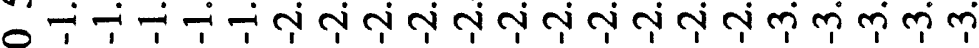

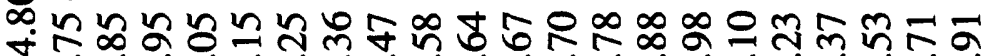
-

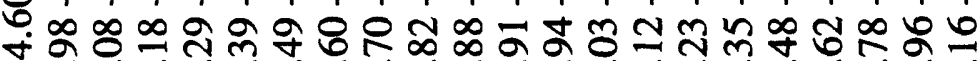

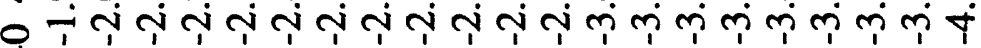

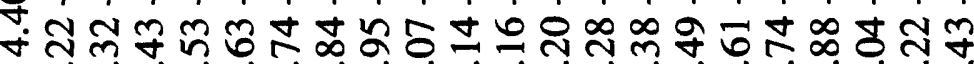

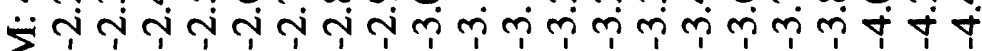
$<$ 
TABLE A5. Input-parameter file for the firm-rock stochastic-model simulations (B-C boundary). The format of this input file and the meaning of the parameters are discussed in Boore (1996)

rho, beta, prtitn, rtp, fs:

2.83 .60 .710 .552 .0

spectral shape: source number ( $1=$ Single Corner; $2=$ Joyner; $3=A 93 ; 4=$ custom $)$, pf, pd (1-comer spectrum $=1 /\left(1+(\mathrm{f} / \mathrm{fc})^{* *} \mathrm{pf}\right) * * \mathrm{pd} ; 0.0$ otherwise $)$

(usual model: $\mathrm{pf}=2.0, \mathrm{pd}=1.0$; Butterworth: $\mathrm{pf}=4.0, \mathrm{pd}=0.5$ )

12.01 .0

(Note: power of high freq decay $->\mathrm{pf*}$ pd)

spectral scaling: stressc, dlsdm, fbdfa, amagc

(stress $=$ stressc $* 10.0 * *($ dlsdm* $($ amag-amagc $))$

(fbdfa, amagc tor Joyner model, usually 4.0, 7.0)

(not used for source 3 , but placeholders still needed)

150.00 .04 .07 .0

gsprd: nsegs, (rlow(i), slope(i)) (Set rlow $(1)=1.0)$

3

$1.0-1.0$

$70.0 \quad 0.0$

$130.0-0.5$

q: fr1, Qr1, s1, ft1, ft2, fr2, qr2, s2

1.06800 .360 .060 .11 .0680 .00 .36

source duration: weights of $1 / \mathrm{fa}, 1 / \mathrm{fb}$

1.00 .0

path duration: nknots, (rdur(i), dur(i), slope of last segment

1

0.00 .0

0.05

site amplification: namps, (famp(i), amp(i))

14

0.011 .000

0.10141 .058

0.24021 .129

0.44681 .220

0.78651 .375

1.38401 .649

1.92601 .858

2.85302 .051

4.02602 .172

6.34102 .282

12.54002 .378

21.23002 .419

33.39002 .440

82.00002 .463

site diminution parameters: fm, akappa

100.00 .01

low-cut filter parameters: fcut, norder

0.02

rv integration params: zup, eps_int (integration accuracy), amp_cutoff (for fup)

10.00 .000010 .001

window params: indxwind $(0=$ box, $1=\exp )$, taper $(<1)$, twdtmotion, eps_wind, eta_wind 
10.051 .00 .20 .05

timing stuff: tsimdur, dt, tshift, seed, nruns 40.00 .0057 .0640 .0 万4 40

remove $\mathrm{dc}$ from random series before transforming to freq. domain $(0=\mathrm{no} ; 1=\mathrm{yes})$ ? 0 
TABLE A6. Shear-wave velocities and densities for B-C boundary site (CEUS) used to compute amplification as a function of frequency.

source vel $\&$ dens $=3.600 \mathrm{E}+002.800 \mathrm{E}+00$

$\operatorname{depth}(\mathrm{km}) \mathrm{Vel}(\mathrm{km} / \mathrm{s}) \operatorname{dens}(\mathrm{gm} / \mathrm{cc})$

$0.00 \mathrm{E}+006.480 \mathrm{E}-012.533 \mathrm{E}+00$

$1.00 \mathrm{E}-036.560 \mathrm{E}-012.533 \mathrm{E}+00$

1.00E-03 6.560E-01 2.533E+00

2.00E-03 6.640E-01 $2.534 \mathrm{E}+00$

$3.00 \mathrm{E}-03$ 6.720E-01 2.535E+00

4.00E-03 6.800E-01 2.536E+00

$5.00 \mathrm{E}-036.880 \mathrm{E}-012.536 \mathrm{E}+00$

6.00E-03 6.960E-01 $2.537 \mathrm{E}+00$

7.00E-03 7.040E-01 $2.538 \mathrm{E}+00$

8.00E-03 7.120E-01 2.539E+00

9.00E-03 7.200E-01 2.539E+00

1.00E-02 7.270E-01 2.540E+00

$1.20 \mathrm{E}-027.430 \mathrm{E}-012.542 \mathrm{E}+00$

$1.40 \mathrm{E}-027.590 \mathrm{E}-012.543 \mathrm{E}+00$

$1.60 \mathrm{E}-02$ 7.750E-01 2.545E+00

1.80E-02 7.910E-01 2.546E+00

$2.00 \mathrm{E}-02 \quad 8.070 \mathrm{E}-012.548 \mathrm{E}+00$

$2.20 \mathrm{E}-02 \quad 8.230 \mathrm{E}-012.549 \mathrm{E}+00$

$2.40 \mathrm{E}-02 \quad 8.380 \mathrm{E}-012.550 \mathrm{E}+00$

$2.60 \mathrm{E}-028.540 \mathrm{E}-012.552 \mathrm{E}+00$

$2.80 \mathrm{E}-02 \quad 8.700 \mathrm{E}-012.553 \mathrm{E}+00$

$3.00 \mathrm{E}-028.860 \mathrm{E}-012.555 \mathrm{E}+00$

$3.20 \mathrm{E}-02 \quad 9.020 \mathrm{E}-012.556 \mathrm{E}+00$

$3.40 \mathrm{E}-02$ 9.180E-01 $2.558 \mathrm{E}+00$

$3.60 \mathrm{E}-02 \quad 9.340 \mathrm{E}-012.559 \mathrm{E}+00$

$3.80 \mathrm{E}-02$ 9.490E-01 2.561E+00

4.00E-02 9.650E-01 2.562E+00

4.20E-02 9.810E-01 2.564E+00

4.40E-02 9.970E-01 2.565E+00

4.60E-02 $1.013 \mathrm{E}+002.567 \mathrm{E}+00$

$4.80 \mathrm{E}-021.029 \mathrm{E}+002.568 \mathrm{E}+00$

$5.00 \mathrm{E}-02 \quad 1.045 \mathrm{E}+002.570 \mathrm{E}+00$

$5.20 \mathrm{E}-021.061 \mathrm{E}+002.571 \mathrm{E}+00$

$5.40 \mathrm{E}-021.076 \mathrm{E}+002.573 \mathrm{E}+00$

$5.60 \mathrm{E}-02 \quad 1.092 \mathrm{E}+002.574 \mathrm{E}+00$

$5.80 \mathrm{E}-021.108 \mathrm{E}+002.576 \mathrm{E}+00$

$6.00 \mathrm{E}-021.124 \mathrm{E}+002.577 \mathrm{E}+00$

$6.20 \mathrm{E}-021.140 \mathrm{E}+002.579 \mathrm{E}+00$

$6.40 \mathrm{E}-021.156 \mathrm{E}+002.580 \mathrm{E}+00$

$6.60 \mathrm{E}-021.172 \mathrm{E}+002.582 \mathrm{E}+00$

$6.80 \mathrm{E}-02 \quad 1.187 \mathrm{E}+002.583 \mathrm{E}+00$

$7.00 \mathrm{E}-021.203 \mathrm{E}+002.585 \mathrm{E}+00$

$7.20 \mathrm{E}-021.219 \mathrm{E}+002.586 \mathrm{E}+00$

$7.40 \mathrm{E}-021.235 \mathrm{E}+002.588 \mathrm{E}+00$

$7.60 \mathrm{E}-021.251 \mathrm{E}+002.589 \mathrm{E}+00$

$7.80 \mathrm{E}-021.267 \mathrm{E}+002.591 \mathrm{E}+00$

$8.00 \mathrm{E}-021.283 \mathrm{E}+002.592 \mathrm{E}+00$

$8.20 \mathrm{E}-021.298 \mathrm{E}+002.594 \mathrm{E}+00$ 
1.04E-01 1.473E+00 2.610E+00 $1.26 \mathrm{E}-011.647 \mathrm{E}+002.626 \mathrm{E}+00$ $1.47 \mathrm{E}-011.814 \mathrm{E}+002.642 \mathrm{E}+00$ $1.75 \mathrm{E}-012.036 \mathrm{E}+002.663 \mathrm{E}+00$ $2.02 \mathrm{E}-012.250 \mathrm{E}+002.683 \mathrm{E}+00$ $2.30 \mathrm{E}-012.325 \mathrm{E}+002.690 \mathrm{E}+00$ $2.57 \mathrm{E}-012.400 \mathrm{E}+002.697 \mathrm{E}+00$ $2.89 \mathrm{E}-012.480 \mathrm{E}+002.704 \mathrm{E}+00$ $3.21 \mathrm{E}-012.570 \mathrm{E}+002.713 \mathrm{E}+00$ 3.53E-01 2.640E+00 2.719E+00 $3.85 \mathrm{E}-012.725 \mathrm{E}+002.727 \mathrm{E}+00$ 4.20E-01 2.780E+00 2.733E+00 4.55E-01 2.830E+00 2.737E+00 4.90E-01 2.880E+00 2.742E+00 $5.25 \mathrm{E}-012.930 \mathrm{E}+002.747 \mathrm{E}+00$ $5.62 \mathrm{E}-012.950 \mathrm{E}+002.748 \mathrm{E}+00$ $5.99 \mathrm{E}-012.980 \mathrm{E}+002.751 \mathrm{E}+00$ 6.37E-01 3.010E+00 2.754E+00 $6.74 \mathrm{E}-013.035 \mathrm{E}+002.756 \mathrm{E}+00$ 7.12E-01 3.055E+00 2.758E+00 $7.51 \mathrm{E}-013.080 \mathrm{E}+002.761 \mathrm{E}+00$ $7.89 \mathrm{E}-013.100 \mathrm{E}+002.763 \mathrm{E}+00$ 8.27E-01 3.110E+00 2.763E+00 8.66E-01 3.125E+00 2.755E+00 9.06E-01 3.145E+00 2.767E+00 9.45E-01 3.160E+00 2.768E+00 9.84E-01 3.165E+00 2.769E+00 $1.02 \mathrm{E}+003.175 \mathrm{E}+002.770 \mathrm{E}+00$ $1.06 \mathrm{E}+003.185 \mathrm{E}+002.770 \mathrm{E}+00$ $1.10 \mathrm{E}+003.190 \mathrm{E}+002.771 \mathrm{E}+00$ $1.14 \mathrm{E}+003.200 \mathrm{E}+002.772 \mathrm{E}+00$ $1.20 \mathrm{E}+003.209 \mathrm{E}+002.773 \mathrm{E}+00$ $1.40 \mathrm{E}+003.240 \mathrm{E}+002.776 \mathrm{E}+00$ $1.60 \mathrm{E}+003.266 \mathrm{E}+002.778 \mathrm{E}+00$ $1.80 \mathrm{E}+003.289 \mathrm{E}+002.780 \mathrm{E}+00$ $2.00 \mathrm{E}+003.310 \mathrm{E}+002.782 \mathrm{E}+00$ $2.20 \mathrm{E}+003.329 \mathrm{E}+002.784 \mathrm{E}+00$ $2.40 \mathrm{E}+003.347 \mathrm{E}+002.786 \mathrm{E}+00$ $2.60 \mathrm{E}+003.363 \mathrm{E}+002.787 \mathrm{E}+00$ $2.80 \mathrm{E}+003.378 \mathrm{E}+002.789 \mathrm{E}+00$ $3.00 \mathrm{E}+003.392 \mathrm{E}+002.790 \mathrm{E}+00$ $3.50 \mathrm{E}+003.424 \mathrm{E}+002.793 \mathrm{E}+00$ $4.00 \mathrm{E}+003.452 \mathrm{E}+002.796 \mathrm{E}+00$ $4.50 \mathrm{E}+003.477 \mathrm{E}+002.798 \mathrm{E}+00$ $5.00 \mathrm{E}+003.499 \mathrm{E}+002.800 \mathrm{E}+00$ $5.50 \mathrm{E}+003.519 \mathrm{E}+002.800 \mathrm{E}+00$ $6.00 \mathrm{E}+003.538 \mathrm{E}+002.800 \mathrm{E}+00$ $6.50 \mathrm{E}+003.555 \mathrm{E}+002.800 \mathrm{E}+00$ $7.00 \mathrm{E}+003.571 \mathrm{E}+002.800 \mathrm{E}+00$ $7.50 \mathrm{E}+003.586 \mathrm{E}+002.800 \mathrm{E}+00$. $8.00 \mathrm{E}+003.600 \mathrm{E}+002.800 \mathrm{E}+00$ 
TABLE A7. Input-parameter file for the hard-rock stochastic-model simulations. The format of this input file and the meaning of the parameters is discussed in Boore (1996).

rho, beta, prtitn, rtp, fs:

$$
\text { ENA hard-rock (kappa }=0.006, \text { hard-rock amps) }
$$

2.83 .60 .710 .552 .0

spectral shape: source number ( $1=$ Single Corner; $2=$ Joyner;3=A93;4=custom),

pf, pd $(1$-corner spectrum $=1 /(1+(\mathrm{f} / \mathrm{fc}) * * \mathrm{pf}) * * \mathrm{pd} ; 0.0$ otherwise $)$

(usual model: $\mathrm{pf}=2.0, \mathrm{pd}=1.0 ;$ Butterworth: $\mathrm{pf}=4.0, \mathrm{pd}=0.5$ )

(Note: power of high freq decay --> pf*pd)

12.01 .0

spectral scaling: stressc, flsdm, fbdfa, amagc

(stress=stressc $* 10.0^{* *}(\mathrm{dlsdm} *($ amag-amagc $))$

(fbdfa, amagc for Joyner model, usually 4.0, 7.0)

(not used for source 3, but placeholders still needed)

150.00 .04 .07 .0

gsprd: nsegs, (rlow(i), slope(i)) (Set rlow $(1)=1.0)$

3

$1.0-1.0$

$70.0 \quad 0.0$

$130.0-0.5$

q: fr1, Qr1, s1, ft1, ft2, fr2, qr2, s2

1.06800 .360 .060 .11 .0680 .00 .36

source duration: weights of $1 / \mathrm{fa}, 1 / \mathrm{fb}$

1.00 .0

path duration: nknots, (rdur(i), dur(i), slope of last segment

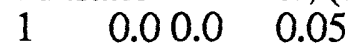

site amplification: namps, (famp(i), amp(i))

7

0.10001 .000

0.40791 .074

0.85241 .120

1.63001 .154

3.56001 .177

7.02501 .187

13.95001 .193

site diminution parameters: fm, akappa

100.00 .006

low-cut filter parameters: fcut, norder

0.02

rv integration params: zup, eps_int (integration accuracy), amp_cutoff (for fup)

10.00 .000010 .001

window params: indxwind $(0=$ box, $1=\exp )$, taper $(<1)$, twdtmotion, eps_wind, eta_wind 10.051 .00 .20 .05

timing stuff: tsimdur, dt, tshift, seed, nruns

40.00 .0057 .0640 .0640

remove $\mathrm{dc}$ from random series before transforming to freq. domain $(0=$ no; $1=y e s)$ ?

0 


\section{APPENDIX B}

Seismic-Hazard Maps For The Conterminous United States (Available on the WEB site @ http://gldage.cr.usgs.gov/eq/) 


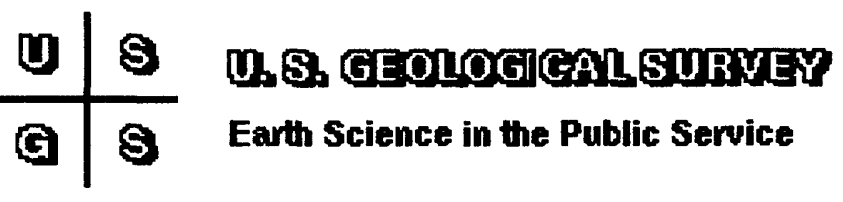

\section{SEISMIC HAZARD MAPS}

Although these maps have been used by the U.S. Geological Survey, no warranty, expressed or implied is made by the USGS

as to the accuracy of the maps and related material nor shall the fact of distribution constitute any such warranty, and no responsibility is assumed by the USGS in connection therewith.

We welcome comments on the maps. Please send us e-mail on this form or to this address: afrankel@usgs.gov

The California portions of the maps were produced jointly by the USGS and the California Division of Mines and Geology

We have hazard maps for the following regions:

National, California/Nevada and Central and Eastern U.S.

There are 12 maps for each region ( $\mathrm{PE}=$ probability of exceedance,

PGA = peak ground acceleration, $\mathbf{S A}=$ spectral acceleration):

$10 \%$ PE in 50 years, PGA

$5 \% \mathrm{PE}$ in 50 years, $\mathrm{PGA}$

$2 \% \mathrm{PE}$ in 50 years, PGA

$10 \% \mathrm{PE}$ in 50 years, $0.3 \mathrm{sec} \mathrm{SA}$

$5 \% \mathrm{PE}$ in 50 years, $0.3 \mathrm{sec} \mathrm{SA}$

$2 \% \mathrm{PE}$ in 50 years, $0.3 \mathrm{sec} \mathrm{SA}$
$10 \% \mathrm{PE}$ in 50 years, $0.2 \mathrm{sec} \mathrm{SA}$

$5 \% \mathrm{PE}$ in 50 years, $0.2 \mathrm{sec} \mathrm{SA}$

$2 \% \mathrm{PE}$ in 50 years, $0.2 \mathrm{sec} \mathrm{SA}$

$10 \%$ PE in 50 years, $1.0 \mathrm{sec}$ SA

$5 \% \mathrm{PE}$ in 50 years, $1.0 \mathrm{sec} \mathrm{SA}$

$2 \% \mathrm{PE}$ in 50 years, $1.0 \mathrm{sec} \mathrm{SA}$

The maps are available in the following formats:

GIFss For viewing on smaller screens, not too good for printing

GIF For viewing on larger screens and printing

PDF For viewing and printing

PS For downloading and printing

To view and print the PDF format you will need the Adobe Acrobat Reader software installed and configured for use with the World Wide Web. This may be obtained free from the Adobe Acrobat page.

The maps may be downloaded in PostScript and PDF format from the Anonymous FTP area. See "Anonymous FTP Information". 


\section{National Maps}

NOTE: The PDF versions of the national maps have been rotated for viewing

There are smaller unrotated PDF files for printing in the Anonymous FTP area (See "Anonymous FTP Information".)

NOTE: The Postscript files are landscape orientation, not suitable for viewing.

There are two sizes of files for the National maps: PSIt $=$ letter size, PSlg = ledger size

Peak Acceleration (\%g) with 10\% Probability of Exceedance in 50 Years, site:NEHRP B-C boundary, map 1 GIFss, 18 kb; GIF, $102 \mathrm{~kb}$; PDF, $712 \mathrm{~kb}$; PSlt, $1.2 \mathrm{Mb}$; PSlg, $1.2 \mathrm{Mb}$

Peak Acceleration (\%g) with 5\% Probability of Exceedance in 50 years, site:NEHRP B-C boundary, map 2 GIFss, $21 \mathrm{~kb}$; $\underline{\mathrm{GIF}}, 118 \mathrm{~kb} ; \underline{\mathrm{PDF}}, 1.2 \mathrm{Mb} ; \underline{\mathrm{PS} l \mathrm{t}}, 1.3 \mathrm{Mb} ; \underline{\mathrm{PS} l g}, 1.3 \mathrm{Mb}$

Peak Acceleration (\%g) with 2\% Probability of Exceedance in 50 Years, site:NEHRP B-C boundary, map 3 GIFss, 20 kb; GIF, $119 \mathrm{~kb}$; PDF, 1.3 Mb; PSlt, 1.3 Mb; PSlg, $1.3 \mathrm{Mb}$

$0.2 \mathrm{sec}$ Spectral Acceleration (\%g) with 10\% Probability of Exceedance in 50 years, site:NEHRP B-C boundary, map 4 GIFss, $20 \mathrm{~kb}$; GIF, $106 \mathrm{~kb}$; PDF, 1.0 Mb; PSlt, 1.2 Mb; PSlg, $1.2 \mathrm{Mb}$

$0.2 \mathrm{sec}$ Spectral Acceleration (\%g) with 5\% Probability of Exceedance in 50 years, site:NEHRP B-C boundary, map 5 GIFss, $21 \mathrm{~kb}$; GIF, $119 \mathrm{~kb}$; PDF, $1.1 \mathrm{Mb}$; PSlt, $1.2 \mathrm{Mb}$; PSlg, $1.3 \mathrm{Mb}$

$0.2 \mathrm{sec}$ Spectral Acceleration (\%g) with 2\% Probability of Exceedance in 50 years, site:NEHRP B-C boundary, map 6 GIFss, $21 \mathrm{~kb}$; GIF, $120 \mathrm{~kb}$; PDF, $12 \mathrm{Mb}$; PSlt, $1.3 \mathrm{Mb}$; PSlg, $1.3 \mathrm{Mb}$

$0.3 \mathrm{sec}$ Spectral Acceleration $(\% \mathrm{~g})$ with $10 \%$ Probability of Exceedance in 50 years, site:NEHRP B-C boundary, map 7

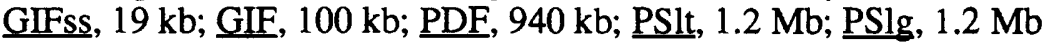

$0.3 \mathrm{sec}$ Spectral Acceleration (\%g) with 5\% Probability of Exceedance in 50 years, site:NEHRP B-C boundary, map 8

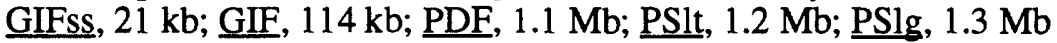

$0.3 \mathrm{sec}$ Spectral Acceleration (\%g) with 2\% Probability of Exceedance in 50 years, site:NEHRP B-C boundary, map 9 GIFss, $20 \mathrm{~kb}$; GIF, $113 \mathrm{~kb}$; PDF, $1.1 \mathrm{Mb}$; PSlt, $1.2 \mathrm{Mb}$; PSlg, $1.3 \mathrm{Mb}$

$1.0 \mathrm{sec}$ Spectral Acceleration (\%g) with 10\% Probability of Exceedance in 50 years, site:NEHRP B-C boundary, map 10 GIFss, $17 \mathrm{~kb}$; GIF, $89 \mathrm{~kb}$; PDF, $829 \mathrm{~kb}$; PSlt, $1.2 \mathrm{Mb}$; PSlg, $1.2 \mathrm{Mb}$

$1.0 \mathrm{sec}$ Spectral Acceleration (\%g) with 5\% Probability of Exceedance in 50 years, site:NEHRP B-C boundary, map 11 GIFss, $20 \mathrm{~kb}$; GIF, $105 \mathrm{~kb}$; PDF, $972 \mathrm{~kb}$; PSlt, $1.2 \mathrm{Mb}$; PSlg, $1.2 \mathrm{Mb}$

$1.0 \mathrm{sec}$ Spectral Acceleration (\%g) with 2\% Probability of Exceedance in 50 years, site:NEHRP B-C boundary, map 12 GIFss, $19 \mathrm{~kb}$; GIF, $101 \mathrm{~kb}$; PDF, 1.0 Mb; PSlt, $1.2 \mathrm{Mb}$; PSlg, $1.2 \mathrm{Mb}$

\section{[Top]}

\section{California/Nevada}

Peak Acceleration (\%g) with 10\% Probability of Exceedance in 50 Years, site:NEHRP B-C boundary, map 1 GIFss, 50kb; GIF, $69 \mathrm{~kb} ; \underline{\mathrm{PDF}}, 259 \mathrm{~kb} ; \underline{\mathrm{PS}}, 1.4 \mathrm{Mb}$

Peak Acceleration (\%g) with 5\% Probability of Exceedance in 50 years, site:NEHRP B-C boundary, map 2 GIFss, 49kb; GIF, 71kb; PDF, 281kb; PS, $1.5 \mathrm{Mb}$ 
Peak Acceleration $(\% \mathrm{~g})$ with $2 \%$ Probability of Exceedance in 50 Years, site:NEHRP B-C boundary, map 3 GIFss, 52kb; GIF, 73kb; PDF, $299 \mathrm{~kb} ;$ PS, $1.5 \mathrm{Mb}$

$0.2 \mathrm{sec}$ Spectral Acceleration (\%g) with $10 \%$ Probability of Exceedance in 50 years, site:NEHRP B-C boundary, map 4

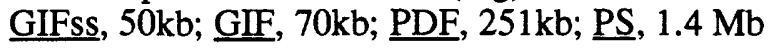

$0.2 \mathrm{sec}$ Spectral Acceleration (\%g) with 5\% Probability of Exceedance in 50 years, site:NEHRP B-C boundary, map 5 GIFss, 48kb; GIF, 70kb; PDF, 259kb; PS, $1.4 \mathrm{Mb}$

$0.2 \mathrm{sec}$ Spectral Acceleration (\%g) with 2\% Probability of Exceedance in 50 years, site:NEHRP B-C boundary, map 6 GIFss, 50kb; GIF, 71kb; PDF, 274kb; PS, $1.5 \mathrm{Mb}$

$0.3 \mathrm{sec}$ Spectral Acceleration (\%g) with 10\% Probability of Exceedance in 50 years, site:NEHRP B-C boundary, map 7 GIFss, 50kb; GIF, 70kb; PDF, 251kb; PS, $1.4 \mathrm{Mb}$

$0.3 \mathrm{sec}$ Spectral Acceleration (\%g) with 5\% Probability of Exceedance in 50 years, site:NEHRP B-C boundary, map 8 GIFss, 49kb; GIF, 71kb; PDF, 267kb; PS, $1.4 \mathrm{Mb}$

$0.3 \mathrm{sec}$ Spectral Acceleration (\%g) with 2\% Probability of Exceedance in 50 years, site:NEHRP B-C boundary, map 9 GIFss, $51 \mathrm{~kb}$; GIF, 73kb; PDF, 284kb; PS, $1.5 \mathrm{Mb}$

$1.0 \mathrm{sec}$ Spectral Acceleration (\%g) with 10\% Probability of Exceedance in 50 years, site:NEHRP B-C boundary, map 10

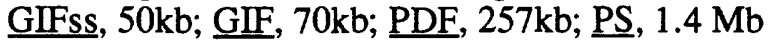

$1.0 \mathrm{sec}$ Spectral Acceleration (\%g) with 5\% Probability of Exceedance in 50 years, site:NEHRP B-C boundary, map 11 GIFss, $51 \mathrm{~kb}$; GIF, $71 \mathrm{~kb}$; PDF, 275kb; PS, $1.5 \mathrm{Mb}$

$1.0 \mathrm{sec}$ Spectral Acceleration (\%g) with 2\% Probability of Exceedance in 50 years, site:NEHRP B-C boundary, map 12 GIFss, 53kb; GIF, 73kb; PDF, 308kb; PS, $1.5 \mathrm{Mb}$

[Top]

Central and Eastern US maps (Color scale is located on right side of maps)

NOTE: The PDF versions of the national maps have been rotated for viewing

There are smaller unrotated PDF files for printing in the Anonymous FTP area (See "Anonymous FTP Information".)

NOTE: The Postscript files are landscape orientation, not suitable for viewing.

Peak Acceleration (\%g) with 10\% Probability of Exceedance in 50 Years, site: NEHRP B-C boundary, map 1 GIFss, 34 kb; GIF, $46 \mathrm{~kb}$; PDF, $798 \mathrm{~kb}$; PS, $706 \mathrm{~kb}$

Peak Acceleration (\%g) with 5\% Probability of Exceedance in 50 years, site: NEHRP B-C boundary, map 2 GIFss, 48 kb; GIF, $69 \mathrm{~kb}$; PDF, $869 \mathrm{~kb}$; PS, $731 \mathrm{~kb}$

Peak Acceleration (\%g) with $2 \%$ Probability of Exceedance in 50 Years, site: NEHRP B-C boundary, map 3 GIFss, 49 kb; GIF, $58 \mathrm{~kb}$; PDF, $906 \mathrm{~kb}$; $\underline{\text { PS }}, 737 \mathrm{~kb}$

$0.2 \mathrm{sec}$ Spectral Acceleration (\%g) with 10\% Probability of Exceedance in 50 years, site: NEHRP B-C boundary, map 4 GIFss, $42 \mathrm{~kb}$; GIF, $44 \mathrm{~kb}$; PDF, $807 \mathrm{~kb}$; PS, $682 \mathrm{~kb}$

$0.2 \mathrm{sec}$ Spectral Acceleration (\%g) with 5\% Probability of Exceedance in 50 years, site: NEHRP B-C boundary, map 5 GIFss, $50 \mathrm{~kb}$; GIF, $54 \mathrm{~kb}$; PDF, $870 \mathrm{~kb}$; PS, $706 \mathrm{~kb}$

$0.2 \mathrm{sec}$ Spectral Acceleration (\%g) with 2\% Probability of Exceedance in 50 years, site: NEHRP B-C boundary, map 6 GIFss, $50 \mathrm{~kb}$; GIF, $53 \mathrm{~kb}$; PDF, $899 \mathrm{~kb}$; PS, $711 \mathrm{~kb}$ 
$0.3 \mathrm{sec}$ Spectral Acceleration (\%g) with 10\% Probability of Exceedance in 50 years, site: NEHRP B-C boundary, map 7 GIFss, $39 \mathrm{~kb}$; GIF, $44 \mathrm{~kb}$; PDF, $769 \mathrm{~kb}$; PS, $682 \mathrm{~kb}$

$0.3 \mathrm{sec}$ Spectral Acceleration (\%g) with 5\% Probability of Exceedance in 50 years, site: NEHRP B-C boundary, map 8 GIFss, $47 \mathrm{~kb}$; GIF, $54 \mathrm{~kb}$; PDF, $835 \mathrm{~kb} ; \underline{\mathrm{PS}}, 706 \mathrm{~Kb}$

$0.3 \mathrm{sec}$ Spectral Acceleration (\%g) with 2\% Probability of Exceedance in 50 years, site: NEHRP B-C boundarys, map 9

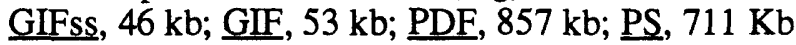

$1.0 \mathrm{sec}$ Spectral Acceleration (\%g) with 10\% Probability of Exceedance in 50 years, site: NEHRP B-C boundary, map 10 GIFss, $34 \mathrm{~kb}$; GIF, $37 \mathrm{~kb}$; PDF, $722 \mathrm{~kb}$; PS, $663 \mathrm{~kb}$

$1.0 \mathrm{sec}$ Spectral Acceleration (\%g) with 5\% Probability of Exceedance in 50 years, site: NEHRP B-C boundary, map 11

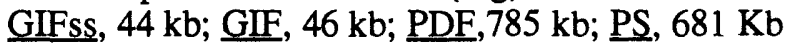

$1.0 \mathrm{sec}$ Spectral Acceleration (\%g) with 2\% Probability of Exceedance in 50 years, site: NEHRP B-C boundary, map 12 GIFss, 43kb; GIF, $45 \mathrm{~kb}$; $\underline{\text { PDF, }} 798 \mathrm{~kb}$; $\underline{\text { PS }}, 683 \mathrm{~Kb}$

We welcome comments on the maps. Please send us e-mail on this form or to this address: afrankel@usgs.gov

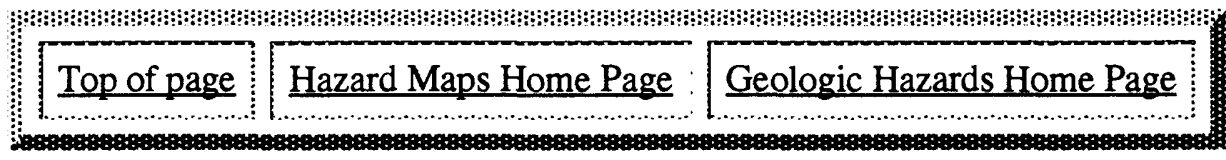

Web Contact: Nancy Dickman (dickman@usgs.gov)

Last edited: Wednesday, 21-Aug-96 11:40:36 MDT 


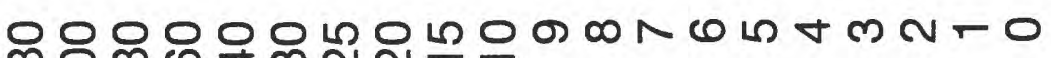

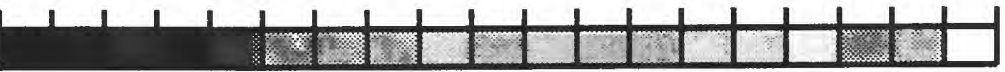

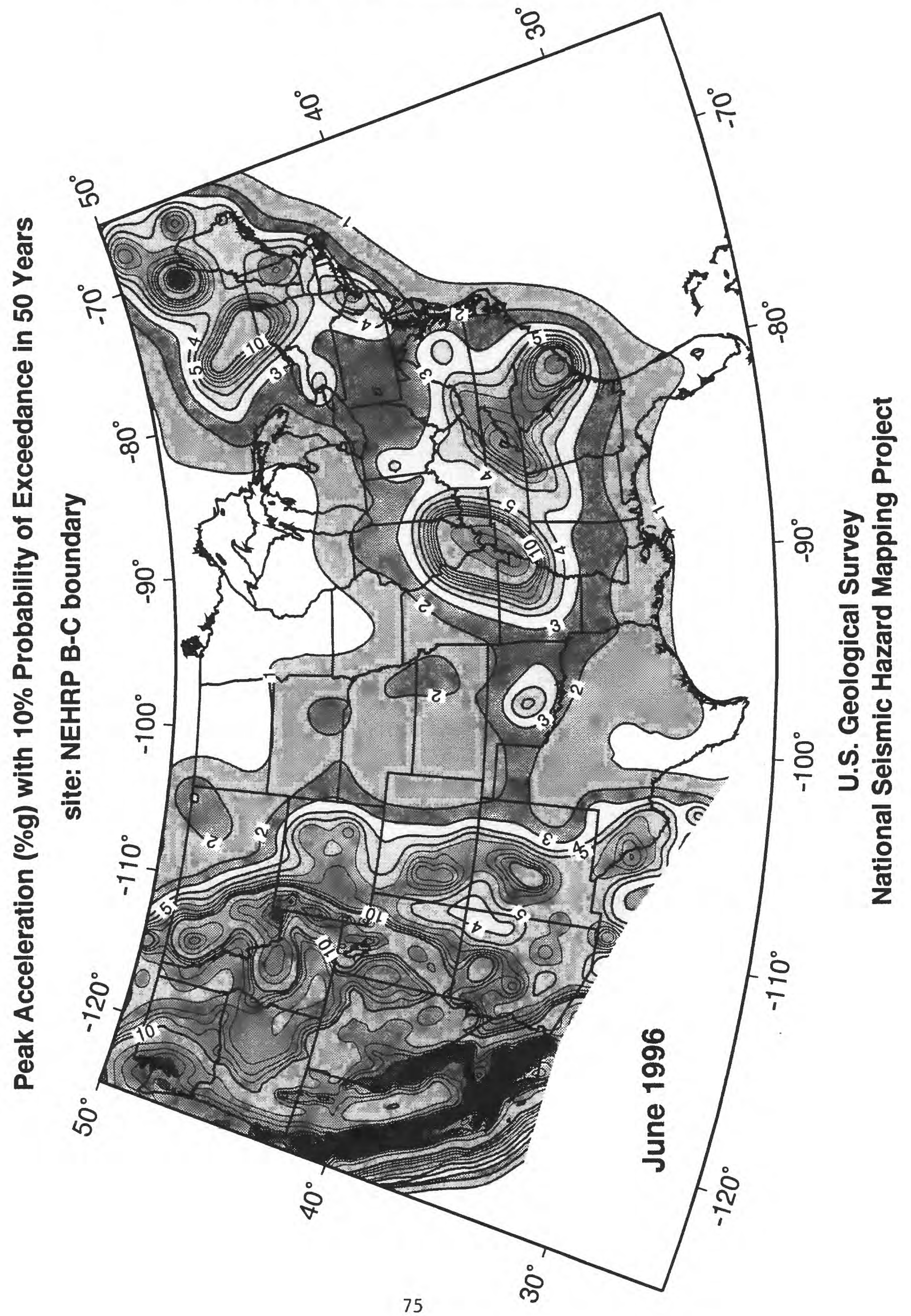




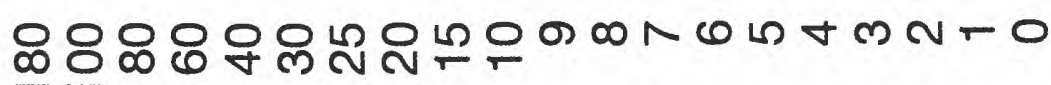

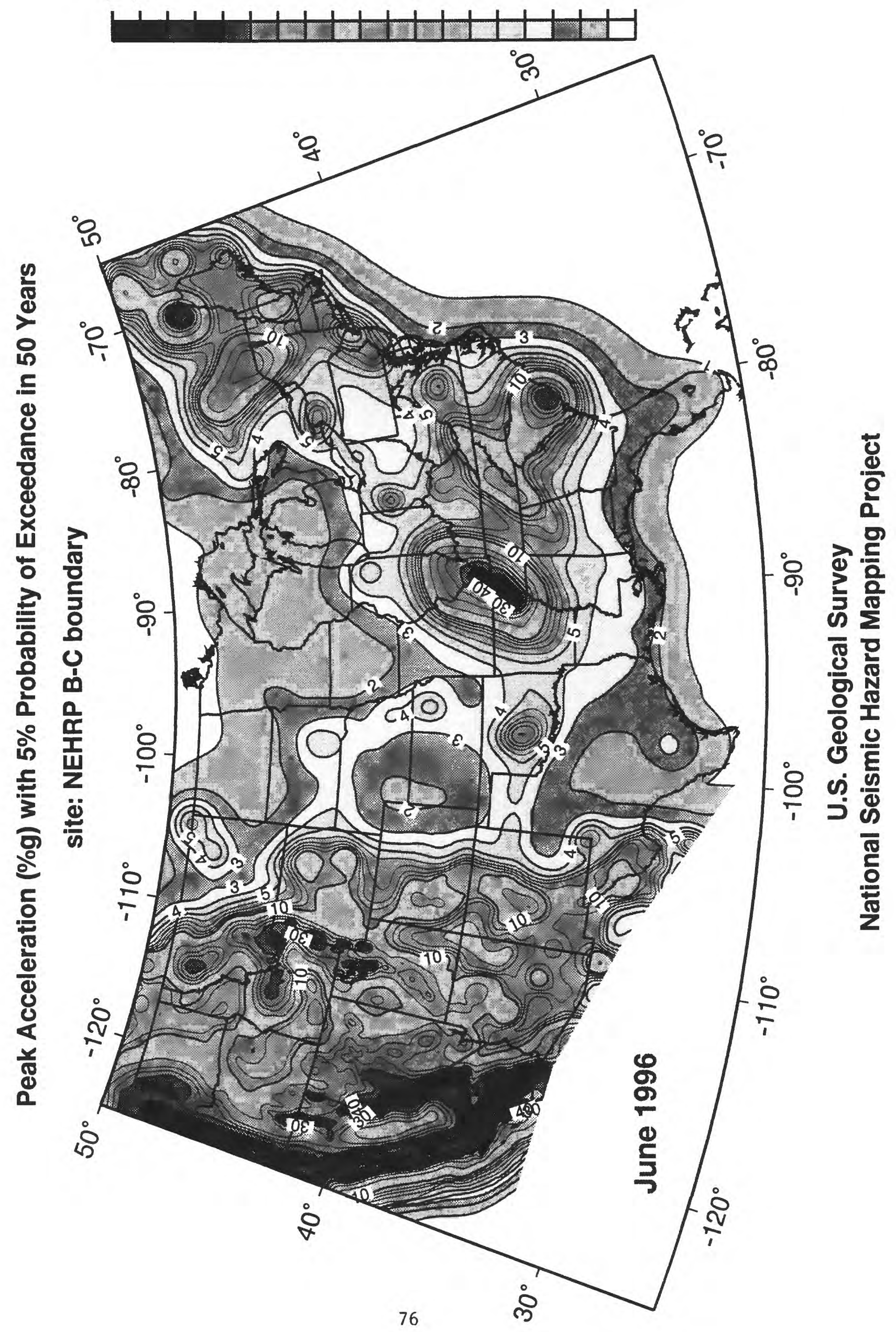




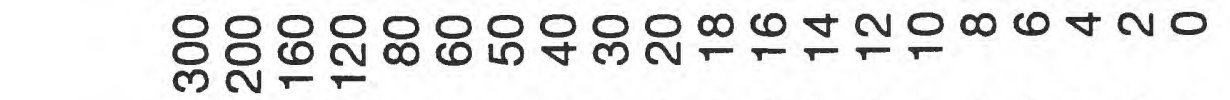

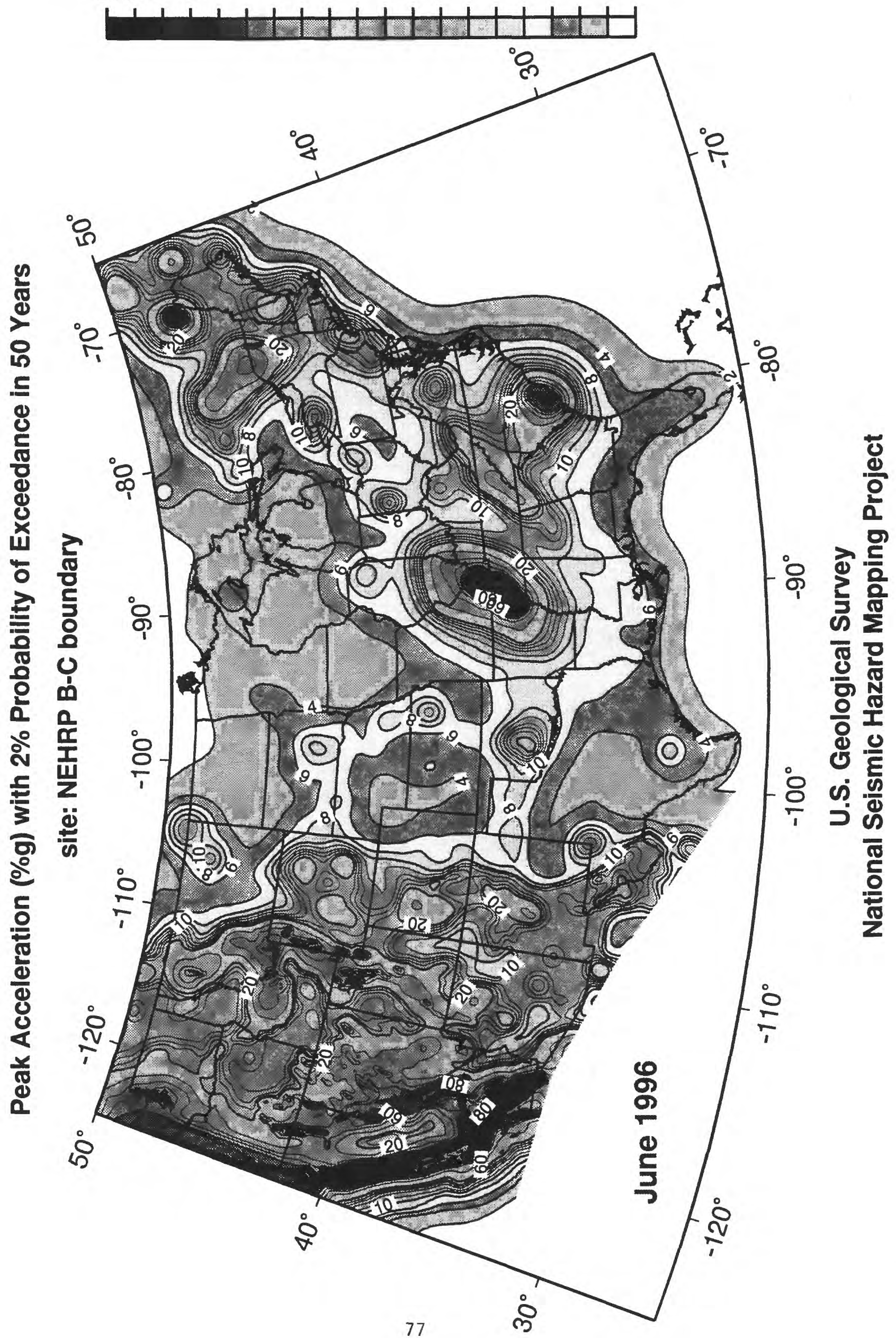


앙ㅇㅇㅇㅇㅇㅇㅇㅇ엔 ल에 느

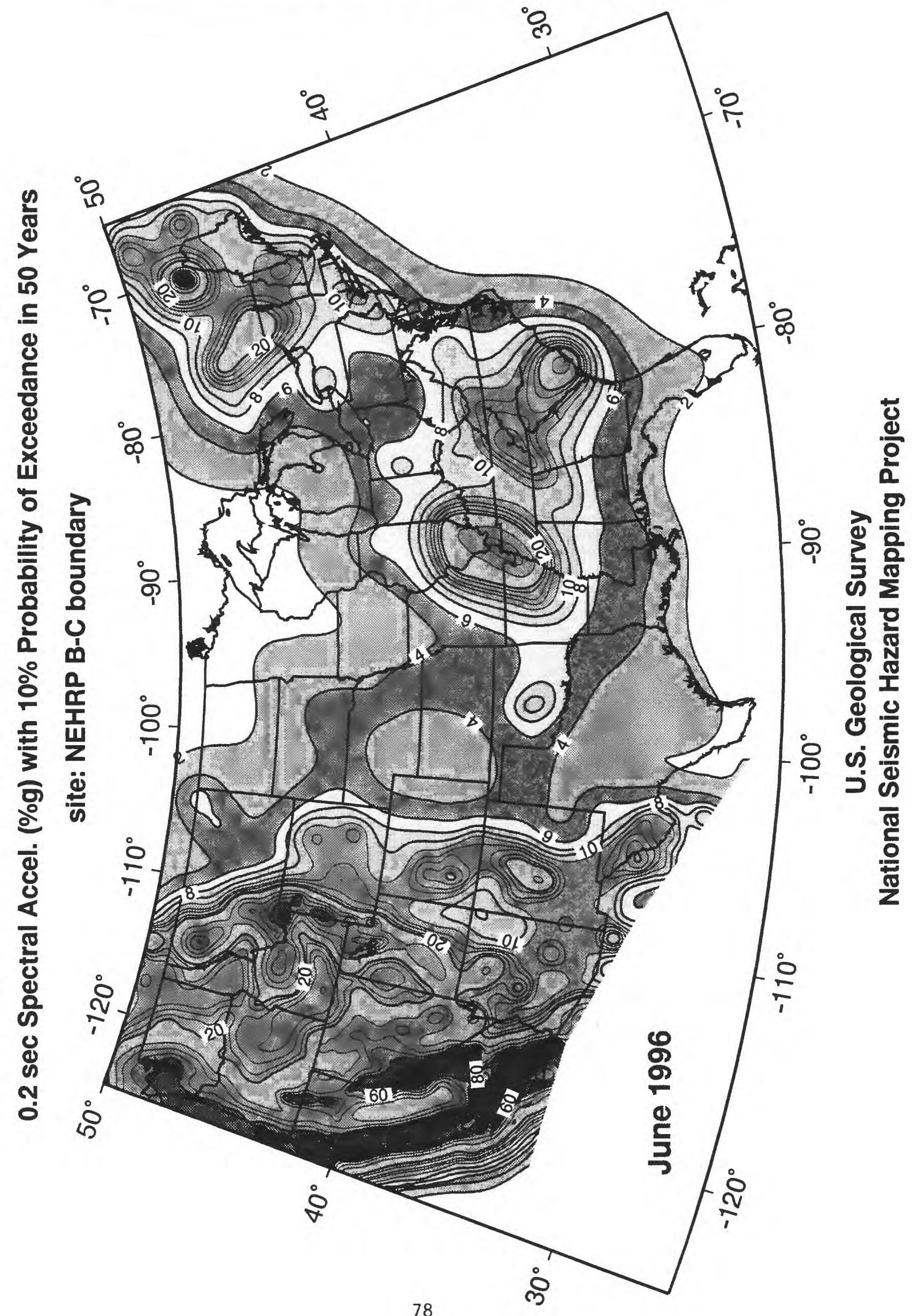




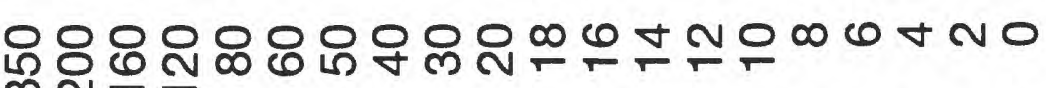
스는

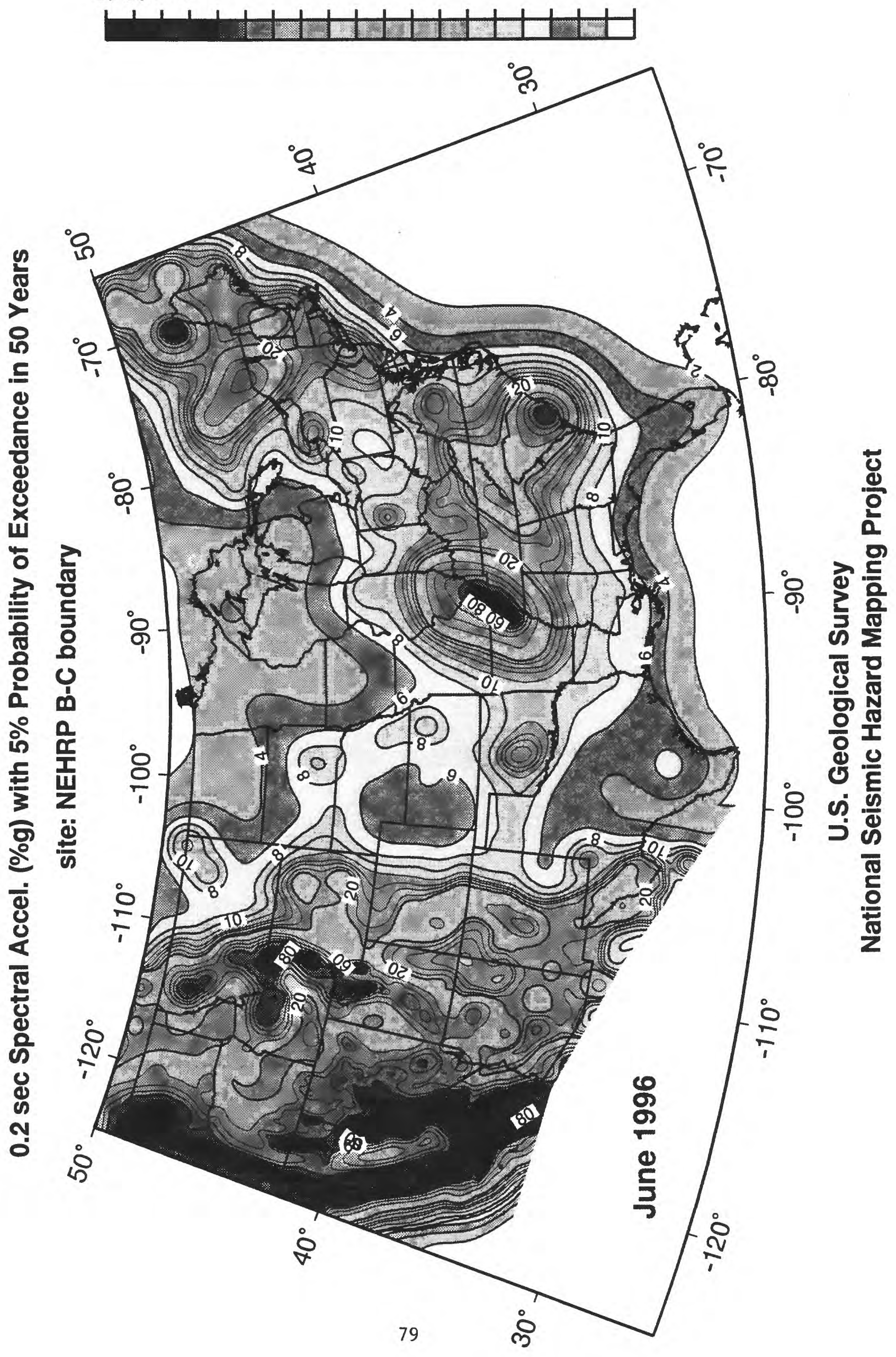


৪ిర్యాస్లి

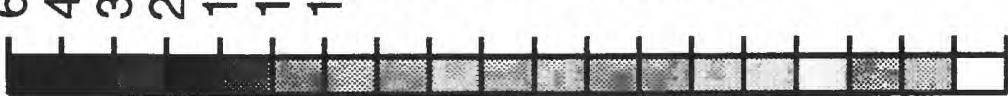

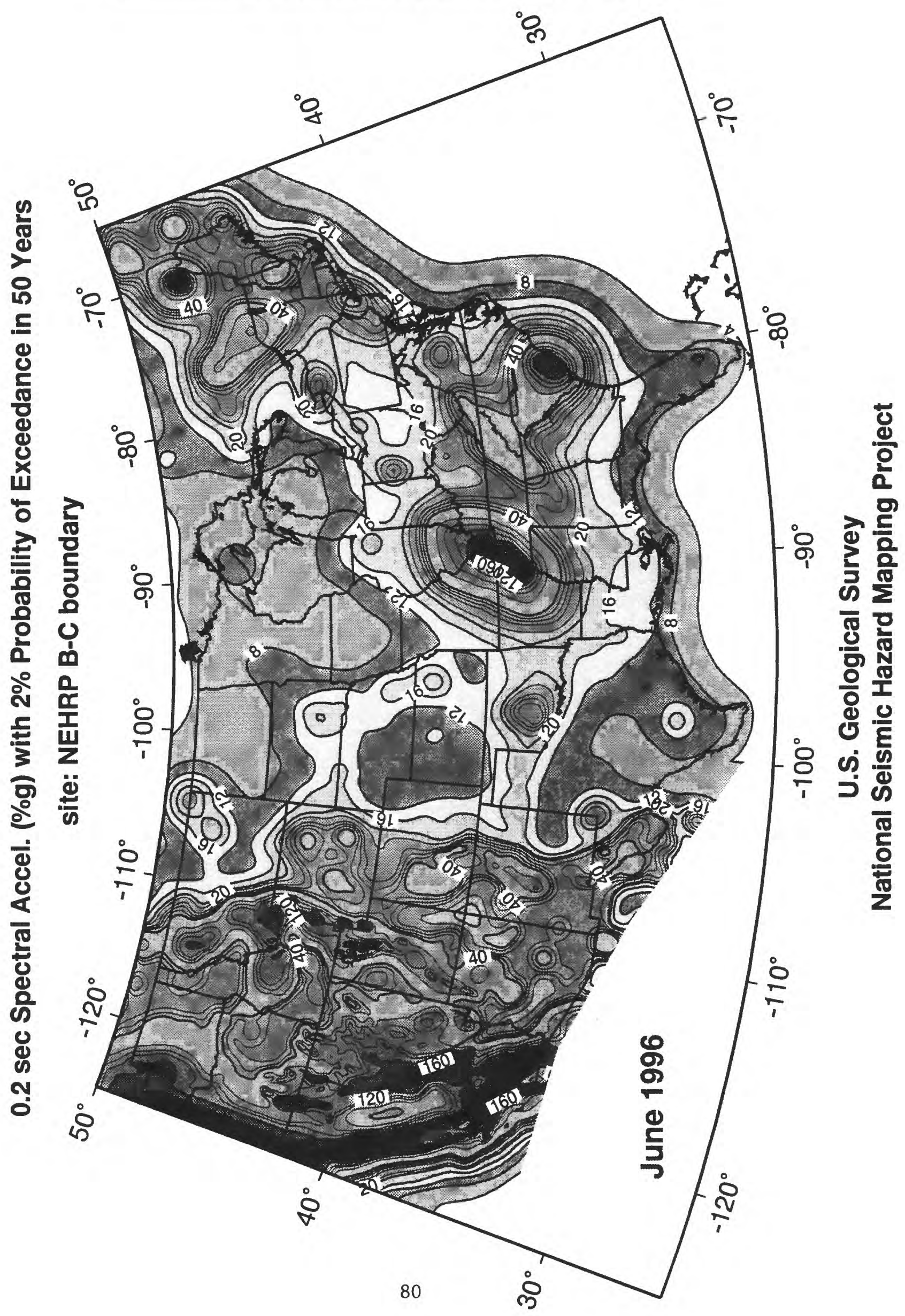




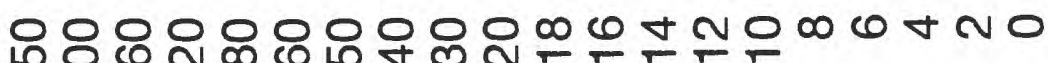
लㄴ-

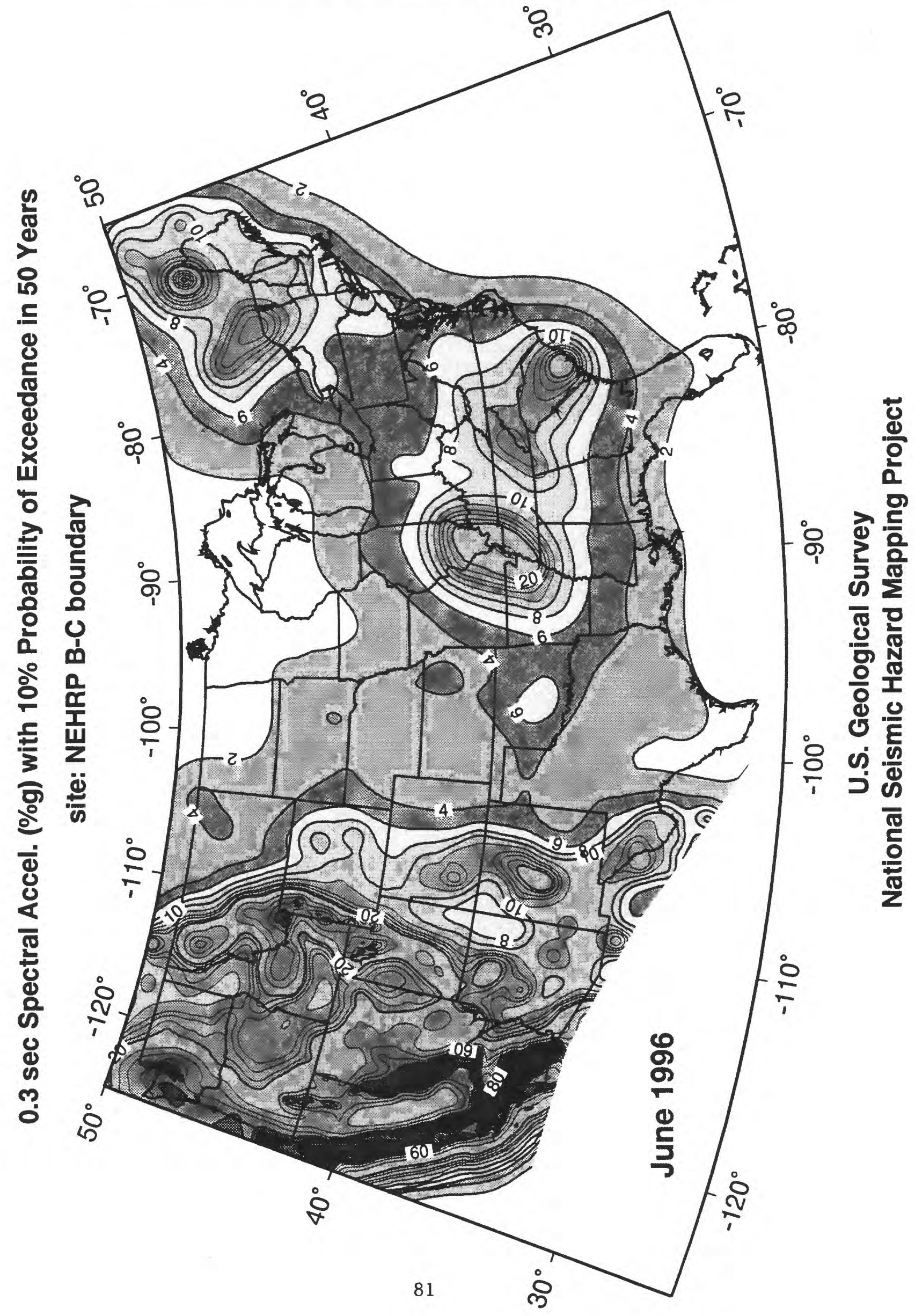




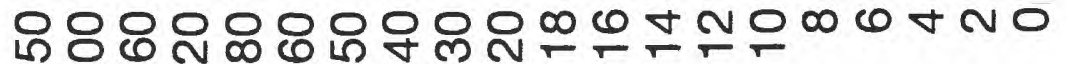
लำ

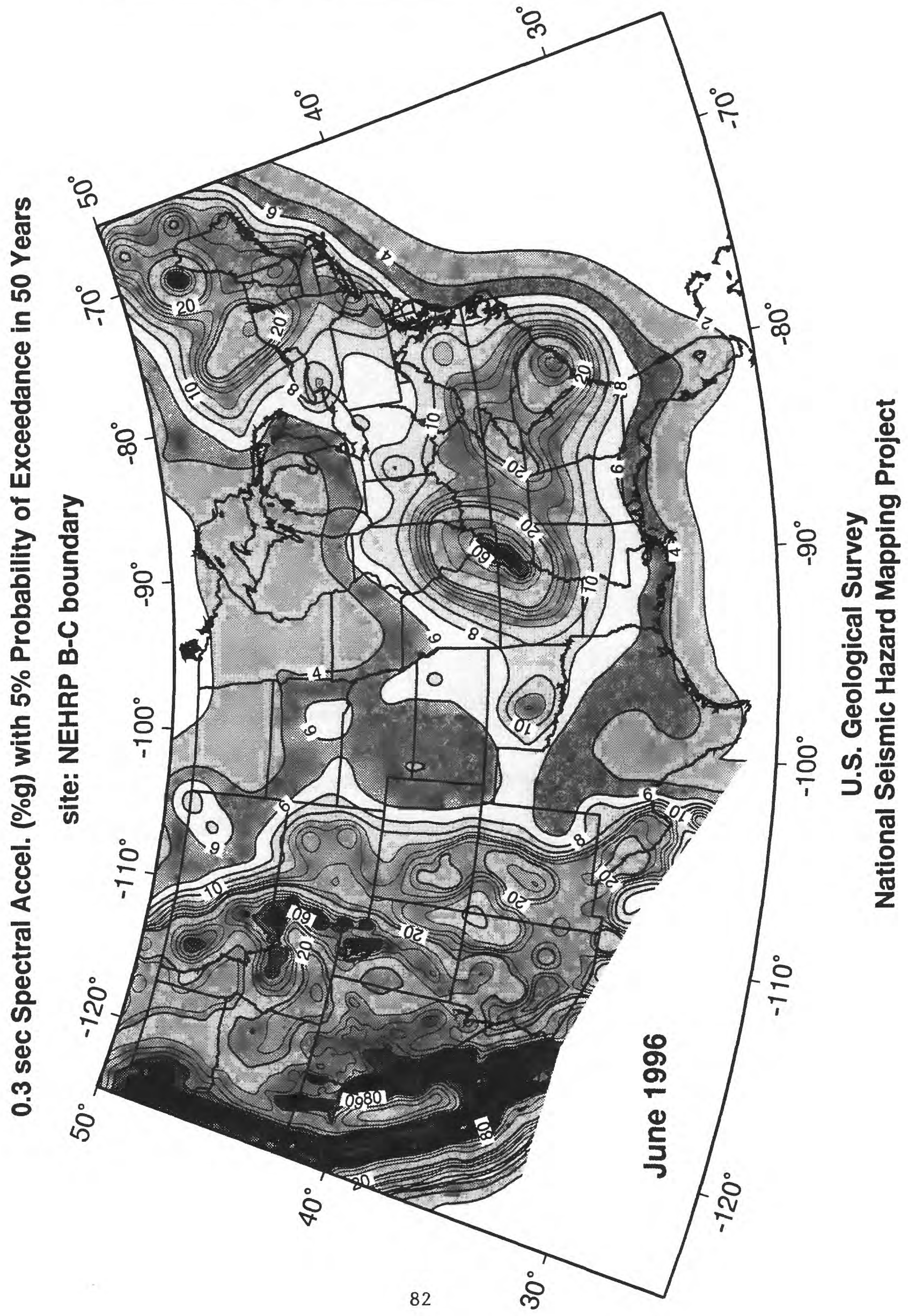




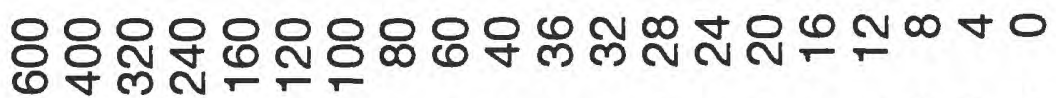
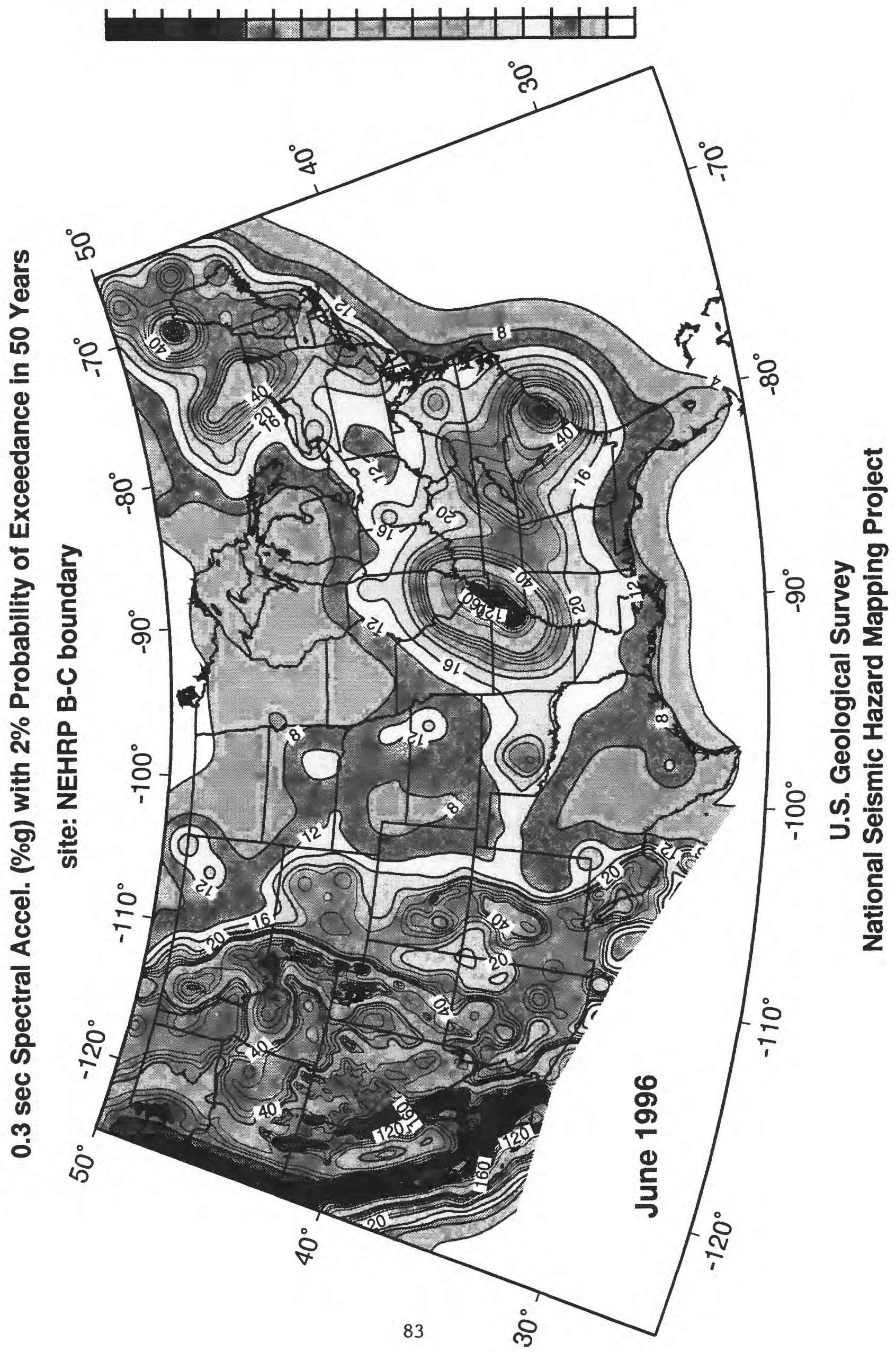


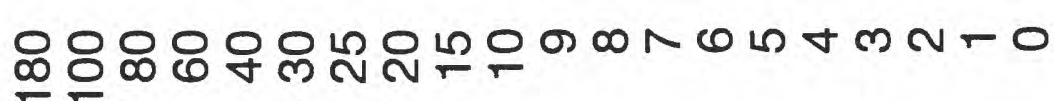
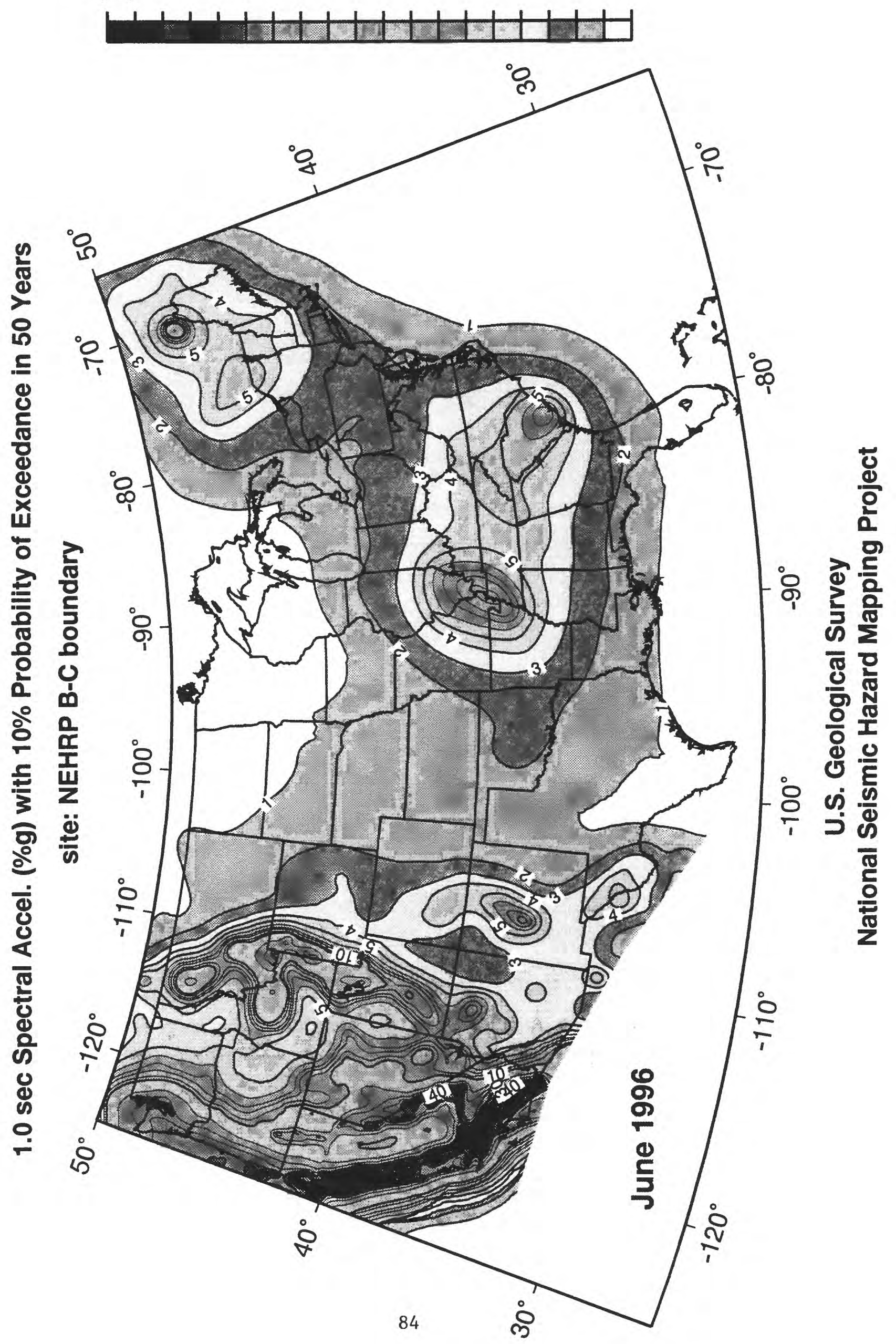


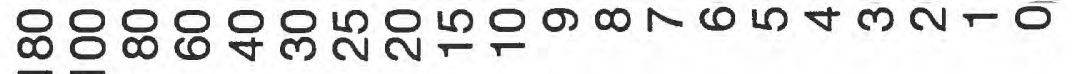

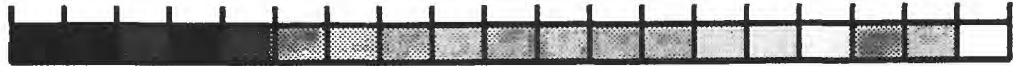

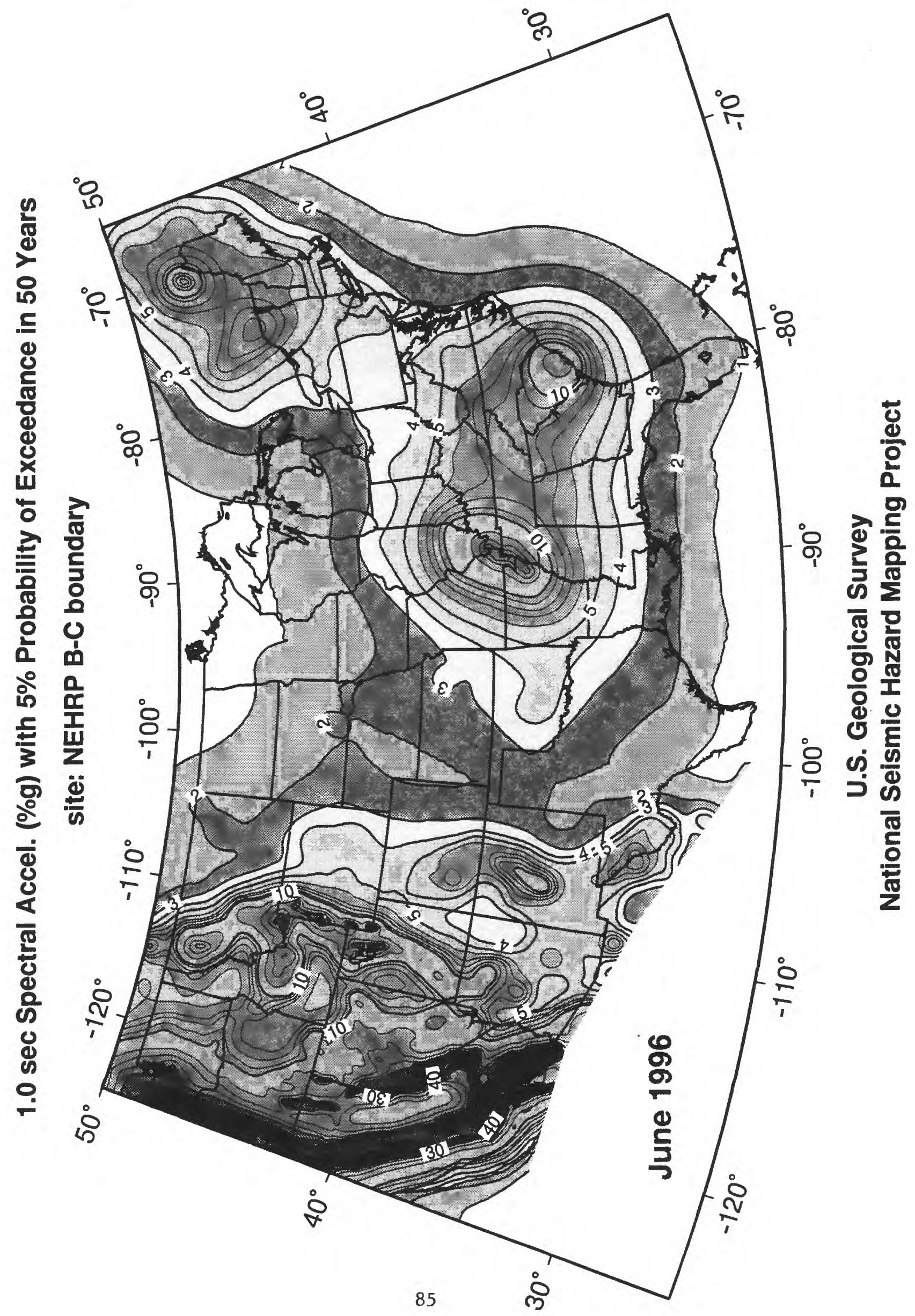




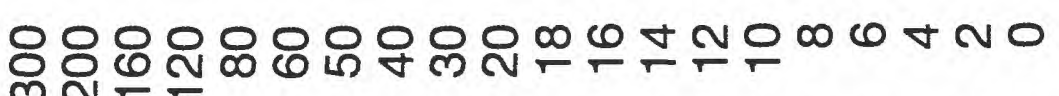

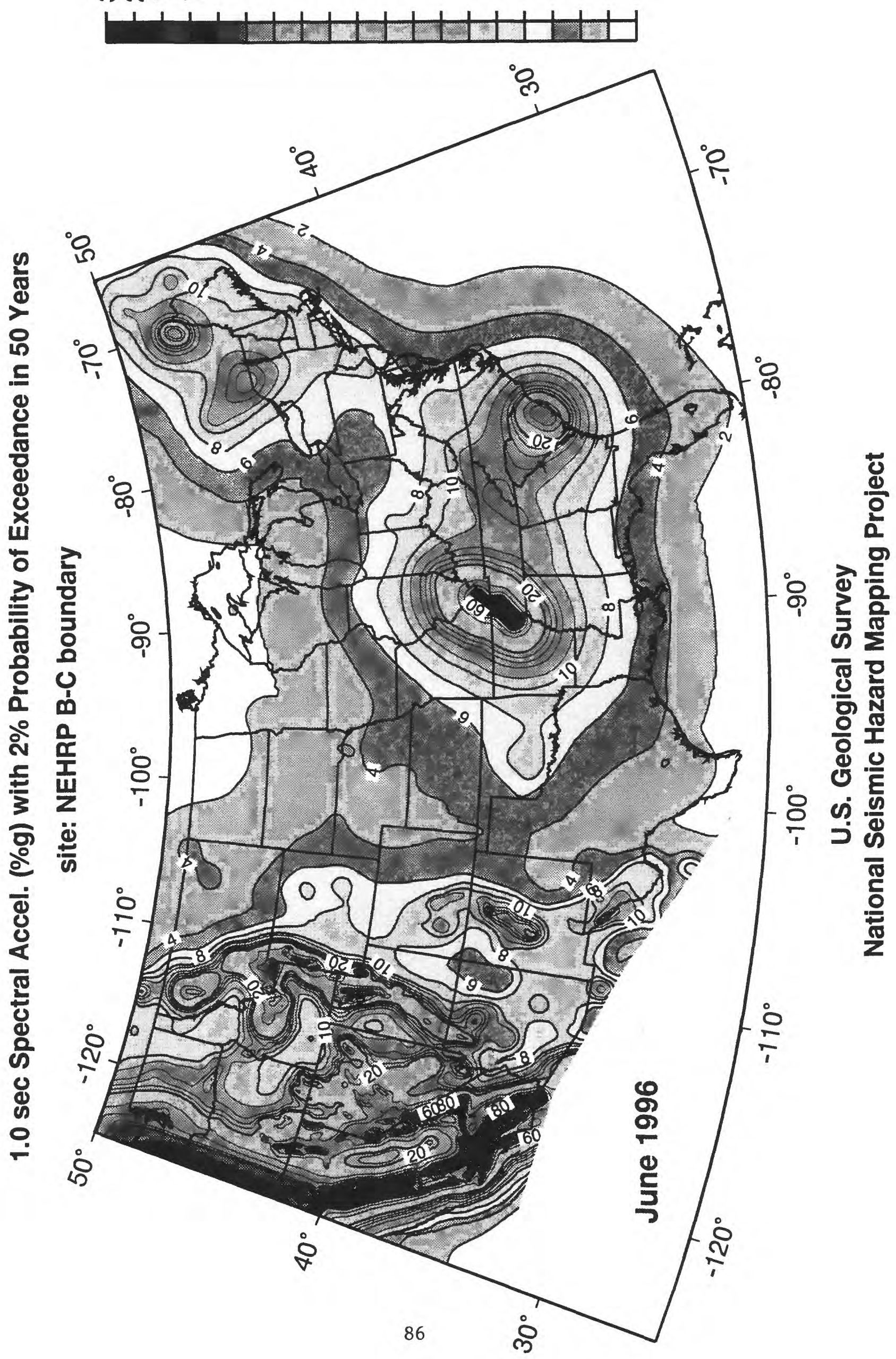


Peak Acceleration (\%g) with $5 \%$ Probability of Exceedance in 50 Years site: NEHRP B-C boundary

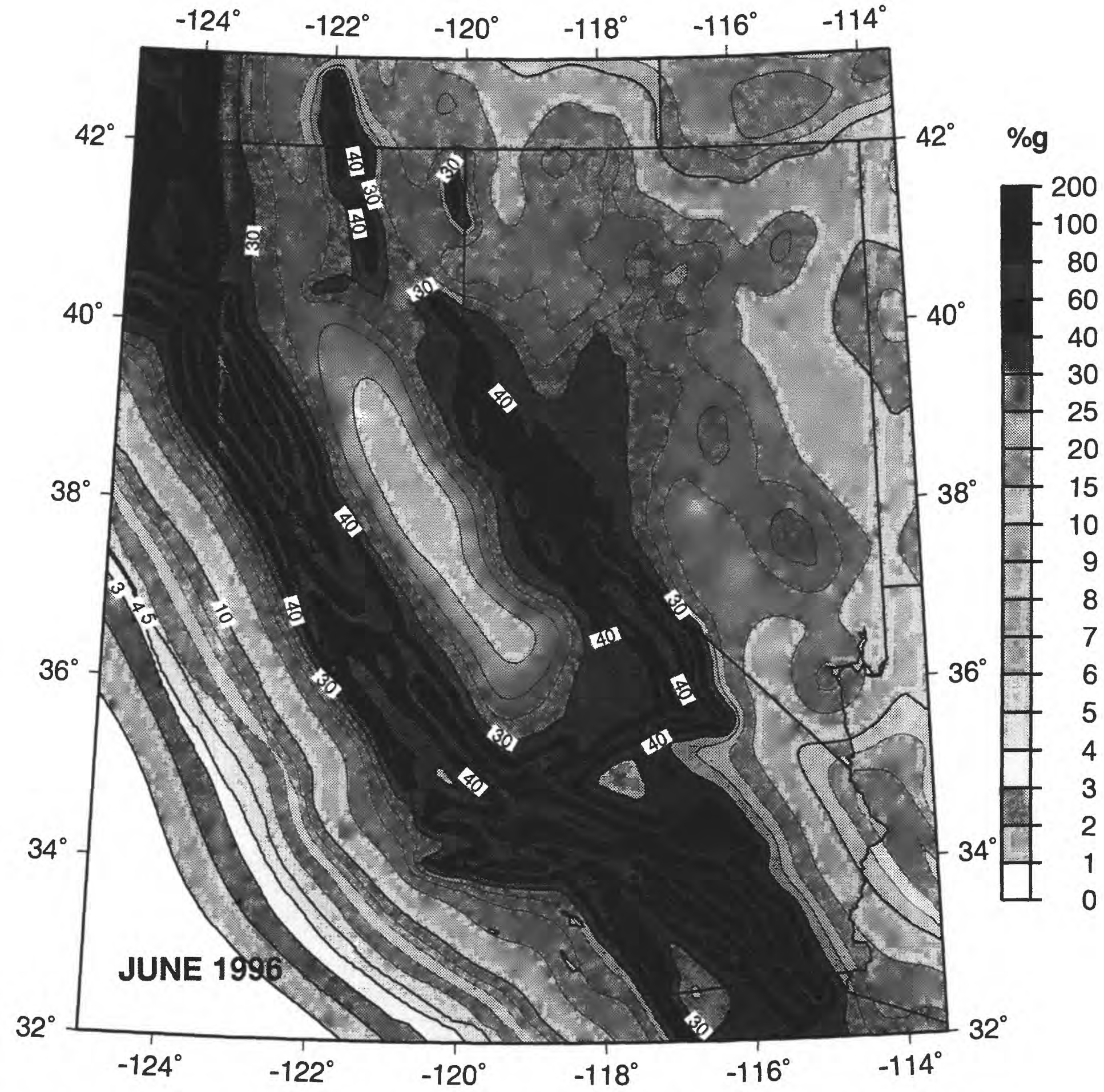

For California portion: U.S. Geological Survey - California Divison of Mines and Geology

For Nevada and surrounding states: USGS 
Peak Acceleration (\%g) with $2 \%$ Probability of Exceedance in 50 Years site: NEHRP B-C boundary

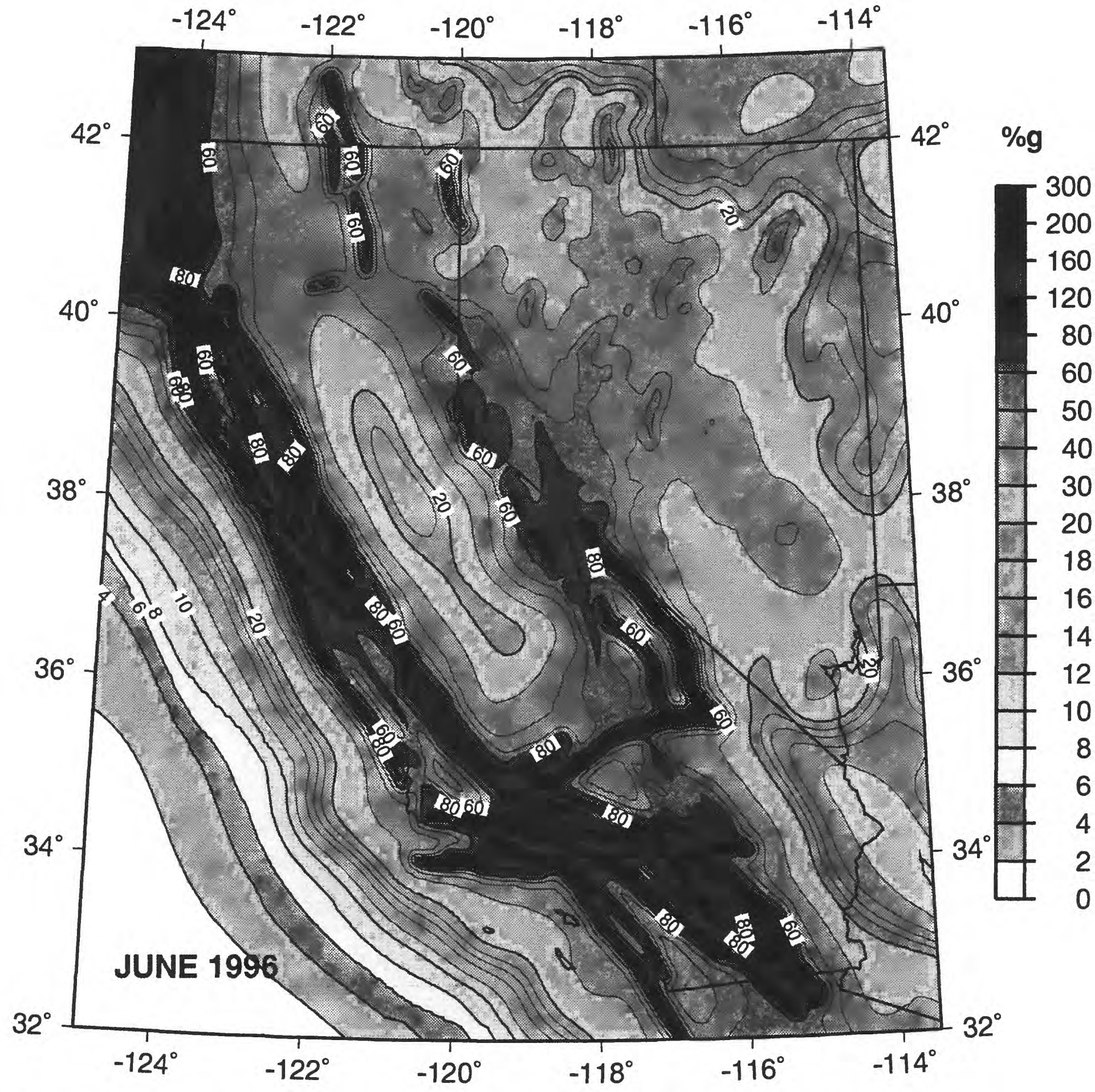

For California portion: U.S. Geological Survey - California Divison of Mines and Geology For Nevada and surrounding states: USGS 
0.2 sec Spectral Accel. (\%g) with $10 \%$ Probability of Exceedance in 50 Years site: NEHRP B-C boundary

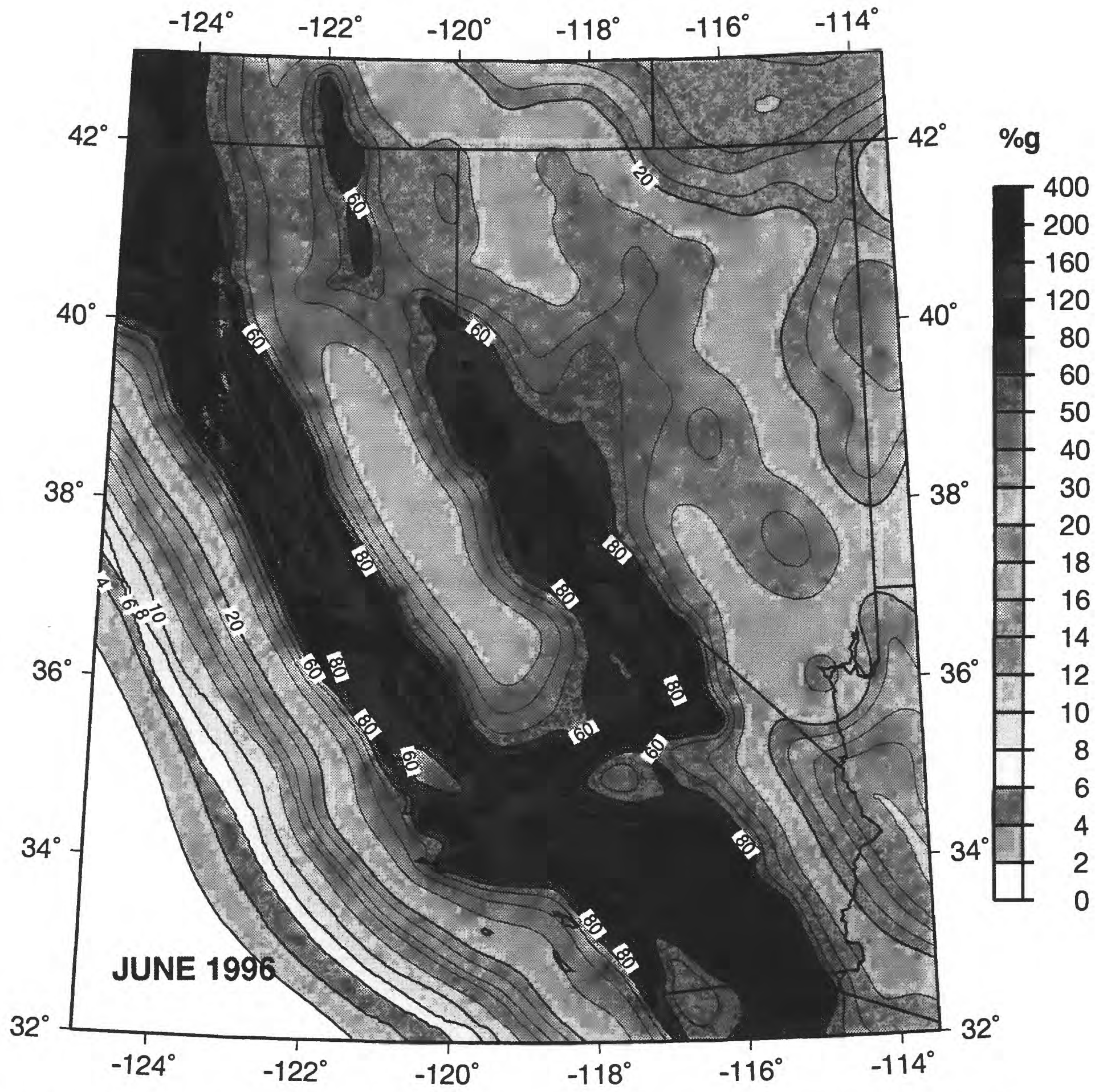

For California portion: U.S. Geological Survey - California Divison of Mines and Geology For Nevada and surrounding states: USGS 
$0.2 \mathrm{sec}$ Spectral Accel. $(\% \mathrm{~g})$ with $2 \%$ Probability of Exceedance in 50 Years site: NEHRP B-C boundary

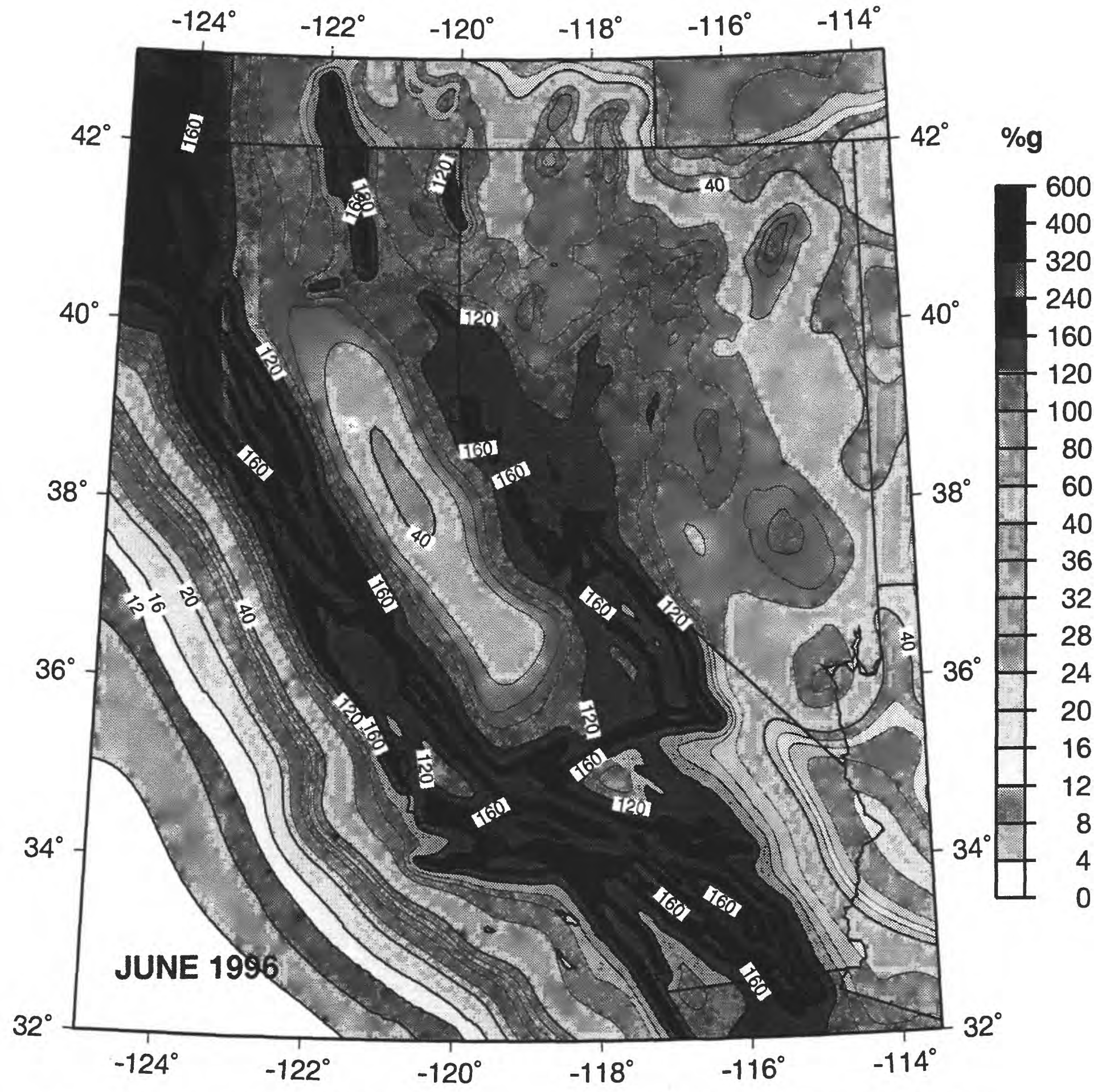

For California portion: U.S. Geological Survey - California Divison of Mines and Geology For Nevada and surrounding states: USGS 
0.3 sec Spectral Accel. (\%g) with 10\% Probability of Exceedance in 50 Years site: NEHRP B-C boundary

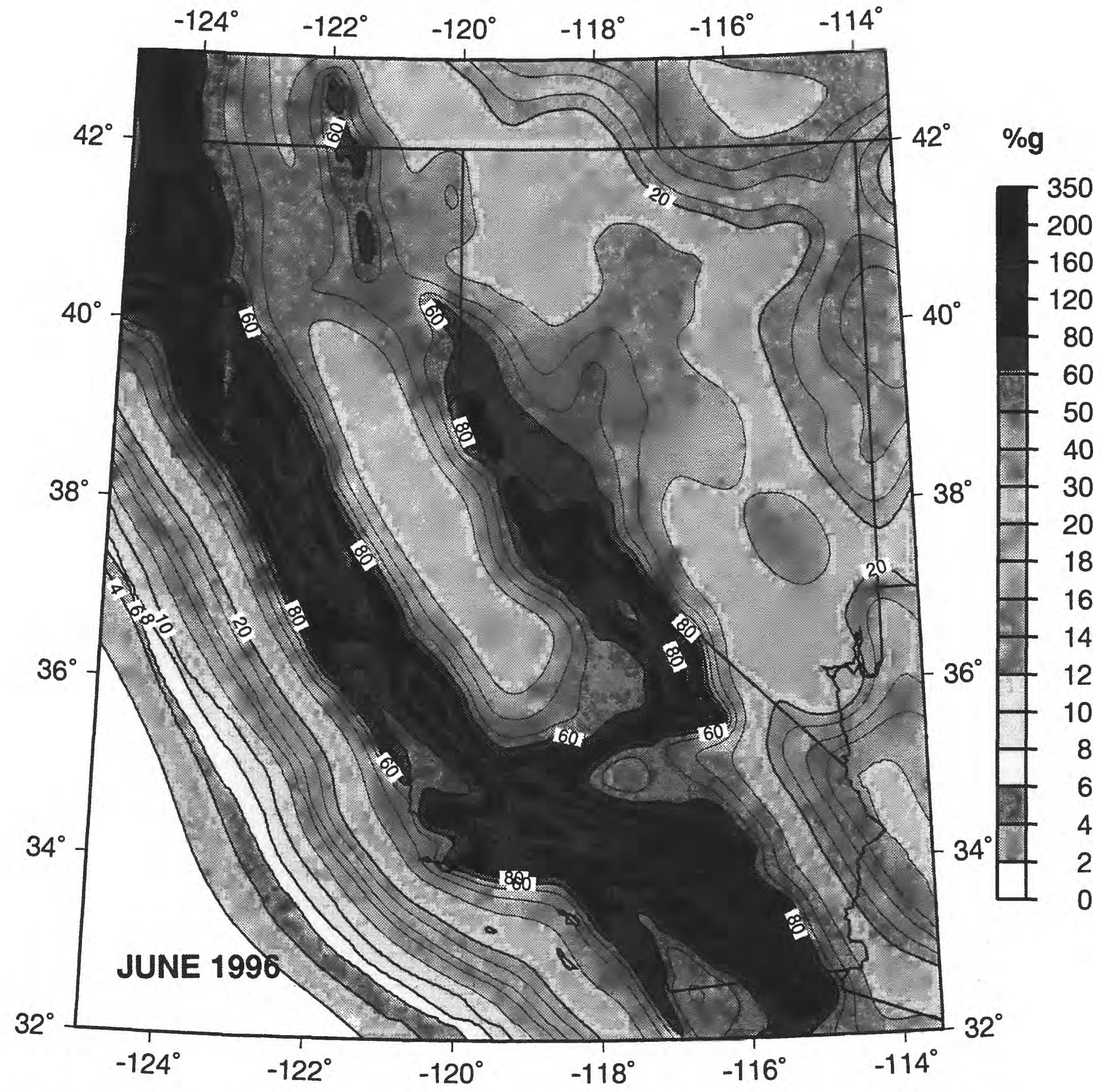

For California portion: U.S. Geological Survey - California Divison of Mines and Geology For Nevada and surrounding states: USGS 
$0.3 \mathrm{sec}$ Spectral Accel. $(\% \mathrm{~g})$ with $5 \%$ Probability of Exceedance in 50 Years site: NEHRP B-C boundary

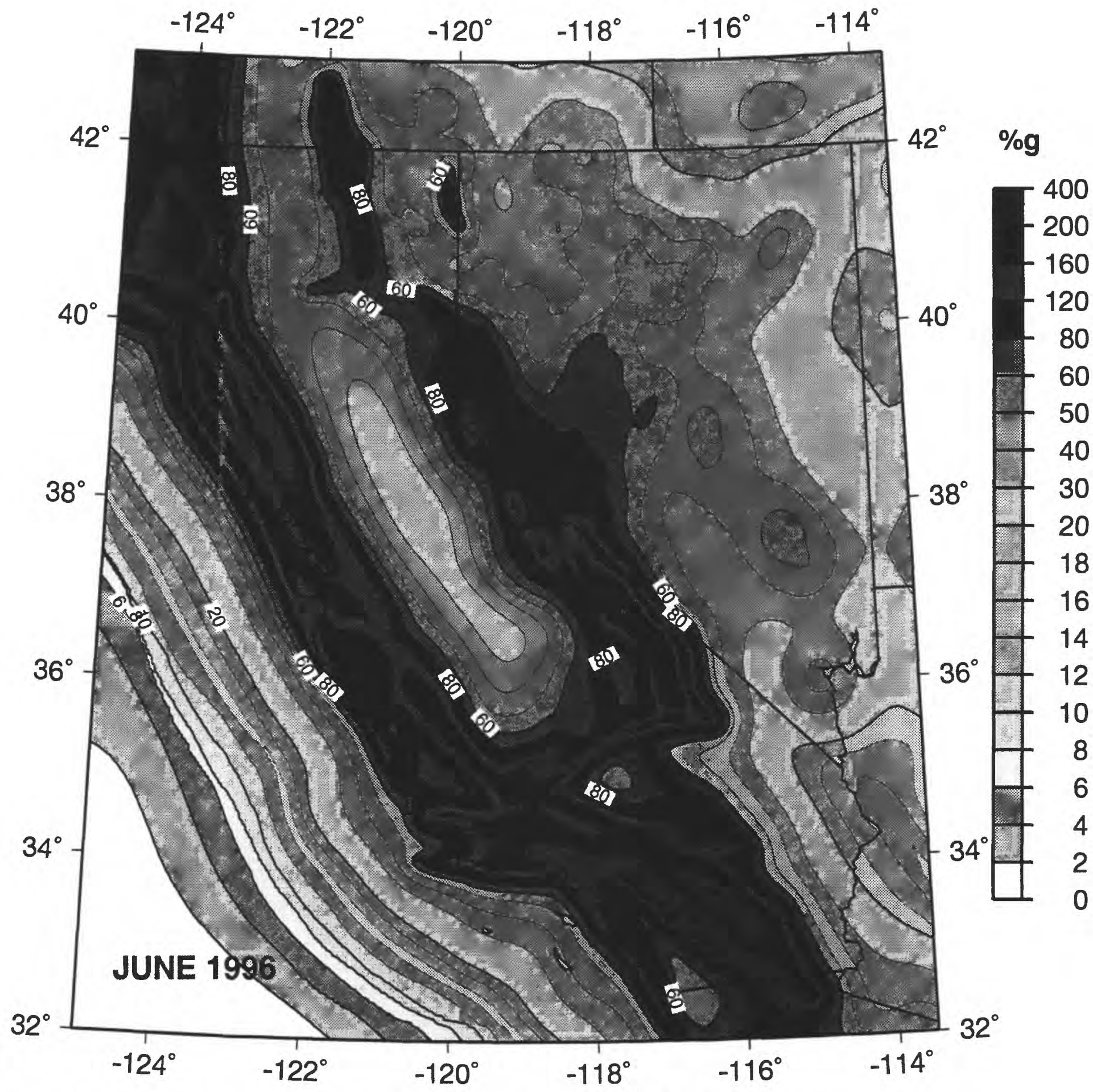

For California portion: U.S. Geological Survey - California Divison of Mines and Geology For Nevada and surrounding states: USGS 
$0.3 \mathrm{sec}$ Spectral Accel. $(\% \mathrm{~g})$ with $2 \%$ Probability of Exceedance in 50 Years site: NEHRP B-C boundary

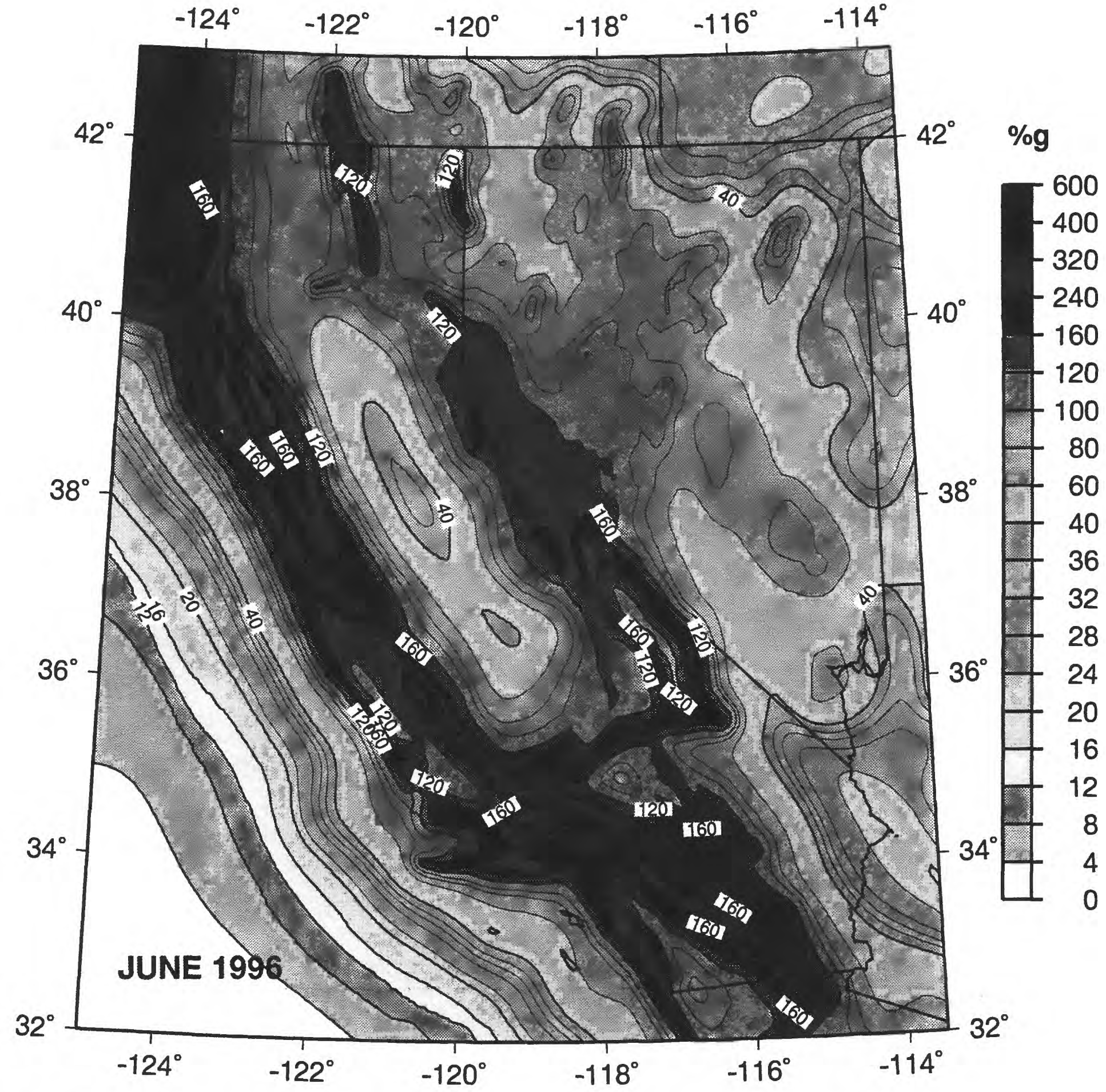

For California portion: U.S. Geological Survey - California Divison of Mines and Geology For Nevada and surrounding states: USGS 
1.0 sec Spectral Accel. $(\% g)$ with $10 \%$ Probability of Exceedance in 50 Years

\section{site: NEHRP B-C boundary}

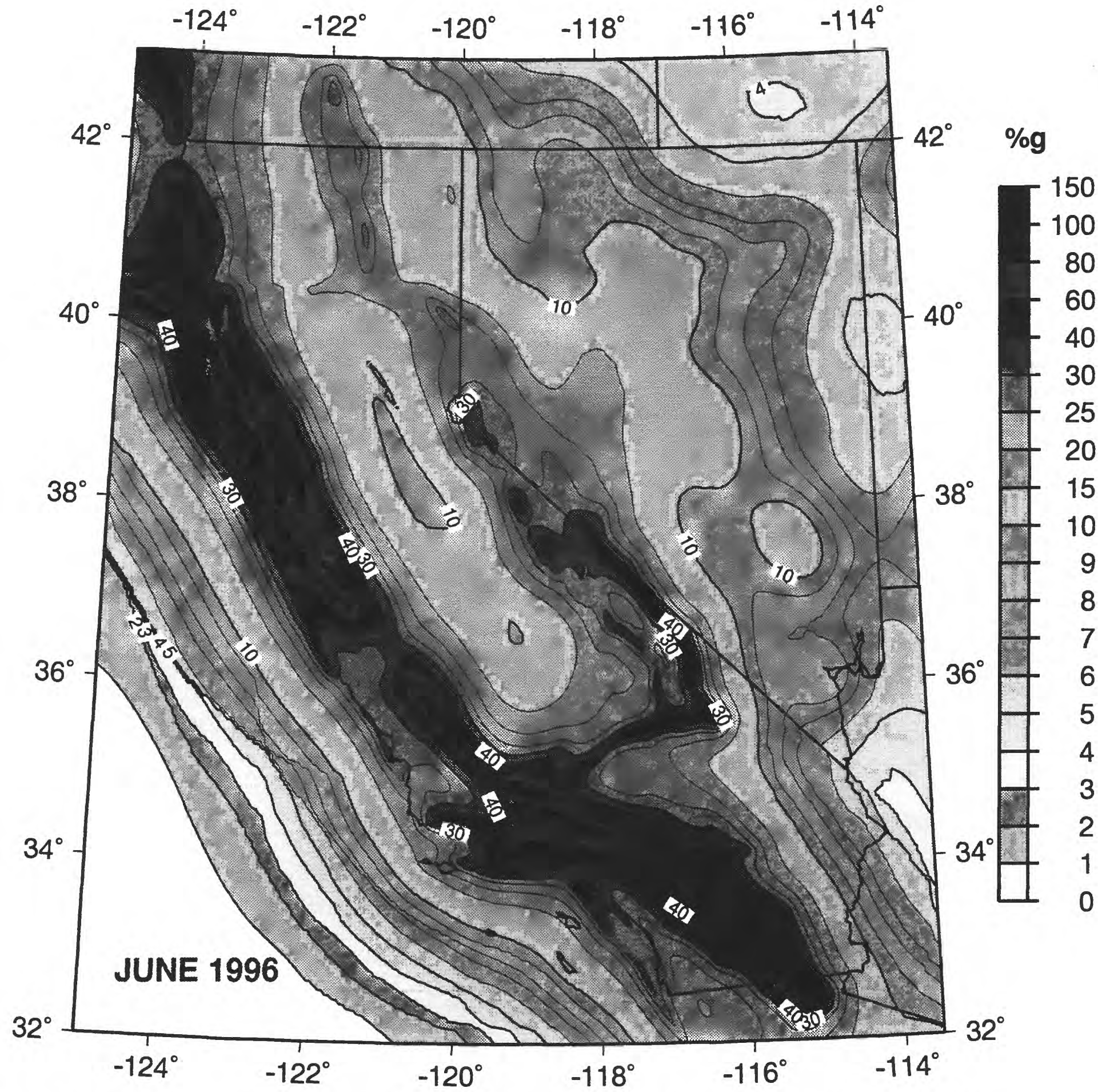

For California portion: U.S. Geological Survey - California Divison of Mines and Geology For Nevada and surrounding states: USGS 
$1.0 \mathrm{sec}$ Spectral Accel. (\%g) with 5\% Probability of Exceedance in 50 Years site: NEHRP B-C boundary

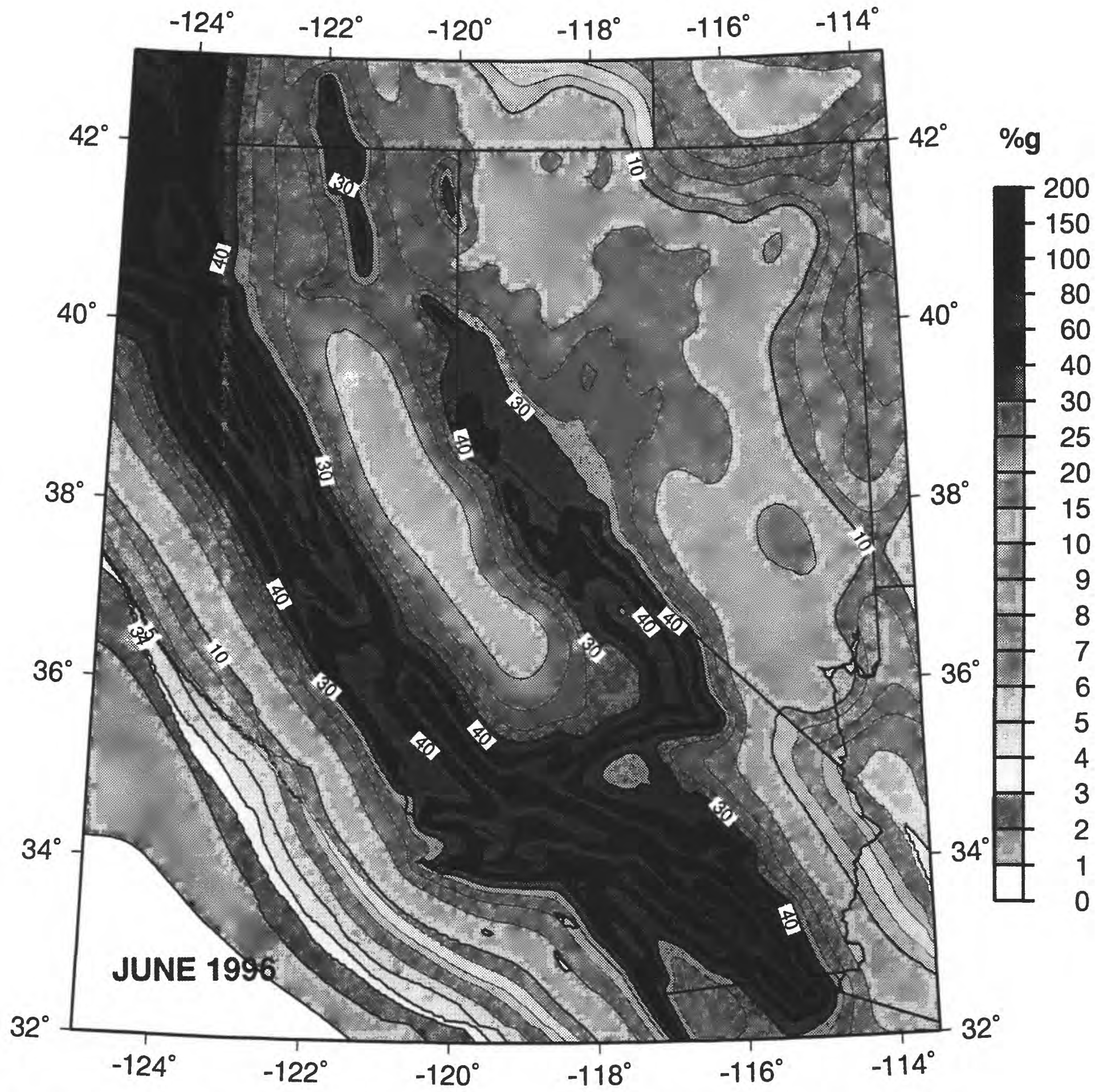

For California portion: U.S. Geological Survey - California Divison of Mines and Geology For Nevada and surrounding states: USGS 
1.0 sec Spectral Accel. $(\% \mathrm{~g})$ with $2 \%$ Probability of Exceedance in 50 Years site: NEHRP B-C boundary

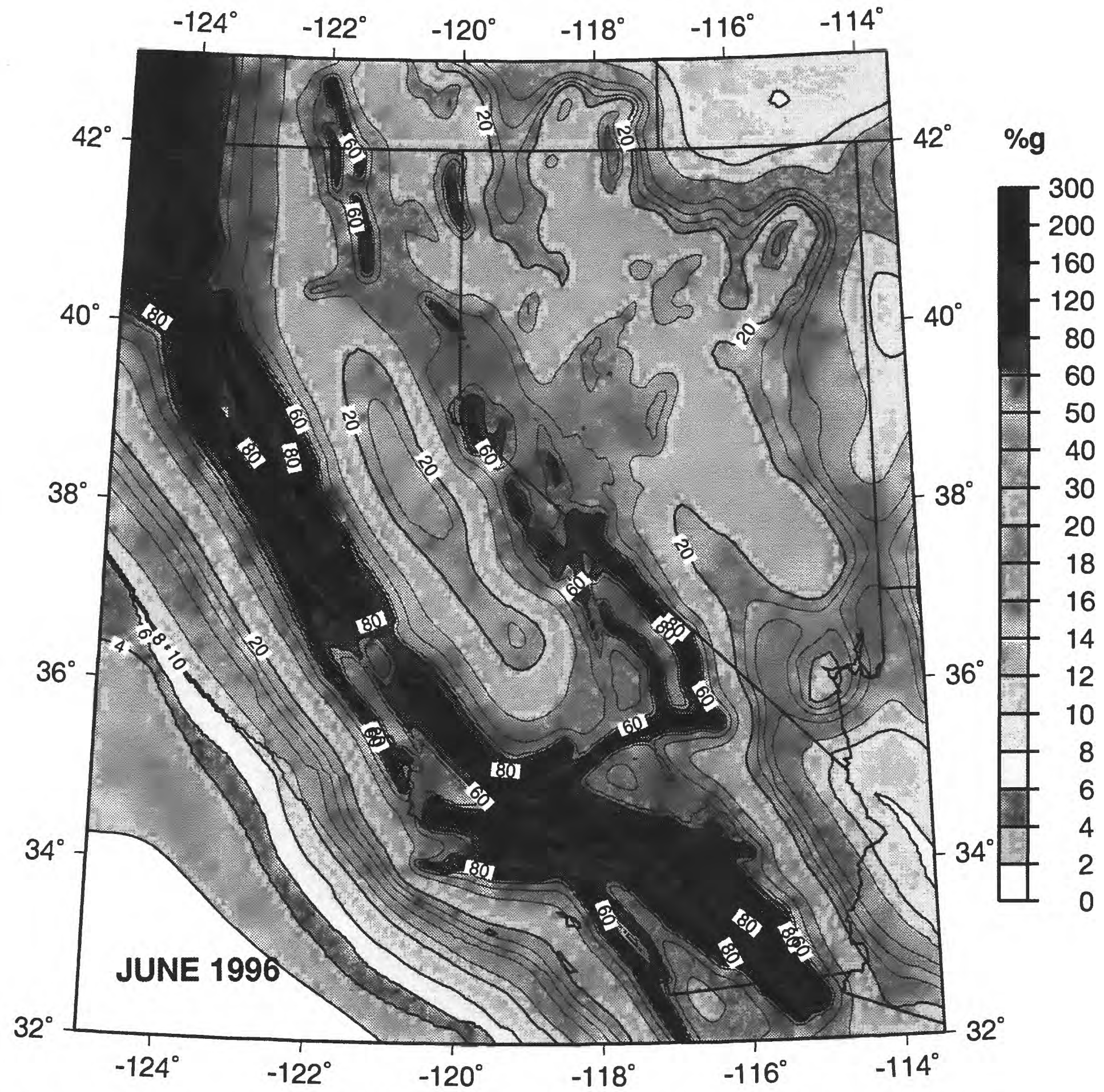

For California portion: U.S. Geological Survey - California Divison of Mines and Geology For Nevada and surrounding states: USGS 


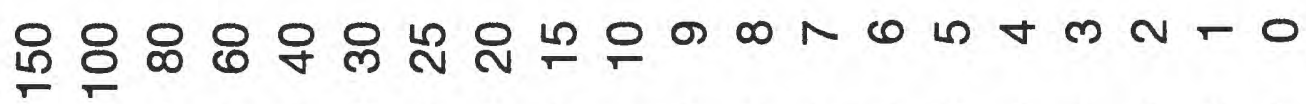

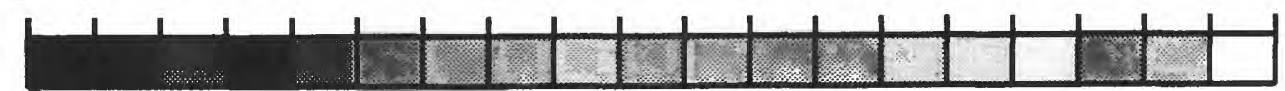

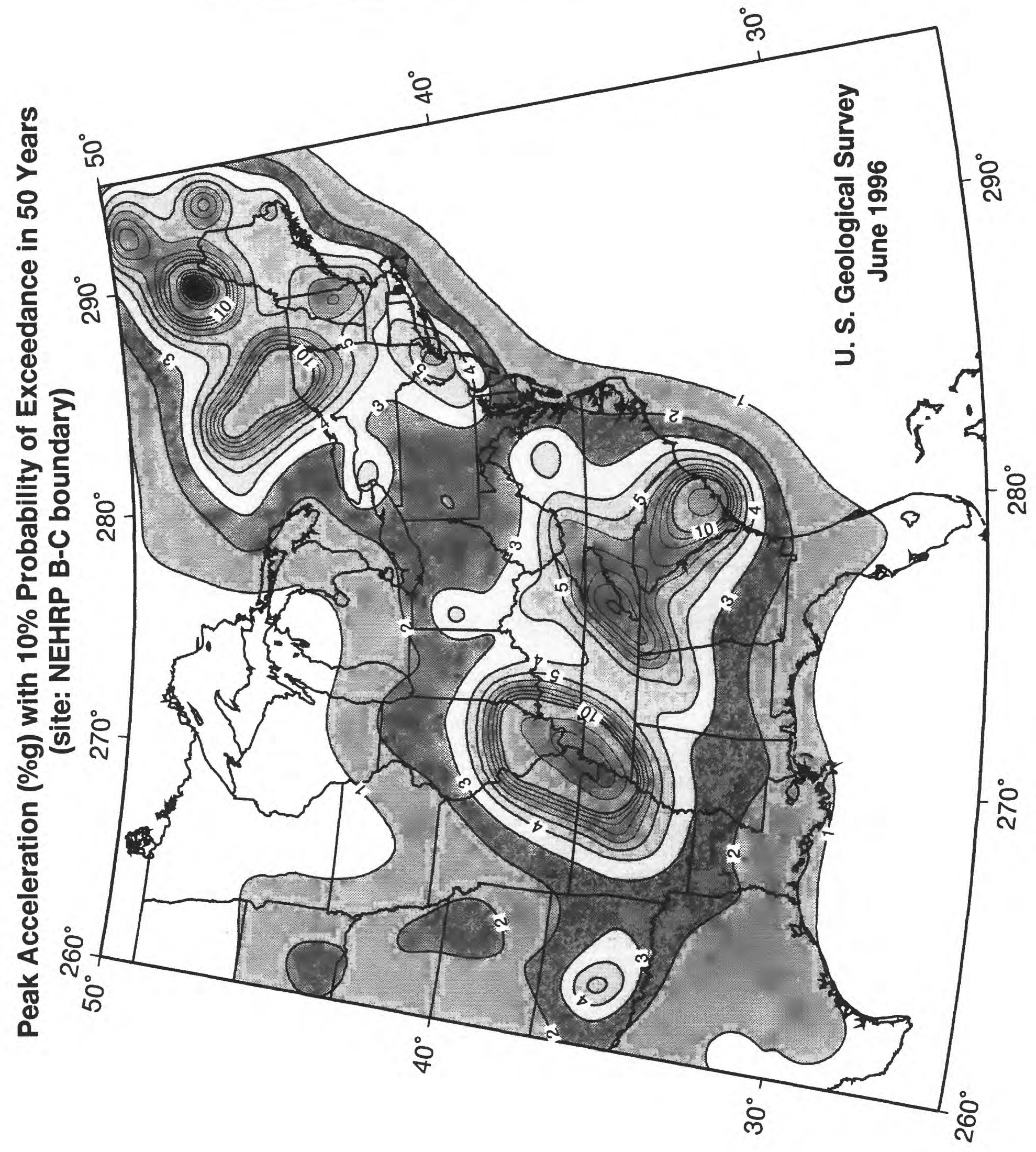




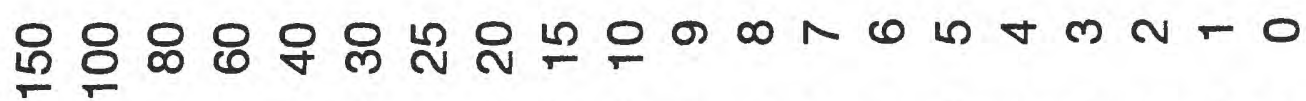






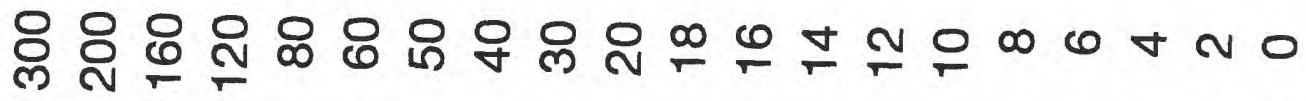

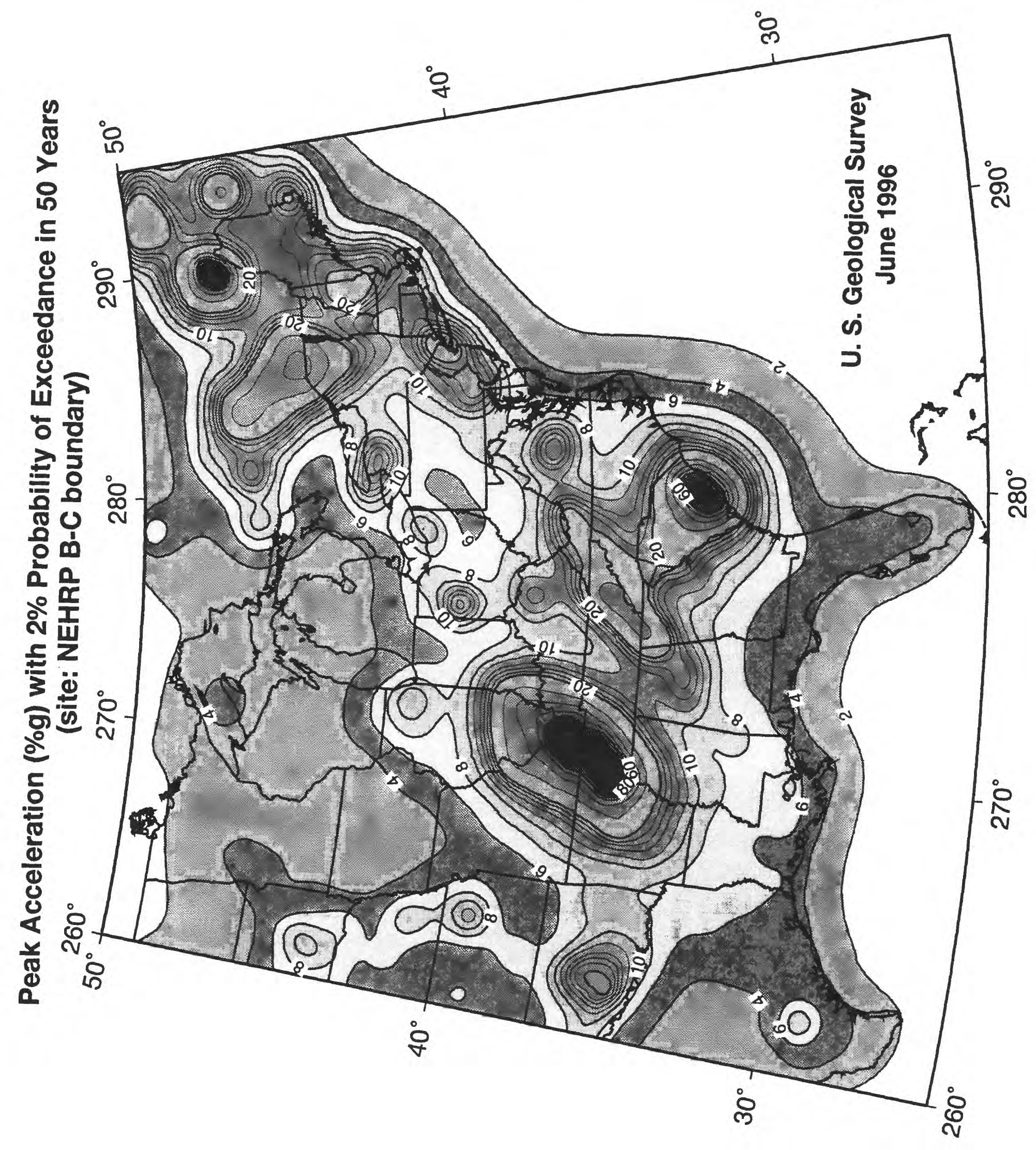




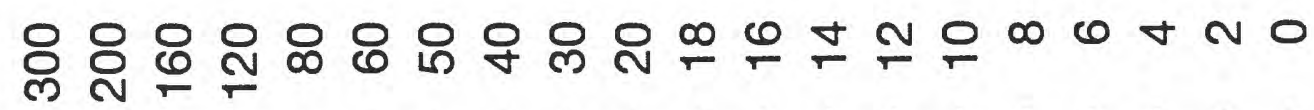

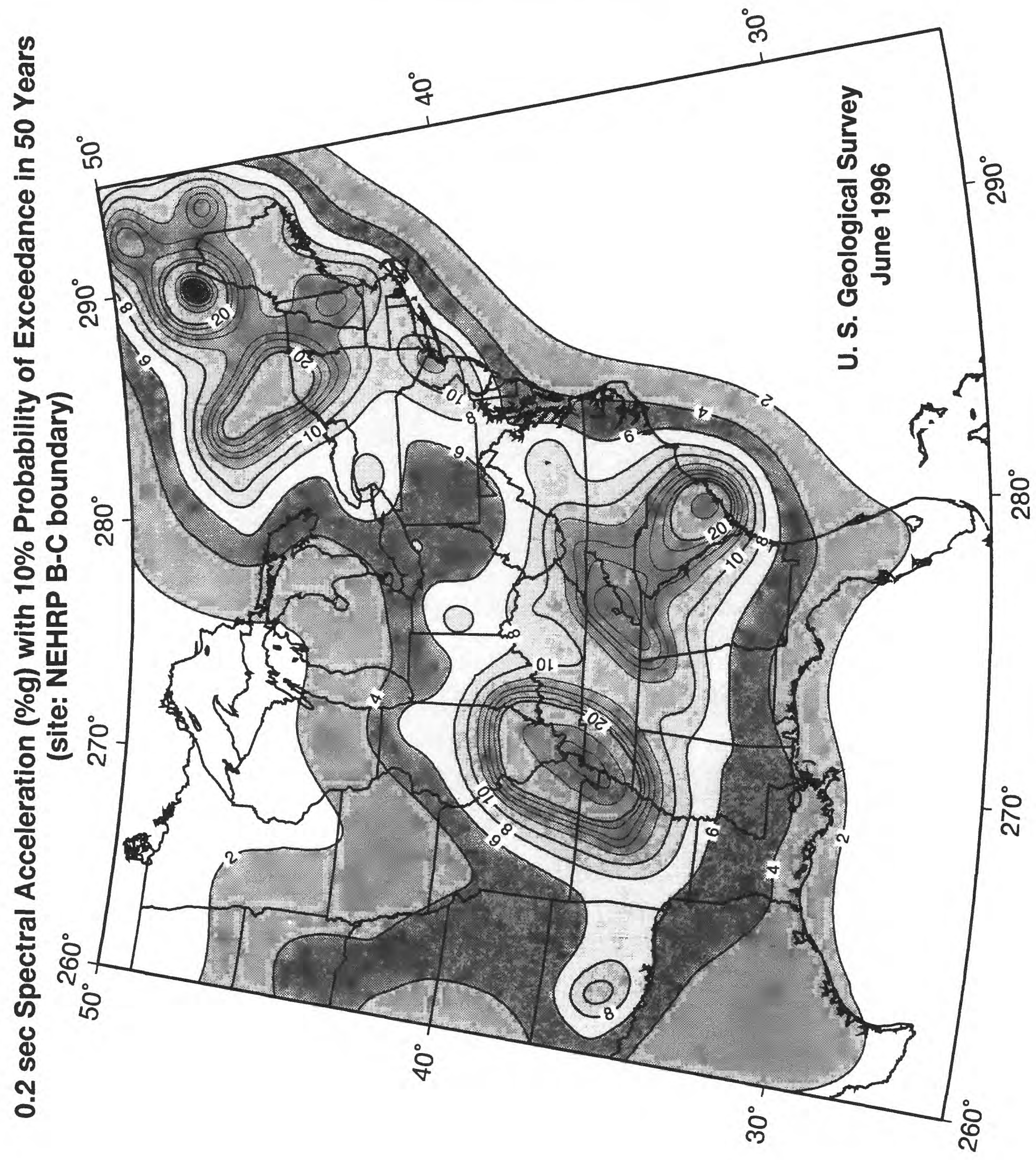




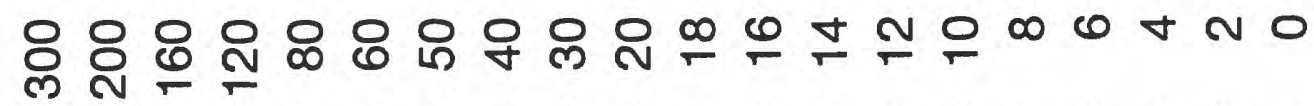

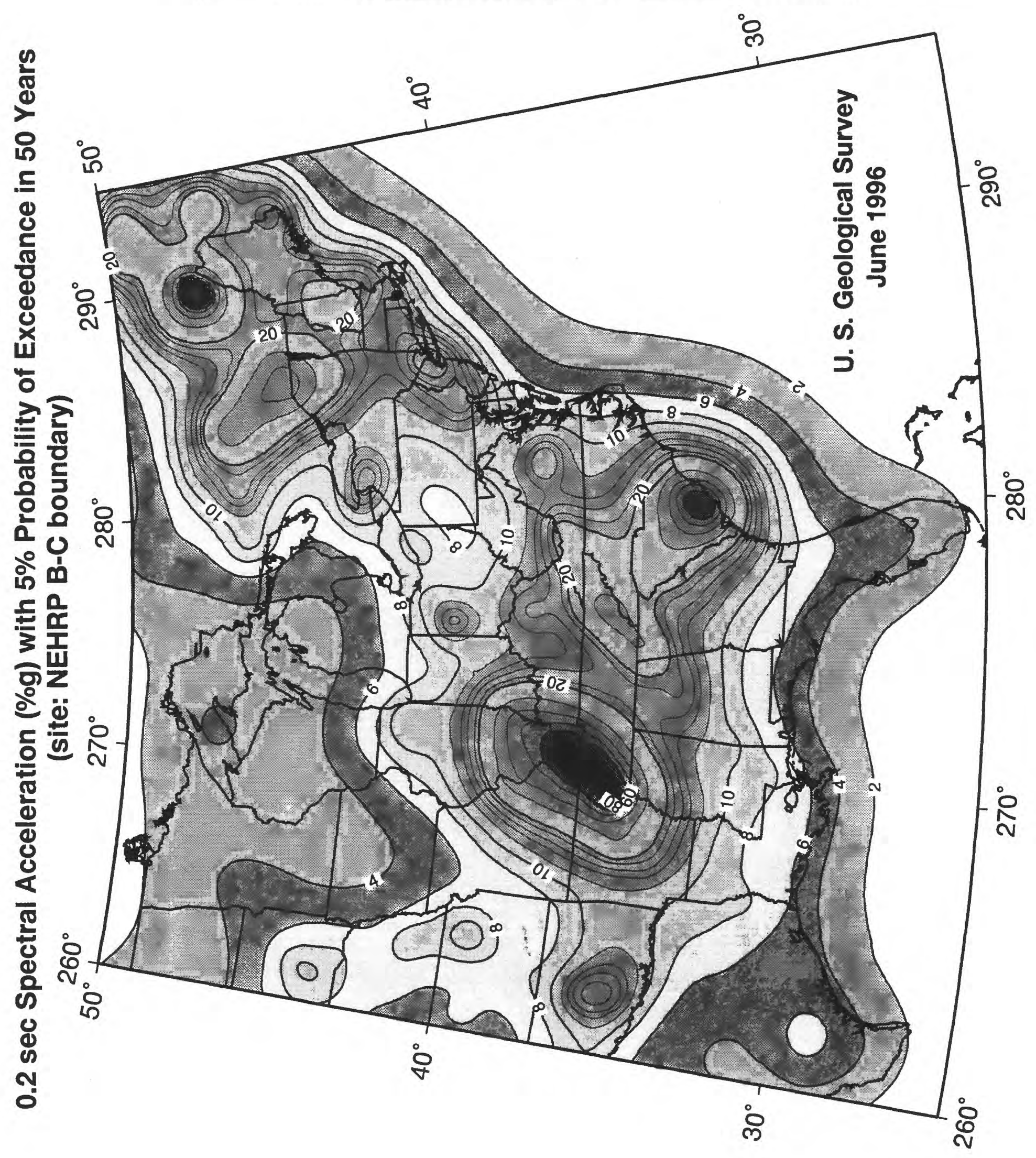




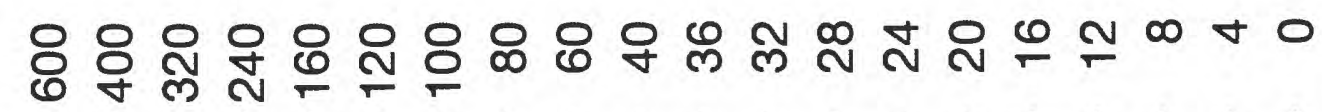

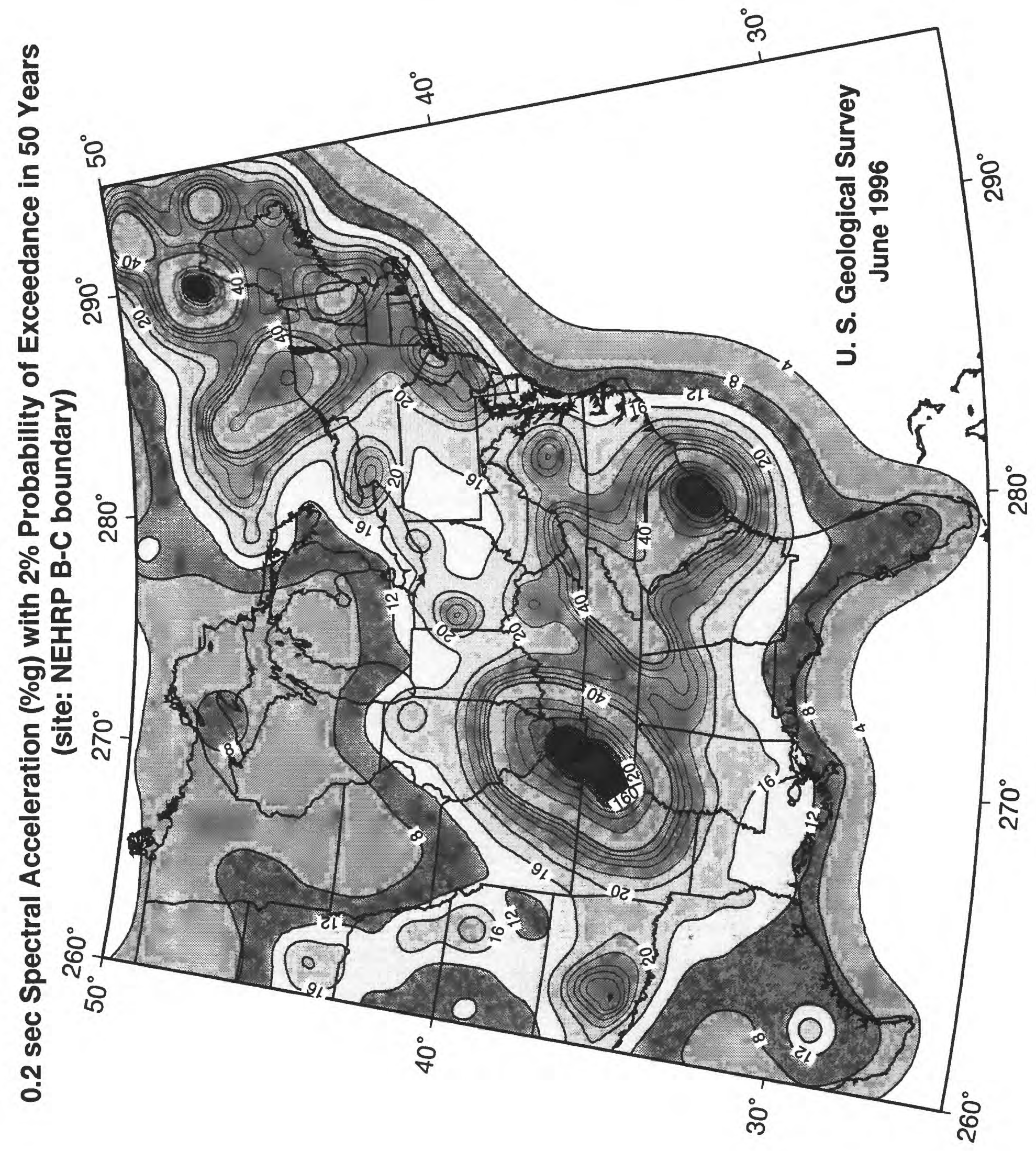




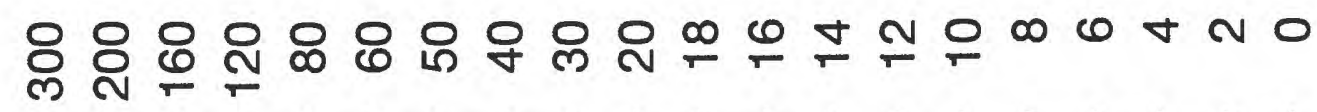

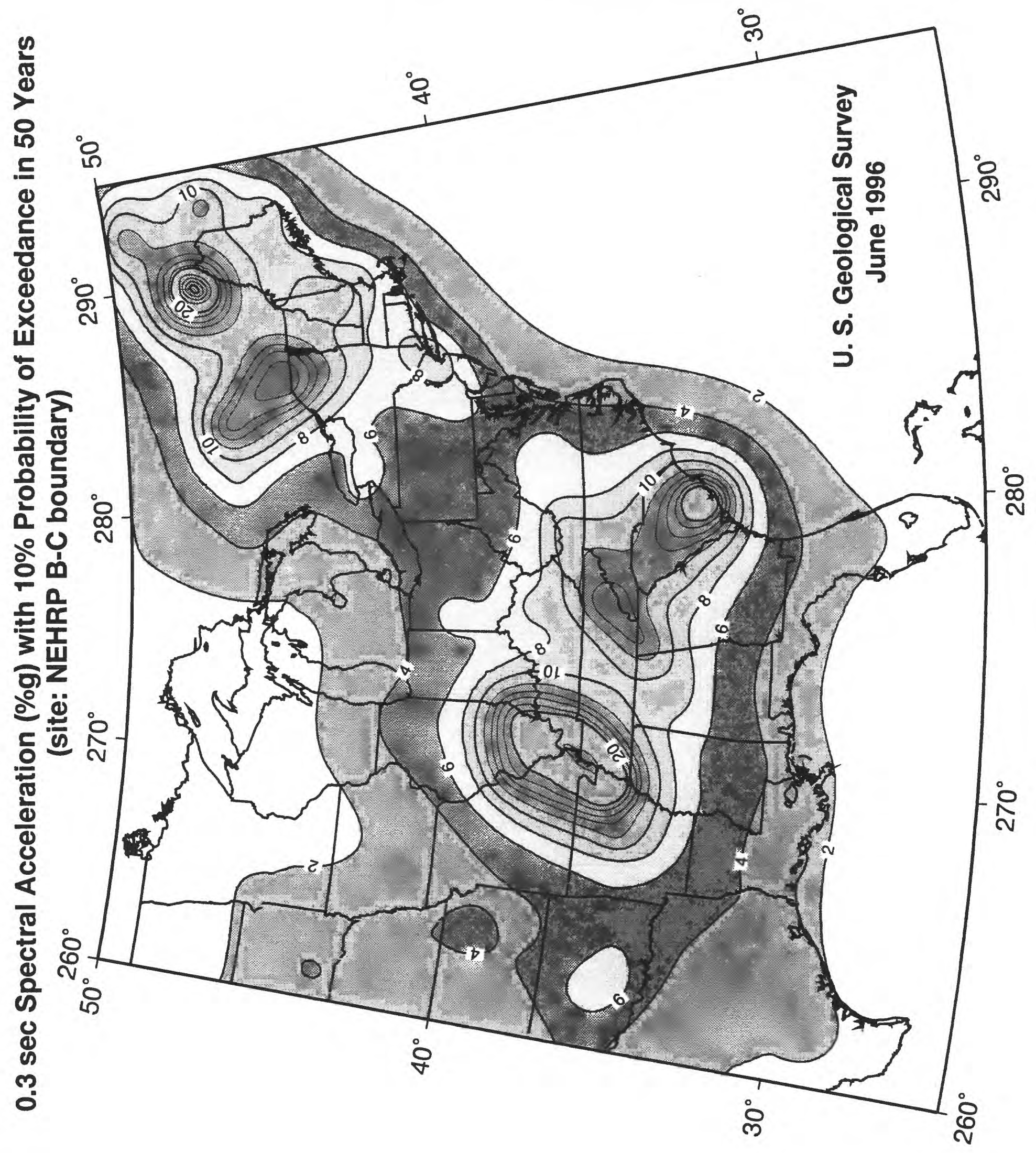




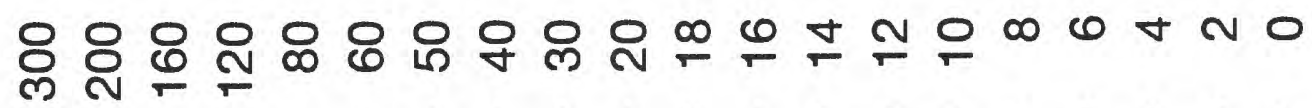

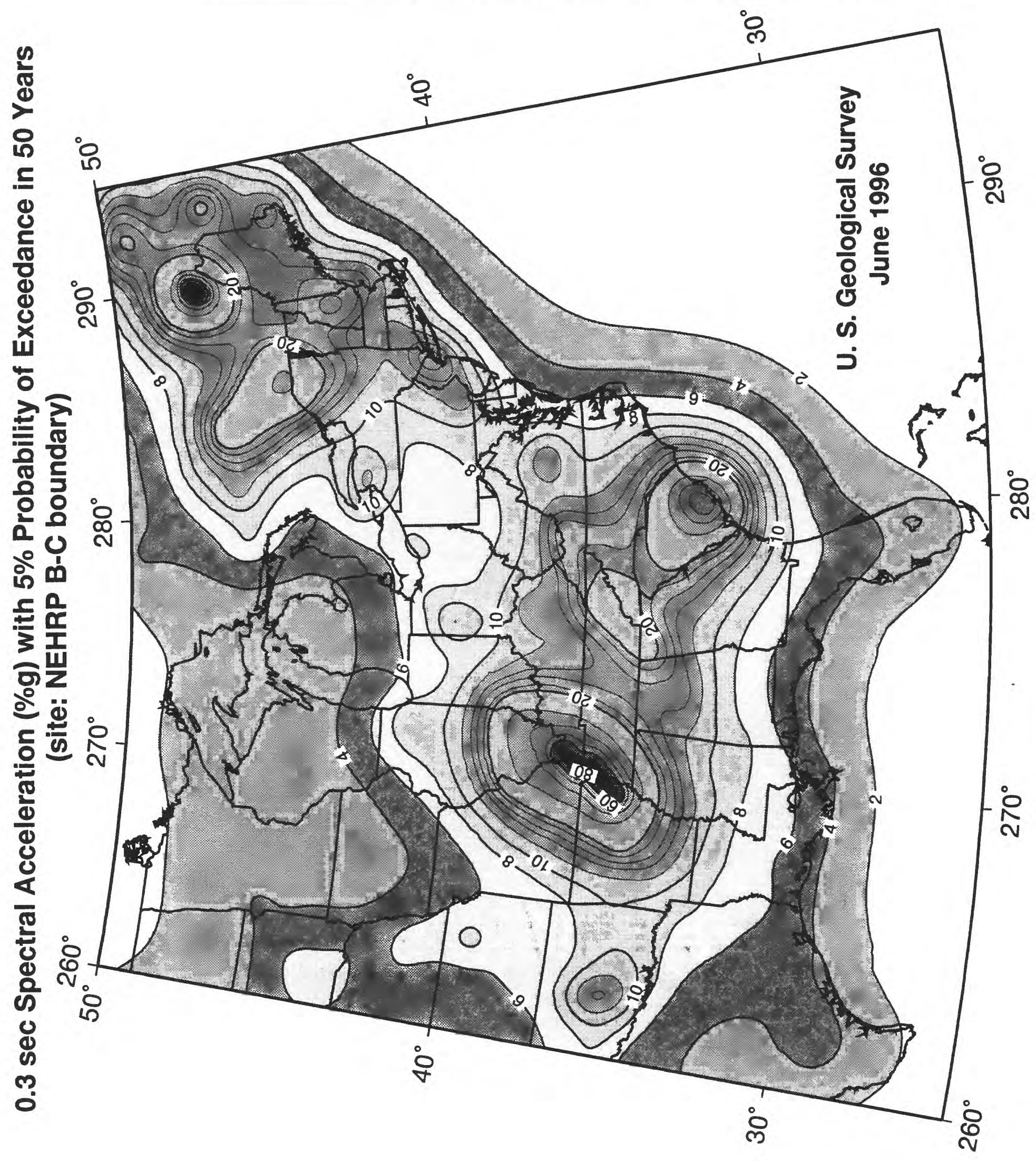




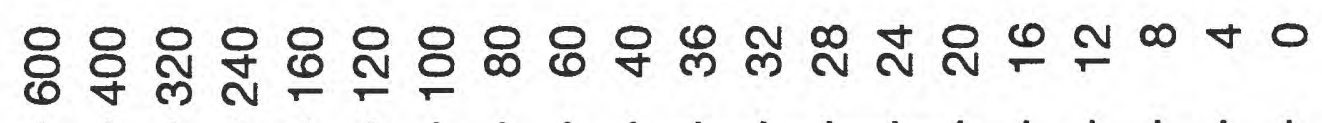

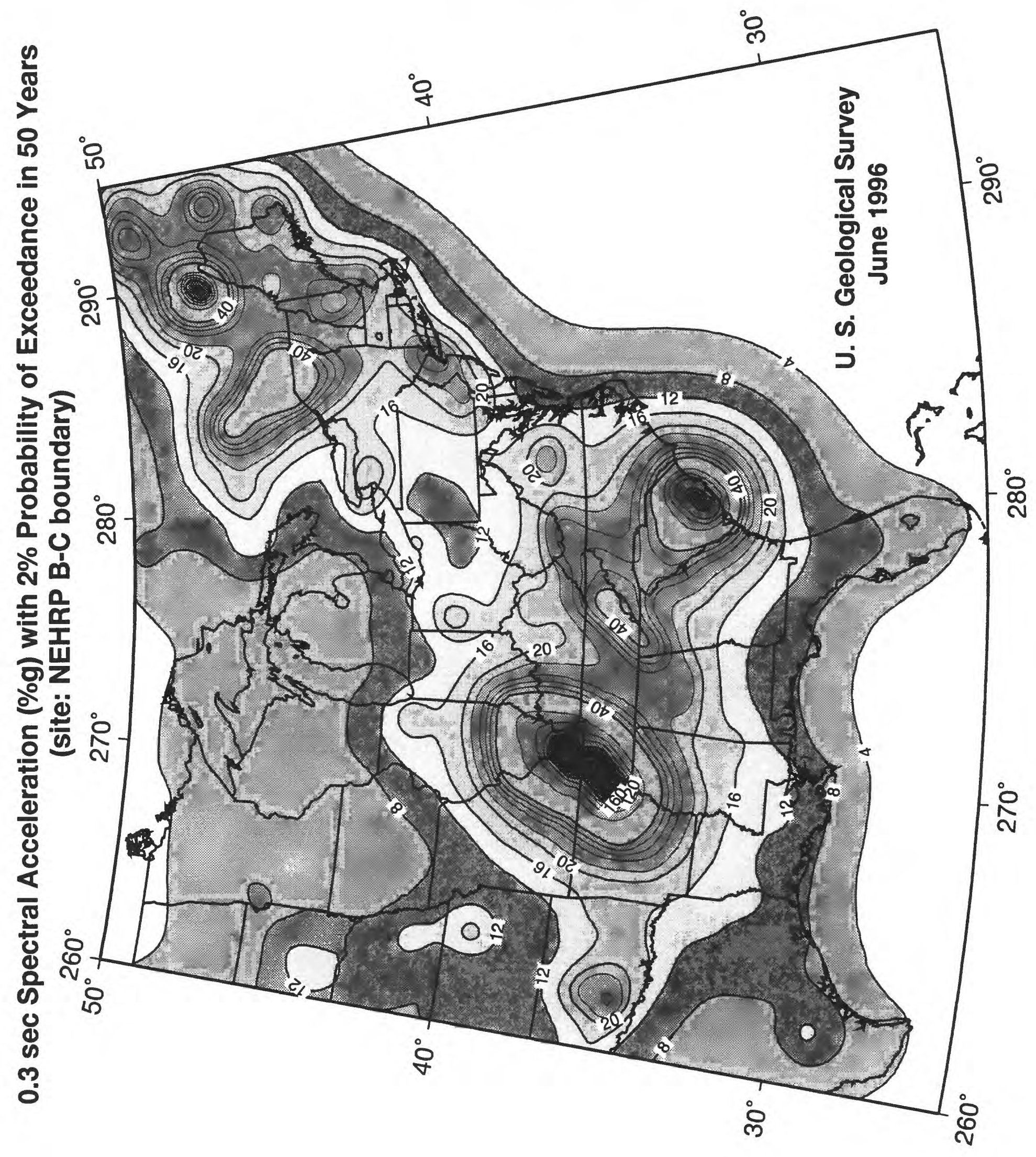




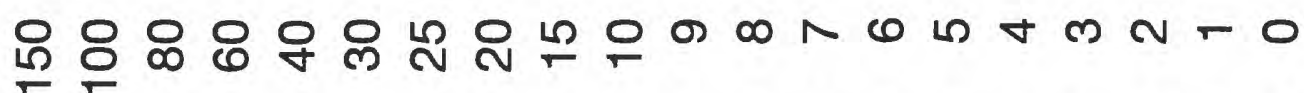






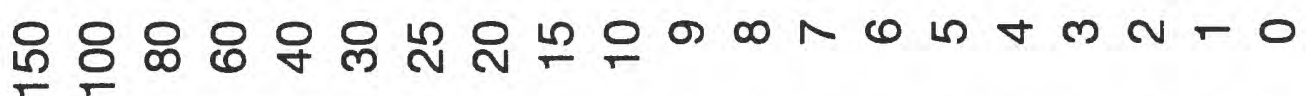

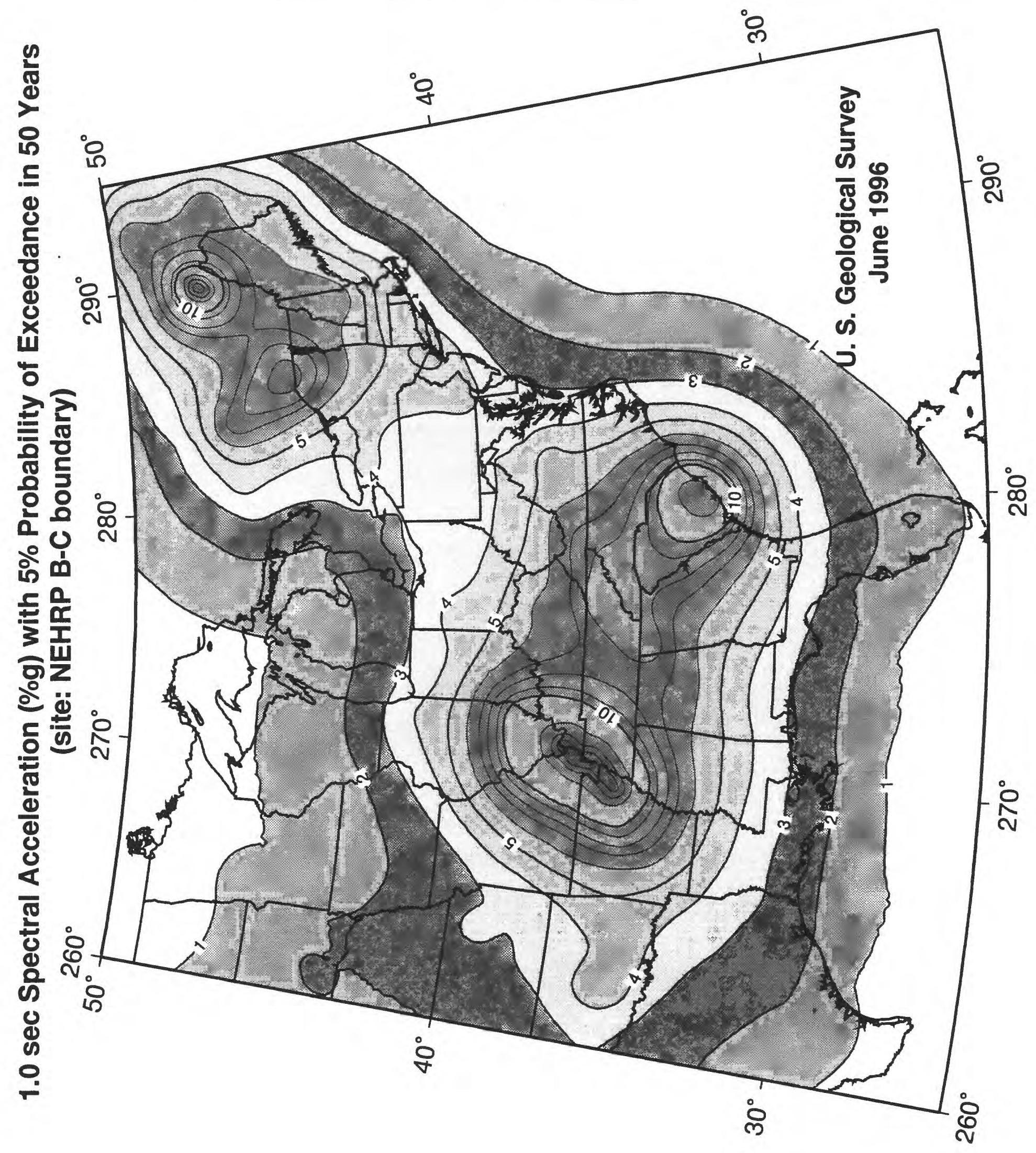




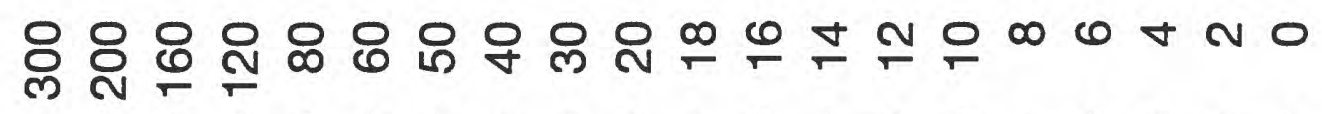

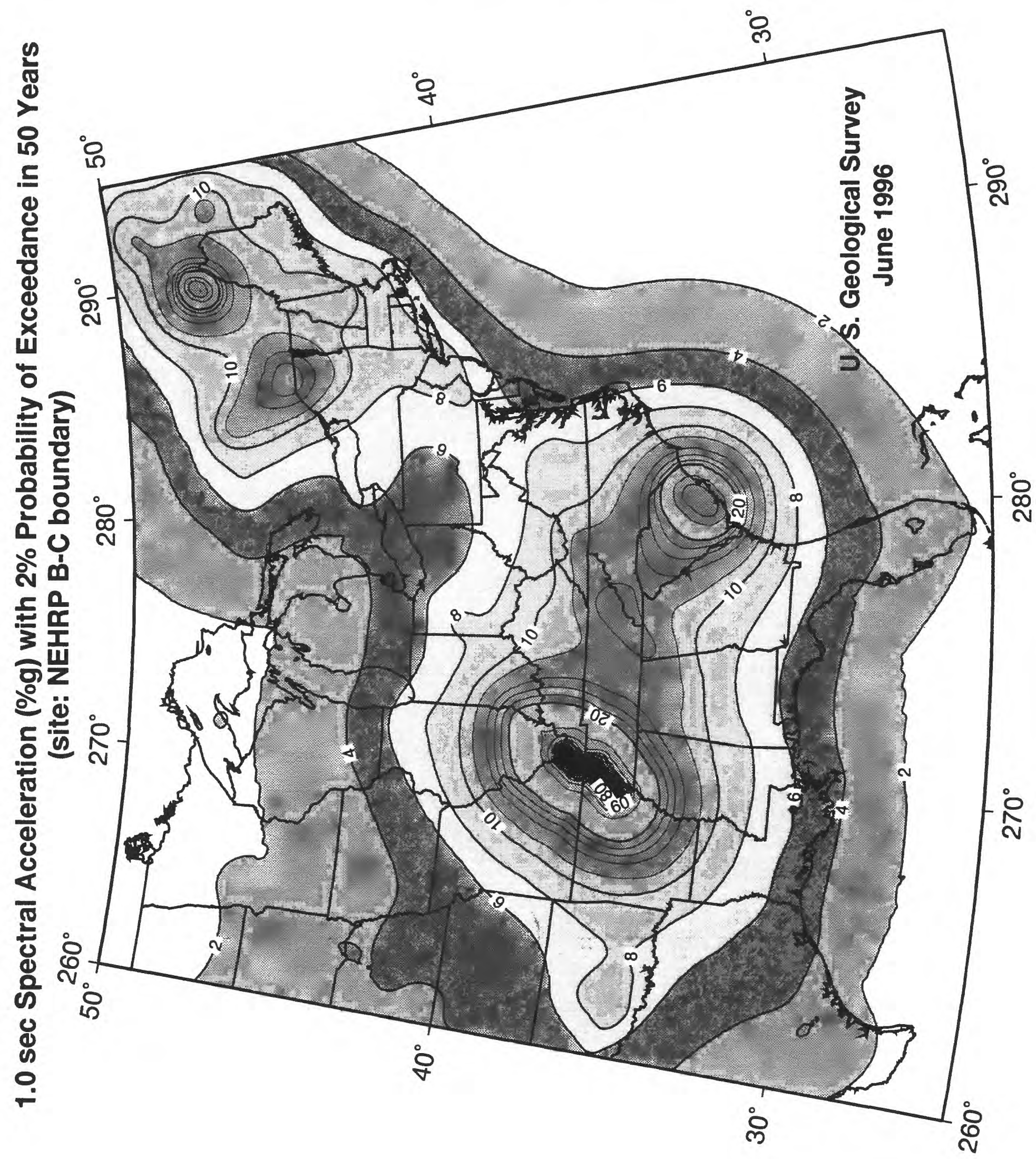

